Portland State University

PDXScholar

\title{
Intercultural factors in business negotiation between Japanese and Americans
}

Yuko Nagatomo

Portland State University

Follow this and additional works at: https://pdxscholar.library.pdx.edu/open_access_etds

Part of the International and Intercultural Communication Commons Let us know how access to this document benefits you.

\section{Recommended Citation}

Nagatomo, Yuko, "Intercultural factors in business negotiation between Japanese and Americans" (1988). Dissertations and Theses. Paper 4055.

https://doi.org/10.15760/etd.5939

This Thesis is brought to you for free and open access. It has been accepted for inclusion in Dissertations and Theses by an authorized administrator of PDXScholar. Please contact us if we can make this document more accessible: pdxscholar@pdx.edu. 
AN ABSTRACT OF THE THESIS OF Yuko Nagatomo for the

Master of Arts in Speech Communication presented May 2, 1988.

Title: Intercultural Factors in Business Negotiation between Japanese and Americans.

APPROVED BY THE MEMBERS OF THE THESIS COMMITTEE:

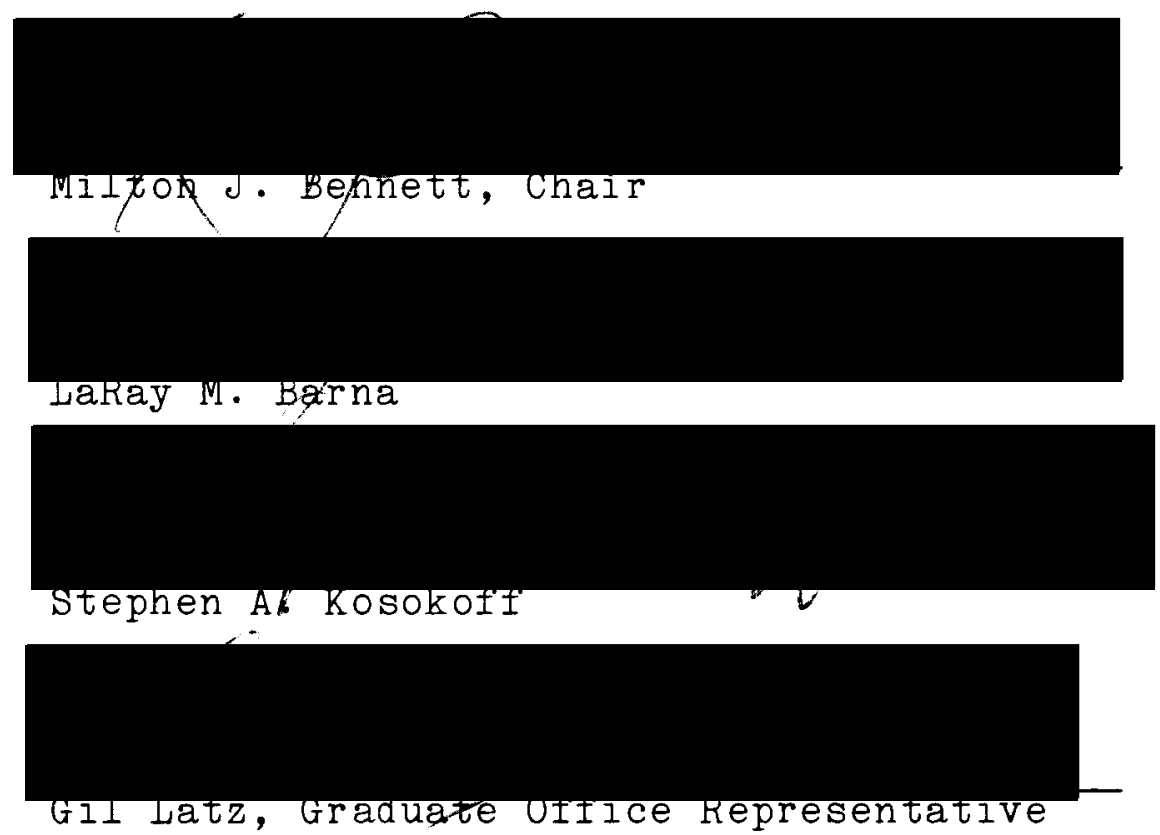

This thesis is a review of relevant literature on business negotiation between Japanese and American and an analysis of cultural differences in negotiation from an intercultural perspective. The following four key issues are explored and analyzed with intercultural communication concepts: 
1) major differences in approaches to the process of business negotiation between the United States and Japan;

2) potential friction between Japanese and Americans in business negotiation that is attributable to Japanese and American cultural differences;

3) the applicability and usefulness of an intercultural perspective in enhancing business negotiation skills; and

4) main factors affecting the use of an intercultural perspective in cross-cultural business negotiation and the degree to which they are manifested in the U.S.-Japan business negotiations.

The review of the relevant literature on Japanese and American business negotiation showed that despite the consistency of stages in the negotiation process between the two cultural groups, the content and duration of each stage differs substantially between cultures. The differences and their consequences, including potential friction between the two groups are attributed to cultural differences in assumptions and values orientations, in philosophies of negotiating, in communication styles, in decision-making processes, and in situational constraints and status relationships.

Culture is operationally defined as subjective culture, i.e., human cognitive and perceptual processes 
either in the individual sense or in the collective sense. Thus, employment of an intercultural perspective is assumed as an indispensable prerequisite for effective human communication of any sort to take place. Thereby, in this study negotiation is also operationally defined as a process of cultural synergy between two (or more) differing entities. The applicability and usefulness of an intercultural perspective in business negotiation is discussed in terms of the assumption of perceptual variance and synergistic conflict resolution.

The thesis includes an examination of the impact of situational constraints upon cultural adaptability. The basic assumption is that motives to cooperate and power relations between parties tend to dictate who accommodates behavior more, thus who is more willing to use an intercultural perspective in cross-cultural business negotiation. A review of the relevant literature on U.S.-Japan business negotiation case studies suggested that the greater a party's motives and stakes are in conflict, the more culturally accommodating a party becomes. The successful U.S.-Japan business negotiation case studies also exemplify the emergence of cultural synergy through strong commitment to collaboration on the part of both sides. 
INTERCULTURAL FACTORS IN BUSINESS NEGOTIATION BETWEEN JAPANESE AND AMERICANS

by

YUKO NAGATOMO

A thesis submitted in partial fulfillment of the requirements for the degree of

\author{
MASTER OF ARTS \\ in \\ SPEECH COMMUNICATION
}

Portland State University

1988 
TO THE OFFICE OF GRADUATE STUDIES:

The members of the Committee approve the thesis of Yuko Nagatomo presented May 2, 1988.

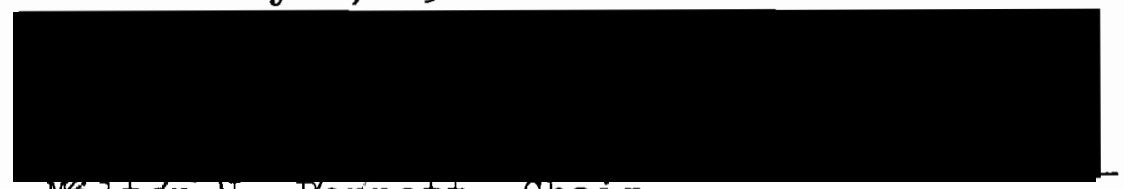

Milt on
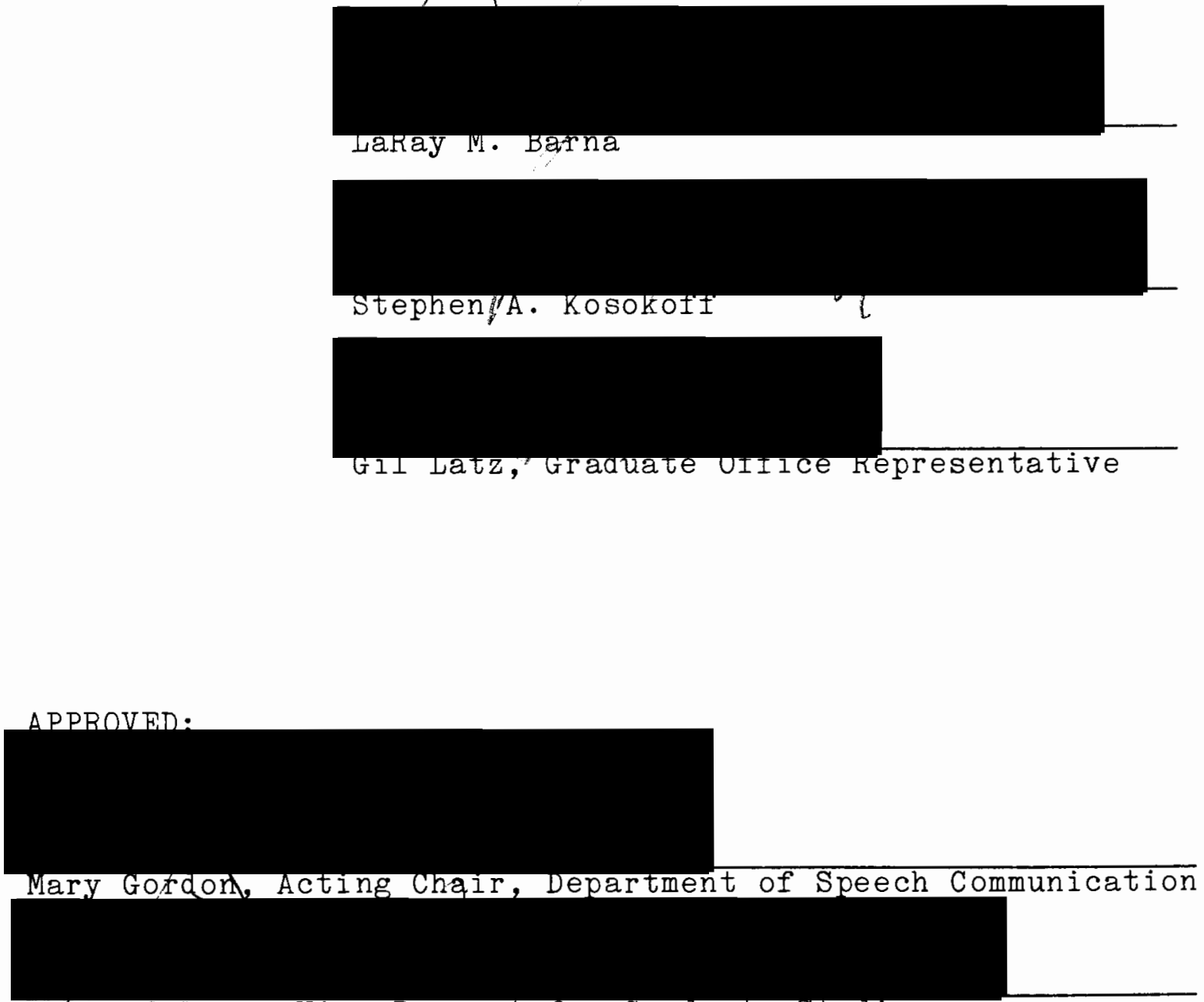

Bernard Ross, Vice Provost for Graduate Studies 


\section{ACKNOWLEDGEMENTS}

I would like to express my heartfelt gratitude to all my committee members for their valuable comments and suggestions that helped shape the final form of this study. In particular, I am deeply indebted to Dr. Bennett, my longtime academic advisor and chair of the committee, for his continued support and guidance. My intellectual debts to him are enormous. My warm thanks to Mrs. Barna for her caring guidance and encouragement. My special thanks to Dr. Kosokoff for filling in for Dr. Steward, who was on sabbatical, on very short notice. I am grateful to Dr. Latz for his presence at the committee.

I would also like to thank a number of people whom I was fortunate enough to get to know and who helped me grow. Finally, my deepest love and gratitude go to my mother, my late father, and my sister, whose faith and confidence in me have been a source of strength in years of my struggling life on this foreign land. Without their love and support, nothing could have been possible. 
TABLE OF CONTENTS

PAGE

ACKNOWLEDGEMENTS

LIST OF TABLES

LIST OF FIGURES

ix

\section{CHAPTER}

I INTRODUCTION $\ldots \ldots \ldots \ldots \ldots \ldots \ldots \ldots \ldots \ldots \ldots$

Rational .......................... 3

Purposes and Research Questions ........ 5

I I CROSS-CULTURAL BUSINESS NEGOTIATION $\ldots \ldots \ldots \ldots 9$

Introduction $\ldots \ldots \ldots \ldots \ldots \ldots \ldots \ldots \ldots$

The Literature on Negotiation .......... 10

A Schism between Institutional

and Empirical Literature .......... 10

Cross-Cultural Business Negotiation .. 12

Negotiation Defined .................. 13

Definitions $\ldots \ldots \ldots \ldots \ldots \ldots \ldots$

The Context of Negotiation ........ 14

Major Problems in Cross-Cultural Business

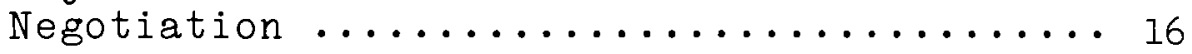

The Process of Business Negotiation ...... 18

The Four Stages of Business

Negotiation..................... 18 
Major Discrepancies in Japanese

PAGE and American Business Negotiation

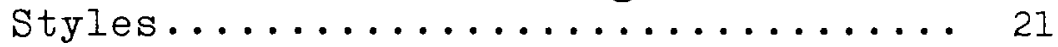

III PROBLEMS IN THE NEGOTIATION PROCESS THAT ARE ATTRIBUTABLE TO CULTURAL DIFFERENCES.......... 25

Introduction..................... 25

Differences in Cultural Assumptions

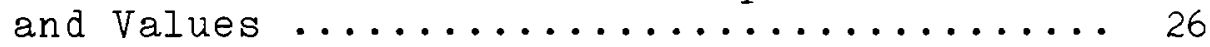

Definitions $\ldots \ldots \ldots \ldots \ldots \ldots \ldots \ldots$

Comparisons of Cultural Assump-

tions and values .............. 27

Differences in Philosophies of Negotiating ............................. 34

Business Relationships .......... 34

Contract ...................... 35

Differences in Communication Styles....... 37

The Language Barrier and Its Implications ....................... 38

Japanese and American Communication Styles ................. 43

Japanese Mentality: the Concept

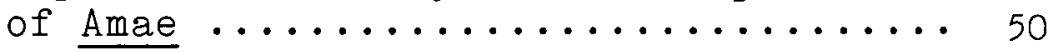

Implications for Negotiation ...... 56

Differences in Decision-Making Processes.... 58

Conception of Decision Making ...... 58

The Locus of Decision-Making

Authority .................... 59

Communitarian Sentiment in the

Japanese Decision-Making Process .... 60

Implications for Negotiation ....... 63

Differences in Situational Constraints and Status Relationships ............ 65 
Situational Constraints, the Role

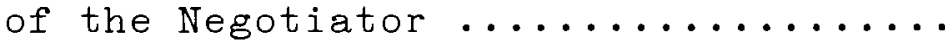

Status Relationships: Horizontal

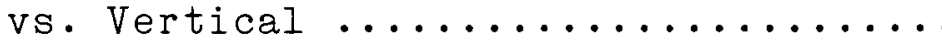

Implications for Negotiation ....... 69

Concluding Remarks .................. 70

IV INTERCULTURAL COMMUNICATION PRINCIPLES ........ 71

Introduction $\ldots \ldots \ldots \ldots \ldots \ldots \ldots \ldots$

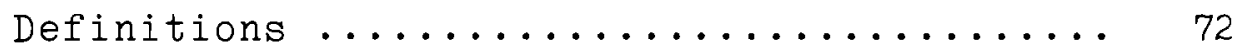

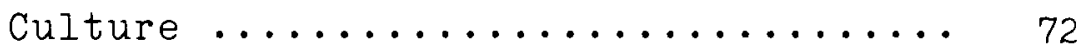

Intercultural Communication

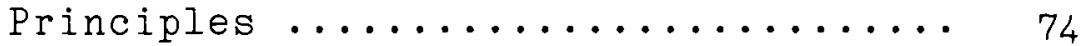

Awareness of Cultural Contrast .......... 76

Cultural Self-Awareness ........... 77

Awareness of Other Culture;

Ethnocentric Awareness ........... 80

Awareness of Cultural Value Conflict.. 90

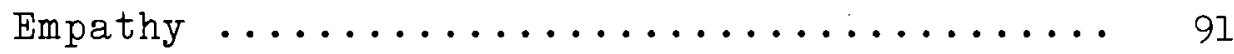

Empathy and Sympathy .............. 91

Developing Empathic Skills ......... 94

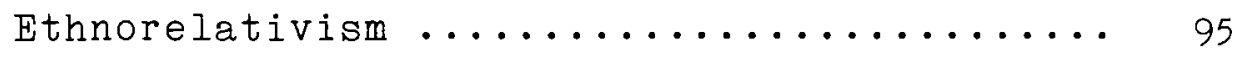

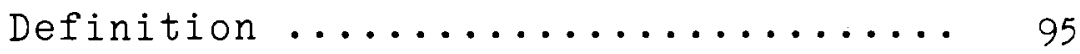

Ethnorelative States and Their

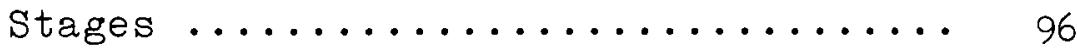

The Applicability and Usefulness of an Intercultural Perspective in Enhancing Nego-

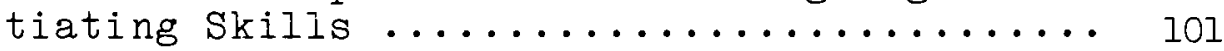

The Assumption of Perceptual

Variance ......................... 101 
Synergistic Conflict Resolu-

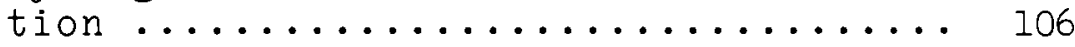

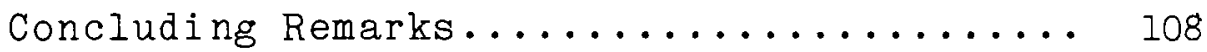

$V$ ANALYSIS OF THE FACTORS AFFECTING THE USE OF AN INTERCULTURAL COMMUNICATION PERSPECTIVE IN CROSS-

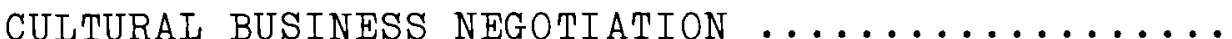

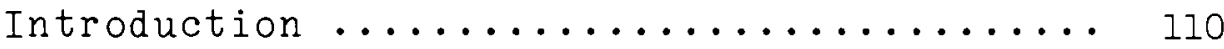

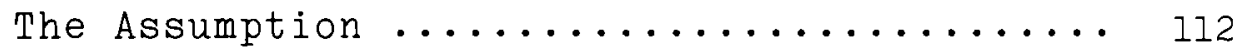

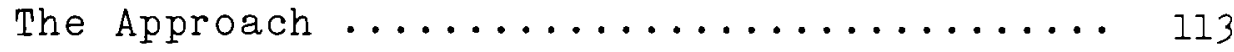

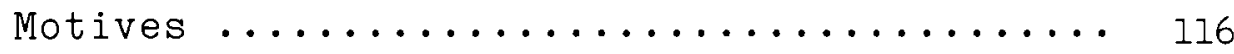

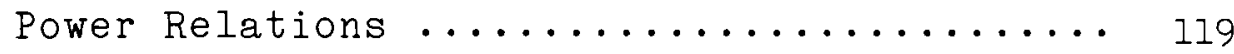

The Reality of Living with

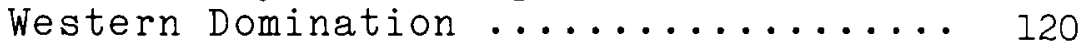

Cultural Accommodation as Nego-

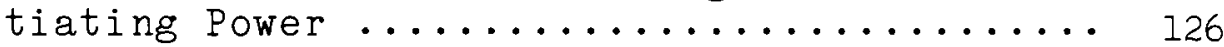

Defining Accommodating ............ 126

Positive Effect of Cultural

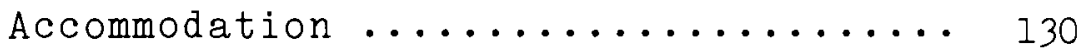

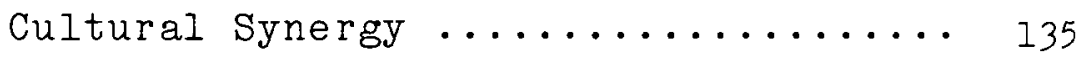

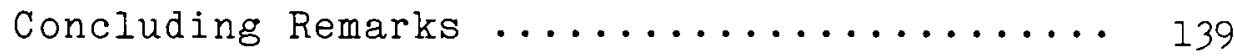

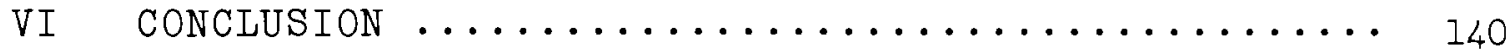

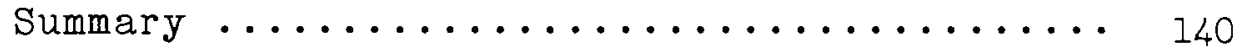

The Future of Cultural Awareness in

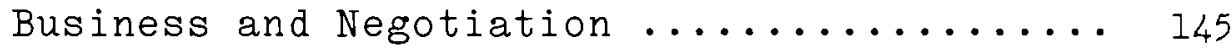

The Importance of Internation-

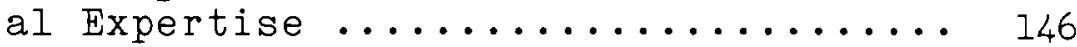

Cultural Training Implications ..... 155

Suggestions for Future Research ......... 160 
I Summary of Japanese and American Business Styles . . . . . . . . . . 20

II Cultural Assumptions and Value Orientations . 28

II Communication and Management Styles . . . . 31

IV Factors Responsible for the Failure of Business Negotiations . . . . . . . . . 39

V Factors Responsible for the Success of Business Negotiations . . . . . . . . . 40

VI Comparison of Communication Styles: USA vs. Japan . . . . . . . . . . . . . 46

VII Communication and Management Styles . • • • 47 VIII The Internationalization of Managers • • • • 157 


\section{IIST OF FIGURES}

FIGURE

PAGE

1. The Context of Negotiation . . . . . . . 15

2. The Dual Concern Model . . . . . . . . 127 
CHAPTER I

INTRODUCTION

The essential difference between international and domestic business negotiations is that international negotiation encompasses a wide diversity of environments of the countries involved. The effective strategies and tactics of international business negotiation, therefore, requires a great degree of modification of perspective and an understanding of the characteristics of the particular foreign environment in which negotiation takes place (Kapoor, 1975, pp. 1-3). However, when individuals enter a foreign environment, what is most likely to happen is that they use a "self-reference criterion -- the unconscious reference to one's own cultural values" in judging situations in the new environment (Lee, 1966; Hays et al., 1972; Kapoor, 1975). This is where one of the basic difficulties in international business negotiation lies. A part of the purposes of this study is to make cultural values more visible, thus adding cultural awareness to international business negotiation. One of the reasons why culture is not taken into account is because of a "convergence hypothesis." The notion of a "convergence hypothesis" claims that "'the logic of in- 
dustrialism' inevitably leads to a convergence which cuts through and undermines 'tradition' irrespective of the main features of culture, history and values with which the industrializing society began" (Karsh and Cole, 1968, pp. 4647). No doubt there is a certain connection (but not correlation) between the superstructure (social change) and the substructure (technology). Yet as many studies on the Japanese managerial system indicate, despite the rapid Westernization of technological aspects of Japanese industries Japan still remains within a non-Western sociocultural context. Japanese society is changing and will continue to change. However, it does not necessarily imply that convergence of the Japanese and Western social structures (not their social organizations but their fundamentals) is actually occurring or could be possible over time (Agegglen, 1958, Nakane, 1970; Dore, 1973; Peterson and Schwind, 1977). Pascale and Maguire's (1978, 1980) studies, for example, provide more support for "sociology of organizations/convergence" argument than for "cultural diversity." Yet those data are not necessarily suggestive of convergence in their fundamentals. The argument on the "convergence" is beyond the scope of this study. But this study takes the view that at least at the present time the two highly industrialized societies are still described as mirror images of one another, even though a number of simi- 
larities may be reflected on the surface.

Needless to say, culture is not the sole determinant of negotiating behavior. For instance, rapid changes in international political and economic situations do contribute to a shift in the bargaining strengths of the parties. Negotiation is dynamic and multidimensional, and subject to various environmental conditions as well as such factors as issues, events, expertise, and personalities. Hence, although culture is a (not the) factor underlying and surrounding the negotiation process, given the quite dissimilar cultural contexts in the United States and Japan, the success or failure of the business negotiation between the two groups would be influenced to a great extent by the degree of their understanding of the fundamental cultural differences underlying their approaches to the negotiation process. This study adds to that understanding.

\section{RATIONAL}

The literature focusing on doing business with the Japanese has yielded numerous books and articles of an analysis of basic differences in philosophies, values, history, economy, politics, and so on. Few studies can be found that synthesize the situations using intercultural concepts. The basic assumption underlying this study is that the application of intercultural communication principles pro- 
vides an analytical framework according to which the act of intercultural business negotiation can be examined, analyzed, and discussed, and that the awareness of its implications helps international business negotiators better prepare for and cope with their problems.

The goal common to all negotiations is the satisfaction of needs. We negotiate to fulfill our needs and resolve our differences in interests. However, we differ in cognition, affection, and behavior and we all have our own unique ways of perceiving and creating reality. If culture is defined as a process of reality construction, "each of us is culture in himself or herself" (Casse and Deol, 1985, xii). All human interactions are intercultural by definition. The basic stance of this study, therefore, is to view all negotiations as culturally loaded. (Culture, in its broadest sense, may be himself/herself, male/female, parent/child, husband/wife, superior/subordinate, or management/labor and so on.)

Hence, if all negotiations are seen as intercultural encounters, it seems reasonable to assume that employment of an intercultural communication perspective is not only a useful tool for effective communication in cross-cultural negotiation but is perhaps a basis for learning some of the skills and strategies necessary for the success of negotiation of any sort. This study, however, is not intended to verify that employment of an intercultural per- 
spective is a panacea for all the ills that may arise in American and Japanese business negotiations. Rather, it is an exploration of the applicability and usefulness of an intercultural communication perspective in providing a direction of improvement in communication and negotiation skills.

There are two factors that have intentionally limited the scape of this study. One is the fact that intercultural communication is a product of an American frame of reference (Hoopes, 1979, pp. 10-13). Thus, only American sources will be consulted for explicating the analytical frame. The second factor is that little Japanese literature on approaches to negotiation is available in the United States. Thus, the purpose of this study is limited to considering possible intercultural factors in business negotiation models that have been constructed by Americans. While it would certainly be of interest to also consider purely Japanese models, it is assumed here that both Japanese and American readers will benefit from considering the impact of culture on the negotiation approaches commonly used by Americans.

\section{PURPOSES AND RESEARCH QUESTIONS}

The ultimate goal of this study is to discuss the extent to which an awareness of an intercultural perspective could contribute to the development of both American and Japanese 
business people's negotiating skills in dealing with one another. Basically, the nature of the study is congruent with two major distinctive characteristics of international management: "adjustment of strategy to varied environmental conditions and behavioral sensitivity and adaptability" (Fayerweather and Kapoor, 1974, p. 19). This study is intended to serve both as a literature review and as an essay on business negotiations between the United States and Japan from an intercultural perspective. The research questions to be asked, therefore, include the following:

1. What are the major differences in the process of business negotiation between the United States and Japan? (Chapter II)

The question includes 1) defining the four stages of business negotiation and 2) identifying major discrepancies in Japanese and American business negotiating styles.

2. What are the major problems confronted by American businessmen negotiating with the Japanese that are attributable to Japanese and American cultural differences? (Chapter III)

This question is concerned with potential friction between Americans and Japanese in business negotiation arising from the cultural differences. (However, it will not inquire specifically into conflict resolution.) The main concern is with cultural sensitivity 
that affects the negotiation process. The question will be construed in terms of cultural differences in 1) assumptions and values, 2) philosophies of negotiating, 3) communication styles, 4) decision-making processes, and 5) situational constraints and status relationships. However, much weight in the literature review will be given to exploration of the nature and characteristics of the Japanese value system that regulates the negotiating behavior of the Japanese, thereby affecting the strategies of the Americans.

3. What are some relevant intercultural communication principles, and what is the applicability and usefulness of an intercultural perspective in enhancing business negotiating skills? (Chapter IV) To answer this question, first certain principles of intercultural communication will be defined and analyzed in terms of their implications for culture-biased communication problems. They are: 1) awareness of cultural contrast, 2) empathy, and 3) ethnorelativism. Then the applicability and usefulness of an intercultural perspective in negotiating skills will be discussed regarding 1) perceptual variance and 2) synergistic conflict resolution.

4. What are the main factors affecting the use of an intercultural perspective in cross-cultural business negotiation, and how are they manifested in the U.S.- 
Japan business negotiations? (Chapter V) The discussion of this question will center around two interrelated factors -- motives and power relations between parties and their impact on the degree of the parties' cultural accommodation. Two U.S.-Japan business negotiation case studies will be reviewed in opposite contexts. Finally with the qualification of the term "accommodating," cultural accommodation as negotiating power will be addressed.

In the final chapter after brief clarification of the main points of the previous chapters, the future of cultural awareness in business and negotiation will be discussed. The discussion will be based on a review of the research on U.S managerial perceptions of intenational expertise by Kobrin (1984). While the study in question is concerned with U.S. firms only ("Fortune 500" industrial firms), its data have enough applicability and generalizability to address the issue of the importance of cultural awareness and cultural training for prospective business leaders of both the United States and Japan. Thus, exploring this issue will be expected to serve to sum up the underlying purposes and efforts of this study. 
CHAPTER II

CROSS-CULTURAL BUSINESS NEGOTIATION

\section{INTRODUCTION}

This chapter serves as an introduction to this study, in particular to the subsequent chapter. It concerns itself mainly with clarifying the scope of this study through an overview of the literature on negotiation and a brief summary of the relevant literature on cross-cultural business negotiation.

The literature review in this chapter consists of four major sections: 1) the literature on negotiation, 2) definitions of negotiation, 3) major problems in crosscultural negotiation, and 4) the process of business negotiation. The final section will address the issues concerning the different approaches to the process of business negotiation in the United States and Japan (research question \#1). 


\section{THE LITERATURE OF NEGOTIATION}

\section{A Schism Between Institutional and Empirical Literature}

The literature on negotiation falls into two categories -- the institutional literature in industrial relations by professional negotiators and the experimental or theoretical literature by negotiation scholars. There is a large schism between the two approaches to the subject (Stevens, 1963, xi-xii; Zartman, 1976, p. 6; Strauss, 1978, pp. 7-11; Rubin, 1985, p. 5). The institutional literature is essentially descriptive accounts of the encounter and "there have been very few studies of real-life encounters that use or test notions derived from theoretical or experimental studies" (Zartman, 1976, p. 6). On the other hand, the theoretical or experimental literature, much of which utilizes game theory paradigms, has rarely reached to the outer world in search of real bargaining incidents (Rubin and Brown, 1975, p. 298). To put it in Zartman's words, "the first is often uninteresting to the scholar, and the second is incomprehensible to the negotiator." The large communication gap between those who practice negotiation and those who study it has hindered a comprehensive understanding of the bargaining process. 
Zartman (1976, pp. 20-32) suggests a useful framework for studying negotiation by categorizing seven schools, where "each explains outcomes in terms of a different variable and each has something to tell both the observer and the practitioner, although it must be said that the line between any two schools is not always very sharp." The seven schools are:

1. Historical description, explaining a given outcome through a particular set of ingredients or through one unique element.

2. Contextual, which sees outcomes determined by a particular phaseological interpretation of history, referring either to the history of the negotiation itself or to the larger phase of history into which it fits.

3. Structural, finding its explanation of outcomes in patterns of relationships between parties or their goals.

4. Strategic, focusing on the element of choice, as determined by the structure of the values at stake and also by the other party's patterns of selection.

5. Personality types to explain outcomes, combining some of the insights of the structualists with those of the behavioralists in the search for a single key to negotiation.

6. Behavioral skills, explaining the impact of specific behavioral traits on negotiation process and outcome.

7. Process, looking at negotiation as a challenge-andresponse encounter in which the moves are the inputs, and negotiating is a learning process. Parties use their bids both to respond to the previous counter offer and to influence the next one; the offers themselves become an exercise in power. 
Zartman claims that none of those approaches alone provides a comprehensive explanation of the negotiation process because "negotiation is a complex process, with many of its complexities still unexplored."

Cross-Cultural Business Negotiation

The business literature that deals exclusively with cross-cultural negotiation is sparse. As Graham (1983) points out, "a few have appeared in business journals (Van Zandt 1970; Jastram 1974; Kapoor 1974; and Wells 1977), but they are primarily descriptive and often anecdotal in nature. No confirmation of findings has been reported and occasionally opposing prescriptions have been suggested" (p. 47). Due to the surge of interest in Japanese management techniques numerous "doing-business-with-the-Japanese" works have appeared in the past several years. But again, they are centered around prescriptive advice and tend not to be grounded in research or testable theory. Graham's (1983) empirical research on the determinants of the outcomes of business negotiation in three cultures -- Japan, Brazil, and the United States deserves close attention as a rare exception to the rule. (The study was designed to simulate the essential elements of the actual negotiations observed in his preliminary field work.)

This paper is not intended either to bridge the aforementioned schism between the two approaches to the nego- 
tiation process (institutional and empirical) or to develop a theoretical model of cross-cultural business negotiation. As already mentioned, the study of negotiation encompasses various theories and practices. When a cultural dimension is added to this broad terrain, the complexities of the issues are further compounded. With this in mind, the issue of cross-cultural negotiation in this study is tackled from a different perspective, by looking at U.S.- Japan business negotiation as a process of cultural synergy between two entities. The main focus, therefore, will be on 1) identifying some of the psychoand-socio-cultural factors underlying the negotiating behavior of the two cultural groups, with particular emphasis on those of the Japanese, and ultimately on 2) exploring the applicability and usefulness of intercultural communication principles in enhancing crosscultural negotiation skills.

\section{NEGOTIATION DEFINED}

\section{Definitions}

Negotiation has been defined in various ways. In its general sense, negotiation can be defined as "the settlement of differences and waging of conflict through verbal exchange" (Rubin, 1985, p. 5). It can be considered as one of the basic processes of decision making among parties concerning the selection of a single value out of many 
(Zartman, 1976, p.7). It is also viewed as a "mixed motive game": the ambivalence of a player's relation to the other player, the mixture of mutual dependence and conflict, of partnership and competition (Schelling, 1963, p. 89). Yet most of the definitions contain common components and some of the basic characteristics of the negotiation process are summarized by Ways (1985, p. 20) as follows: "Negotiation is a process in which two or more parties, who have both common interests and conflicting interests, put forth and discuss explicit proposals concerning specific terms of a possible agreement." More specifically, this definition involves two crucial factors:

1. The existence of "common interests" and "conflicting interests." Unless both are present, in either an overt or a latent way, negotiation makes no sense.

2. The specificity of agreements are not intended to abolish all conflict between the parties. Negotiated accords work best when their substance is quite limited and clearly defined. (Ways, 1985, p. 20)

The Context of Negotiation

For purposes of this study the analysis of the context of negotiation suggested by Kapoor (1975) is useful in looking at negotiation in relation to the larger structural context within which negotiation occurs. Kapoor argues that the nature of negotiation includes the following dimensions as shown in Figure 1. 


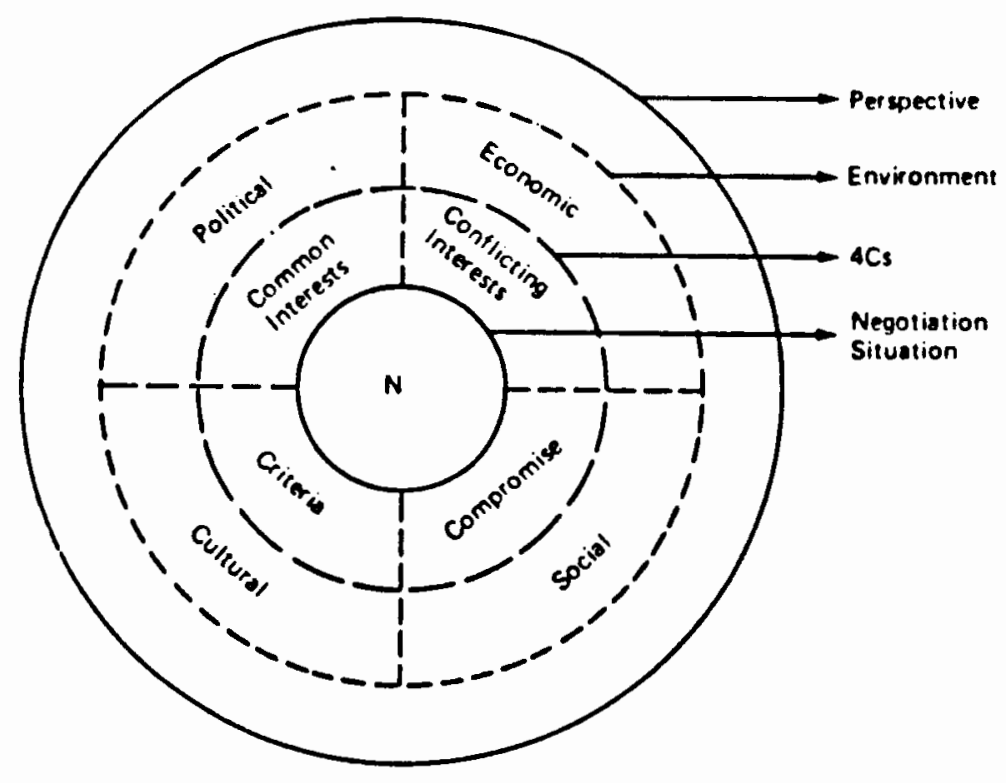

Figure 1. The context of negotiation. Source: Kapoor, 1975, p. 2 .

Thus:

1. Negotiation is typically characterized by four Cs which represent common interests (something to negotiate for), conflicting interests (something to negotiate about), compromise (give and take on points), and criteria or objectives (determining the objective and the criteria for its achievement).

2. Negotiation takes place within the context of an environment composed of the political, economic, social, and cultural systems of a country. The strategies and tactics of negotiation are directly influenced by the environment, which varies with each country. 
3. The negotiator must develop a broad perspective that requires to understand the characteristics of the broader framework within which he negotiates and to be able to interpret the framework for its implications for the specific negotiation he is engaged in.

4. Over times the four $\mathrm{Cs}$ change and the information, know-how, and alternatives available to the internationl company and the host country also change, resulting in a fresh interpretation of the four Cs, the environment, and perspective.

5. The unique characteristic of international versus domestic business negotiations is that international negotiations are influenced by a wide diversity of environments that require changing perspectives which determine the selection of appropriate tactics and strategies of negotiations to be adopted. (Kapoor, 1975, pp. 2-3)

MAJOR PROBLEMS IN CROSS-CULTURAL BUSINESS NEGOTIATION

With respect to the broader framework of negotiations Kapoor (1975) organized some of the major mistakes made in cross-cultural business negotiations into four broad and interrelated categories; empathy, role of government, decision making characteristics, and organizing for negotiations as follows (pp. 5-11):

Empathy

1. Failure to place yourself in the other person's shoes.

2. Insufficient understanding of different ways of thinking.

3. Insufficient attention to saving face of the opponent.

4. Insufficient knowledge of host country. 
Role of Government

1. Insufficient recognition of the nature and characteristics of the role of government in centrally planned economies.

2. Insufficient recognition of the relatively low status assigned to businessmen.

3. Insufficient recognition of the role of host government in negotiations.

4. Insufficient recognition of the perception of host countries of the role of the international company's home government in negotiations.

Decision Making Characteristics

1. Insufficient recognition of the weights assigned to economic and political criteria in decision making.

2. Insufficient recognition of the difference between approval at one level and implementation of such approval at other levels of the government.

3. Insufficient understanding of the role of personal relations and personalities in decision making by the host government.

4. Insufficient allocation of time for negotiations.

Organizing

1. Insufficient attention to planning for changing negotiation strength.

2. Interference by headquarters.

3. Insufficient planning for internal communication and decisions.

4. Insufficient recognition of the role of the negotiator in accommodating the conflicting interests of his group with those of the opposing groups. 
5. Insufficient recognition of the loci of decision making authority.

6. Insufficient recognition of the strength of competitors.

7. Insufficient attention to training executives in the art of negotiation.

Although the four categories are all interrelated with one another and equally essential with regard to the influence on the negotiation process, this is not the place to review all of the issues. This study mainly concerns itself with two of the four categories -- empathy and some of the basic characteristics of decision-making that can be seen most pertinent to an intercultural communication perspective. Consequently, though the issue of role of governments is important in the negotiation between the United States and Japan, the subject will be touched on only briefly in favor of concentrating on face-to-face interaction factors.

THE PROCESS OF BUSINESS NEGOTIATION

The Four Stages of Business Negotiation

Graham (1981) pointed out that in both Japan and the United States business negotiations proceed in the following four stages (p.6).

1. non-task sounding;

2. task-related exchange of information;

3. persuasion; and

4. concessions and agreement. 
The first stage, non-task sounding, refers to all those activities such as "establishing rapport" or sizing up one another, but "does not include information related to the business of the meeting." The information exchange in the second stage is concerned with "the parties' needs and preferences," in other words, "the parties' subjective expected utilities of the various alternatives open to the interaction." The third stage, persuasion, involves "the parties" attempt to modify one another's subjective expected utilities through the use of various persuasive tactics." The final stage of business negotiation refers to "the consummation of agreement which often is the summation of a series of concessions or smaller agreements." The key point Graham made here is that "despite the consistency of this process across cultures, the content and duration of the four stages differs substantially between the two cultural groups" (p. 6). This finding is congruent with other authors' contention that while the overall negotiation process may be similar across cultures, specific implementation differs (Graham, 1983, p. 49. See also Sawyer and Guetzhow 1965; Kay 1970; Frake 1972; Van Zandt 1970: Condon 1974). Hence, the differences of four stages of business negotiations between Japan and the United States are illustrated in Table I. 
TABLE I

SUMMARY OF JAPANESE AND AMERICAN BUSINESS NEGOTIATION STYLES

\begin{tabular}{|c|c|c|}
\hline Category & Japanese & Americans \\
\hline Four stages of business & negotiations & \\
\hline $\begin{array}{l}\text { 1. Non-task } \\
\text { sounding }\end{array}$ & $\begin{array}{l}\text { Considerable time } \\
\text { and expense de- } \\
\text { voted to such } \\
\text { efforts is the } \\
\text { practice in Japan }\end{array}$ & $\begin{array}{l}\text { Relatively } \\
\text { shorter periods } \\
\text { are typical }\end{array}$ \\
\hline $\begin{array}{l}\text { 2. Task-related } \\
\text { exchange of } \\
\text { information }\end{array}$ & $\begin{array}{l}\text { The most important } \\
\text { step - high first } \\
\text { offers with long } \\
\text { explanations and } \\
\text { in-depth clarifi- } \\
\text { cation. }\end{array}$ & $\begin{array}{l}\text { Information is } \\
\text { given briefly } \\
\text { and directly. } \\
\text { "Fair" first } \\
\text { offers are more } \\
\text { typical. }\end{array}$ \\
\hline 3. Persuasion & $\begin{array}{l}\text { Persuasion is } \\
\text { accomplished pri- } \\
\text { marily behind the } \\
\text { scenes. Vertical } \\
\text { status relations } \\
\text { dictate bargain- } \\
\text { ing outcomes. }\end{array}$ & $\begin{array}{l}\text { The most import- } \\
\text { ant step: Minds } \\
\text { are changed at } \\
\text { negotiation } \\
\text { table and } \\
\text { aggressive per- } \\
\text { suasive tactics } \\
\text { used. }\end{array}$ \\
\hline $\begin{array}{l}\text { 4. Concessions } \\
\text { and agreement }\end{array}$ & $\begin{array}{l}\text { Concessions are } \\
\text { made toward the } \\
\text { end of negotia- } \\
\text { tions - holistic } \\
\text { approach to de- } \\
\text { cision making. } \\
\text { Progress is } \\
\text { difficult to } \\
\text { measure for } \\
\text { Americans. }\end{array}$ & $\begin{array}{l}\text { Concession and } \\
\text { commitments are } \\
\text { made throughout } \\
\text { - a sequential } \\
\text { approach to de- } \\
\text { cision making. }\end{array}$ \\
\hline
\end{tabular}

Source: Graham, 1981, p. 14. 
Major Discrepancies in Japanese and American Business Negotiation Styles

A significant difference in business negotiations between the two cultural groups is presented by Graham's (1981, 1983) studies. In American negotiations the outcomes of business negotiations are primarily determined by events at the negotiation table (problem-solving oriented bargaining strategies), while interpersonal relations, which refer to both impression formation accuracy (sizing up one another, establishing an interpersonal rapport) and situational constraints (vertical/status power relations between buyer and seller), are a more important variable in Japanese negotiations. In other words, Americans tend to spend the most time in the third stage of negotiation, i.e., persuasion where "they openly disagree and use aggressive persuasive tactics such as threats and warning;" alternatively, Japanese negotiators spend much more time in "trying to understand the situation and associated details of one another's bargaining position" during the first two stages of the negotiation, so that "little persuasian is necessary" (Graham, 1981, p. 7). As a result, Graham's (1981) findings showed that "Americans consistently report frustrations because of the long periods and great expense of non-task sounding and the ambiguous responses during information exchange," while "Japanese businessmen report discomfort with the American 'need to get down to business now' and their 
aggressive and relentless persuasive tactics" ( $p .7)$. Furthermore, according to Graham (1981, 1983), in negotiation games between Japanese the players who were able to make bargaining opponents feel comfortable achieved higher profits (implicit power plays). Conversely, the negative effect of interpersonal attraction on individual profits was found in American negotiations; Americans achieved higher profits by making opponents feel uncomfortable (explicit power plays).

However, those findings need to be interpreted with caution. With regard to "compliance-gaining" communication there are contradictory findings reported by researchers using different methods. Iustig and Myers (1983), for example, who used the Marwell and Schmitt (1967) strategies found that "American subjects were less likely to use persuasive strategies than subjects from five other countries. Japanese subjects were found to be unlikely users of contingency strategies (e.g., threat, altruism, promise, and pregiving) but likely to use dispositional strategies (e.g., positive self-feeling, positive expertise, and positive altercasting)" (Neuliep and Hazleton, 1985, p. 390). The study of Burgoon et al., (1982) using the same Marwell and Schmitt (1967) strategies also found "a tendency for Asians to have a higher likelihood of using virtually all of the persuasive strategies, but particularly the positively oriented ones" (p. 97). However, Neuliep and Hazleton (1985), who claim 
a lack of representational validity of the Marwell and Schmitt typology, provide data that contradict the findings of Lustig et al., (1983) and Burgoon et al., (1982). They found "a clear preference among the American sample to use both promise and positive expertise significantly more than the Japanese" (p. 401). Furthermore, in their study the three strategies most preferred by the Japanese sample include 1) explanation, 2) direct request, and 3) deceit ( $p$. 399).

Any laboratory experiments are problematic in nature in terms of the external validity and the generalizability of the findings. Aside from the potential limitations in the representativeness of the sample and in the methodology as well as the bias of the researcher, which are common to any study, the main reasons for the limited applicability of game experiments in bargaining lie in the lack of "the long-term context" and "the richness and importance of the context of bargaining situation" (Ikle, 1985, p. 171). In real-life settings the value of the long-term relationship with the opponent (the cumulative long-term effects) often outweighs that of the outcome of a particular one-shot-deal negotiation (short-term gains), thereby affecting a whole set of negotiating behavior among the parties. For this and other reasons careful consideration needs to be given on "the validity of the principal outcome measure, individual profits" in Graham's (1983) study. 
Nevertheless, for the purposes of this study the findings presented by Graham (1981, 1983) are considered useful in providing some evidence that suggests that regardless of the change of the context (from domestic to international) both American and Japanese negotiators have cultural idiosyncracies that dictate their negotiating behavior, particularly at the unconscious level. There are several important cultural considerations involved in those findings:

1) differences in cultural assumptions and value orientations;

2) differences in philosophies of negotiating;

3) differences in communication styles;

4) differences in decision-making processes;

and last but not least,

5) differences in status relationships (vertical vs. horizontal) between buyer and seller.

Those issues will be examined in detail in the following chapter. 


\section{CHAPTER III}

PROBLEMS IN THE NEGOTIATION PROCESS THAT ARE ATTRIBUTABLE TO CULTURAL DIFFERENCES

\section{INTRODUCTION}

This chapter will focus upon identifying some of the psycho-and-socio-cultural factors underlying the negotiating behavior of Japanese and Americans. The research question (\#2) to be explored is: What are the major problems confronted by American businessmen negotiating with the Japanese that are attributable to Japanese and American cultural differences? The discussion will be centered around the following five major issues: 1) differences in cultural assumptions and values; 2) differences in philosophies of negotiating; 3) differences in communication styles; 4) differences in decision-making processes, and 5) differences in situational constraints and status relationships. 
DIFFERENCES IN CULTURAL ASSUMPTIONS AND VALUES

\section{Definitions}

Cultural assumptions may be understood as basic cultural conceptualizations of reality -- the self, family, society, and the universe, which affect people's behavior. Stewart (1972) defined cultural assumptions as "abstract, organized, and general concepts which pervade a person's outlook and behavior" and something that lies behind "values" which refer to "oughtness" (pp. 16-17). He claimed that in contrast to "cultural norms" (some values are called cultural norms) which are explicit and consciously used to describe and justify one's behavior as "adaptation of values to specific situations," cultural assumptions are so "fundamental to the individual's outlook" (the individual's subjective reality is built up out of internalized cultural assumptions) that "they are likely to be considered as a part of the real world and therefore remain unquestioned" (Stewart, 1972, pp. 19-20).

Condon and Yousef (1981), for example, developed twenty-five sets of cultural assumptions and value orientations, each with three variations. (See Table II.) Although diversity in assumptions and value orientations within the same culture does exist, predominance of one 
orientation can be acknowledged in any given culture. Individuals do vary. But dominant regularities of mass behavior found in any given culture are describable as approximations according to the assumptions and value orientations and become more apparent by contrast with those of another culture.

Comparison of Cultural Assumptions and Values: U.S. vs. Japan

A comparison between the United States and Japan can be seen in some of the social ramifications of the basic differences in conceptualization noted in Table II. These specific differences are summarized in Table III. Given the vast cultural differences between the United States and Japan, culture-based problems in the negotiating process could be many. If the existence of differing cultural assumptions and value orientations behind behavior is neither acknowledged nor coped with by either party, it is most likely that problems will arise in the negotiating process. In other words, problems could occur when it is assumed that since "the normal process of business negotiation is basically the same in the United States and Japan," things are done in the same way (Graham, 1981, p. 6) In fact, "parties from different cultures hold different expectations about the normal process of negotiation," which is "one of the major difficulties in any cross-cultural business negotiations" (Graham, 1981, p. 6). 
TABIE II

CULTURAL ASSUMPTIONS AND VALUE ORIENTATIONS

1. All variations may exist in any one society.

2. While those orientations listed in the left-hand column are those often attributed to the United States as a culture, there is no necessary relationship among all of the values in either of the other two columns.

3. This outline is neither definitive nor exhaustive; to be applicable to specific communication between persons from particular cultures, further refinement would be necessary.

SELF

Individualism-interdependence

1. individualism 2. individuality 3. interdependence

Age

1. 2. midile years 3. old age

Sex

1. equality of sexes 2. female superior- 3. male superiority ity

Activity

2. doing being-in-becoming 3 . being

THE FAMILY

Relational orientations

$\begin{array}{lll}\text { 1. individualistic 2. collateral 3. lineal } & \text { 2. }\end{array}$

Authority

1. democratic

2. authority-center- 3. authoritarian ed

Positional role

behavior

1. open

2. general

3. specific

Mobility

1. high mobility 2. phasic mobility 3. Iow mobility, status

SOCIETY

Social reciprocity

1. independence

2. symmetrical-

obligatory

3. complementaryobligatory 
TABLE II

(continued)

Group membership

1. many groups, brief identification, subordination of group to individual

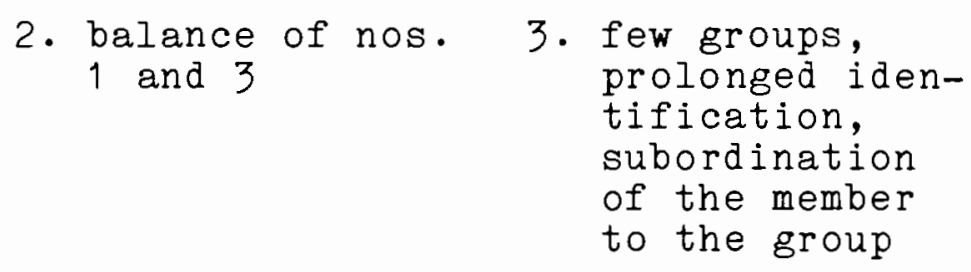

Intermediaries

1. no interme-

diaries

(directness)

2. specialist intermediaries only

2. selective formality

3. pervasive formality

3. community

2. utilitarian

3. essential

Property

1. private intermediaries

HUMAN NATURE

Rationality

1. rational

2. intuitive

3. irrational

Good and evil

1. good
2. mixture of good and evil

3. evil

Happiness, pleasure
1. happiness as goal
2. inextricable bond of happi- ness and sad- ness
3. life is mostly sadness

2. some change

3. unchanging

Mutability

1. change, growth, learning

\section{NATURE}

Relationship of man and nature
1. man dominating nature
2. man in harmony with nature
3. nature domi- nating man

Ways of knowing nature
1. abstract
2. circle of induction- deduction


TABIE II

(continued)

Structure of nature

1. mechanistic

2. spiritual

3. organic

Concept of time

1. future

2. present

3. past

SUPERNATURAL

Relationship of man and the supernatural

1. man as god 2. pantheism

3. man controlled by the supernatural

Meaning of life

1. physical, material goals

2. intellectual goals

3. spiritual goals

Providence

1. good in life is unlimited

2. balance of good and misfortune

3. good in life limited

Knowledge of the cosmic order

1. order is com- 2. faith and reason prehensible

3. mysterious and unknowable

Source: Condon and Yousf, 1985, pp. 60-62. 
TABLE III

COMMUNICATION AND MANAGEMENT STYLES

\begin{tabular}{|c|c|c|}
\hline Theme & U.S. pattern & Japanese pattern \\
\hline $\begin{array}{l}\text { Basis of personal } \\
\text { identification }\end{array}$ & $\begin{array}{l}\text { primarily as an in- } \\
\text { dividual, and then } \\
\text { as part of a larger } \\
\text { group }\end{array}$ & $\begin{array}{l}\text { always as part of } \\
\text { some larger group } \\
\text { (family, school, } \\
\text { work, nation) }\end{array}$ \\
\hline \multirow[t]{2}{*}{$\begin{array}{l}\text { Nature of inter- } \\
\text { personal rela- } \\
\text { tion }\end{array}$} & $\begin{array}{l}\text { independent individ- } \\
\text { uals who work to- } \\
\text { gether based on ex- } \\
\text { plicit matual } \\
\text { agreement }\end{array}$ & $\begin{array}{l}\text { interdependent re- } \\
\text { lations among } \\
\text { people who work } \\
\text { within a context } \\
\text { of unstated mutual } \\
\text { expectations and } \\
\text { obligations }\end{array}$ \\
\hline & $\begin{array}{l}\text { differences in age, } \\
\text { sex, role and rank } \\
\text { should not be em- } \\
\text { phasized outwardly }\end{array}$ & $\begin{array}{l}\text { differences in age, } \\
\text { sex, role, rank, } \\
\text { etc. are outwardly } \\
\text { acknowledged in } \\
\text { interpersonal re- } \\
\text { lations- such as } \\
\text { deference shown } \\
\text { in speech }\end{array}$ \\
\hline $\begin{array}{l}\text { Valued qualities } \\
\text { in work relations }\end{array}$ & $\begin{array}{l}\text { talent, experience; } \\
\text { specialists are } \\
\text { sought }\end{array}$ & $\begin{array}{l}\text { ability to get } \\
\text { along with others, } \\
\text { to evoke and re- } \\
\text { spond to trust; } \\
\text { the generalist } \\
\text { is cultivated }\end{array}$ \\
\hline $\begin{array}{l}\text { Promotion and } \\
\text { mobility in work } \\
\text { relations }\end{array}$ & $\begin{array}{l}\text { based on merit; re- } \\
\text { latively high up- } \\
\text { ward mobility; } \\
\text { relatively less } \\
\text { horizontal } \\
\text { mobility }\end{array}$ & $\begin{array}{l}\text { based on seniority } \\
\text { and merit; re- } \\
\text { latively low up- } \\
\text { ward mobility and } \\
\text { more horizontal } \\
\text { movement; life- } \\
\text { long employment }\end{array}$ \\
\hline $\begin{array}{l}\text { Preferred inter- } \\
\text { personal communi- }\end{array}$ & $\begin{array}{l}\text { directness with } \\
\text { persons of comparable }\end{array}$ & $\begin{array}{l}\text { intermediaries } \\
\text { essential prior }\end{array}$ \\
\hline
\end{tabular}


TABLE III

(continued) cation channels

Social interaction

Family and work loyalties status; indirect with subordinates

some degree of spontaneity, novelty is desired; repartee, "one-upmanship," must be enjoyed. Disagreements can be basis for desired social conversation and stimulation to direct contact; direct and frequent contact between superiors and subordinates

predictability and ritualized interaction valued until very clear friendships or working relations are established. Repartee, sarcasm, "one-upmanship" can be embarrassing or threatening; disagreement in public or social settings (parties) can cause discomfort and embarrassment

loyalty to organization is very strong and may take precedence over immediate family desires (e.g., company outing vs. family vacation); loyalties to parents, benefactors, past teachers, etc., strong; school ties strong and viable; task orientation is subordinate to organizational goals, if in conflict 
TABLE III

(continued)

Time orientation present and immediate

past, present, and future (within months future, all

or few years); past serves as reference point for subsequent change or for nostalgia rather than as guide to action; future serves as an attraction but too uncertain for basis of much planning viable, due to deference to age (age of organizations as well as people), interdependence, and lifetime employment. Manager is responsible for stewardship of ongoing institution.

Source: Condon, 1984, pp. 64-66. 
DIFFERENCES IN PHILOSOPHIES OF NEGOTIATING

Business Relationships

A fundamental difference in the nature of business relationships between the United States and Japan is that where the American managerial system is characterized by contractual relationships (legalistic and formal), the Japanese system is characterized by more interpersonal relationships. This fact has a great deal to do with a basic difference in attitudes toward law in the two countries. Unlike Western countries where law is a way of life, based on "fundamental rights pertaining to the individual and to society," in Japan people's lives are revolving, to a great extent, around unwritten laws such as "responsibilities, duties incumbent on both the individuals and on the community" (Norbury and Bownas, 1974, p. 32). In short, "the concept of personal 'duties' as opposed to individual 'rights'" is still the basis of the vertically structured Japanese society; it assumes that "if everyone performs his duties, there is no need for rights as such to be exercised" (Lee, 1974, pp. 34-35). The significantly fewer number of Japanese lawyers and judges per capita than in any other advanced industrial country is illustrative of the minor role played by the legal process in 
Japan, although it is due largely to a Japanese government policy. (See F.K. Upham's "Iitigation in Japan," 1981, pp. 149-155.) Traditionally, conciliation is the preferred means of conflict resolution.

Contract

The difference in attitudes toward law is highlighted by different approaches toward contracts in business negotiations. That is, as often cited, "Americans try to negotiate a contract, while Japanese try to negotiate a relationship." To put it another way, traditionally the Japanese view a contract as secondary in a negotiated transaction. They assume that "problems can be solved on a case by case basis out of the framework of the relationship" in the belief that a business relationship is built on the principles of mutual trust rather than on legalistic grounds (Lee, 1974, p. 47). As a result, "legal documents are usually kept as brief and flexible as possible to accommodate the evolving relationship between the parties" (Tung, 1984, p. 45). On the other hand, the American view of a contract is that it totally binds upon the parties since its validity is upheld by the courts. Therefore, "it defines the rights and responsibilities of parties and seek to cover all possible contingencies, such as dissolution" (Tung, 1984, p. 45). 
A possible explanation for this difference in the nature of business relationships between the two can be derived from Hall's (1977) concept of "high and low contexts." In short, the difference between high and low contexts lies in the degree of contexting needed in communication. In a high-context (HC) communication most of the information is preprogrammed in the receiver and the setting, with only the minimal information vested in the explicit code (verbal or written code); therefore, meaning is mainly taken from the highly contexted situation or relationship. In contrast, a low-context (IC) communication is one where the mass of the information is transmitted in the explicit code so that meaning can be as decontexted as possible in interpretation. Consequently, in a HC culture the basic nature of business relationships tends to be more interpersonal (desire to establish warm and subjective relationships), while there is more stress on a legalistic and formal level (stress on formal rights and obligations) in a IC culture. Although no culture exists exclusively at one end of the high-low context continuum, Hall described Japan as being a high-context culture and American culture as being toward the lower end on the context scale. However, this does not imply that American businessmen are not concerned about good relationships or Japanese businessmen do not care about litigation. These two approaches to 
business are not mutually exclusive. The difference is in emphasis.

Although it has been over one hundred years since Japan adopted various Western codes, as Lee (1974) pointed out, it seems that borrowed Western legal concepts ('rights') have never really changed Japanese traditional concepts ('duties') (p. 47). One of the potential impediments in the process of negotiation between the two cultural groups could be the difference between Western rationalization based on principles and Japanese rationalization based on circumstances and relationships.

\section{DIFFERENCES IN COMMUNICATION STYLES}

A survey conducted by Rosalie L. Tung (1984, p. 74) regarding factors responsible for the failure of U.S. and Japanese business negotiations showed that "communication breakdown" was perceived by 69 percent of the respondent firms (114 American firms in both Japan and the United States) as being responsible for the failure of business negotiations. Although the factor of "product characteristics," which includes two items "Japanese did not need products/services" ( 83 percent) and "too many competitors all offering same products/services" (73 percent), was perceived by U.S. firms as contributing more to the failure of business negotiations, "communication breakdown" was the most frequently mentioned item among those 
pertaining to the factor "cultural differences." This item was followed by such items as "differences in business practices" (59 percent) and "differences in negotiation styles" (58 percent). (See Table IV and also Table v.)

The Language Barrier and Its Implications

Given the fact that interpreters are usually used in negotiations between the two cultural groups, it may be said that communication problems cannot be attributed to the language barrier. Yet, in fact, the barrier is considerable and many of the concepts are often deeply culture-bound and not easily translatable into another language. In other words, semantic miscommunication is an almost inevitable factor contributing to the difficulty of any cross-cultural communication. Tsurumi (1981b) pointed out three typical areas of semantic communication between Japanese and American negotiators:

First, the implied meaning of the Japanese phrase which is translated as "in principle" (gensoku to shite) is the opposite of the English meaning. If your Japanese negotiators agree to a certain point "in principle" that is tantamount to their declaring that they will abide by it 90 percent of the time (the remaining 10 percent being subject to acts of God). I have seen situations in which American negotiators nearly blew an entire deal merely because of their mental block against the Japanese use of the phrase "in principle." Second, the same holds true for the Japanese interpretation of "gentleman's agreement." In a society in which one's trustworthiness (gentlemanliness) carried high social and economic value, a gentleman's agreement - 
TABLE IV

FACTORS RESPONSIBIE FOR THE FAILURE OF BUSINESS NEGOTIATIONS

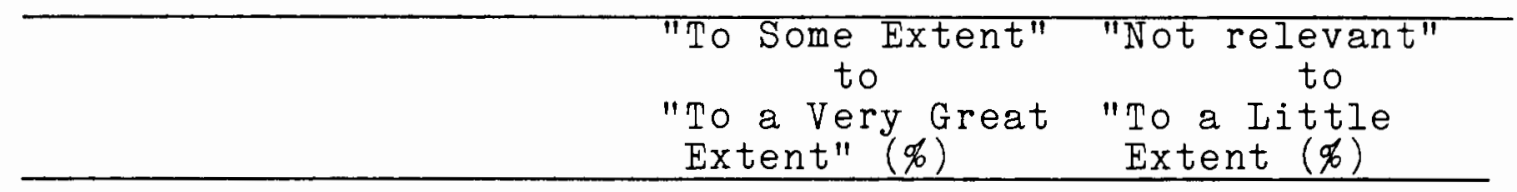

Cultural Differences

Difference in social customs

Communication breakdown

69

Insurmountable cultural differences

Differences in negotiation styles

Differences in business practices

Insincerity on part of Japanese

Product Characteristics Japanese did not need
products/services

Too many competitors

all offering same products/services

Figures indicate the percentage of firms in the total sample that perceive the extent to which the respective items were responsible for failure.

Source: Tung, $1984, \mathrm{p} .74$. 
TABLE V

FACTORS RESPONSIBLE FOR THE SUCCESS OF BUSINESS NEGOTIATIONS

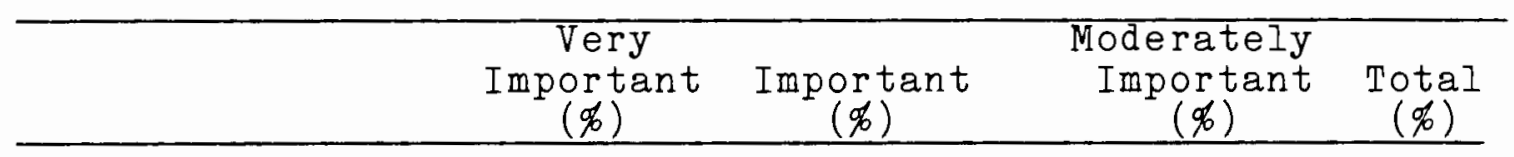

Attitude of U.S.

firm

Preparedness on part of U.S.

Patience on part of U.S. team

U.S. team's sincerity, good

faith, honesty

5

95

59

30

8

97

59

28

10

97

Cultural awareness

Familiarity with Japanese business practices

Familiarity with

31

38

26

95

Japanese customs

22

31

33

86

Uniqueness of Japanese product/service

13

28

38

79

Attitude of Japanese

firm

Japanese team's

sincerity, good

faith, honesty

56

27

15

98

Product character-

istics

Uniqueness of U.S. product/service

40

37

16

93 
TABLE V

(continued)

Personal relationships

Personal ties built-

up over the years

33

38

18

89

Technical expertise

Technical expertise provided by U.S.

firm in the past

29

39

19

87

Figures indicate the percentage of firms in the total sample that perceive the extent to which the respective items were important to success.

Source: Tung, 1984, p. 73 . 
especially on which is witnessed by a respected third party - is, again, almost unbreakable. Third, Japanese have a tendency to say "hai, hai, (yes, yes), or the equivalent of "I understand," or even "I agree," while they are listening to you. These phrases merely mean that they are listening to you and that they understand your positions. ( p. 309)

More importantly, the serious implication of the language barrier is that in terms of the Sapir-Whorf hypothesis the considerable language barrier itself can be a manifestation of the formidable perceptual and cognitive differences between the two. Many communication problems seem to stem largely from the two different ways of culturally programmed mental and thought processes behind the words and concepts that may apparently seem to be understood by both parties. Thought processes here refer to forms of reasoning influenced by cultural assumptions and value orientations. A simple comparison between western and Eastern patterns of thoughts would be Aristotelian modes of reasoning following the logical procedures -- inductive and deductive reasoning (linear) versus intuitional and experiential reasoning characterized by Taoism such as Yang and Ying which emphasizes the organic harmony between the whole and its parts (circular). The components of commu-

\section{1}

The Sapir-Whorf hypothesis (1956) proposed that the forms of our thoughts are to a great extent unconsciously built up on the language system we have learned; thus, our language system predisposes us to think certain thoughts and perceive certain realities. 
nication style are considered as reflections of all those cultural factors, rather than just personal mannerisms. In other words, as Barnlund (1975) said, "all communication behavior derives from a dominant interpersonal orientation" in a given culture, which its members should be predisposed to assimilate as an absolute necessity for survival as well as a prerequisite to effectiveness in human interaction in the community ( $p$. 118).

Japanese and American Communication Styles

In his Public and Private Self in Japan and the United States Barnlund (1975) postulated a basic difference in interpersonal accessibility between Japanese and Americans and investigated its consequences in their communication behavior. He hypothesized that a critical difference between Japanese and American communication styles lies in a difference in the degree of disclosure of the public and private self in everyday encounters. That is, Japanese would prefer a communicative style in which the self made accessible to others (the public self) is relatively small, while the proportion not disclosed (the private self) is relatively large. The opposite would hold true for Americans. Hence, if this postulate is true, it is predicted that Japanese should prefer to avoid further exposure of their inner feelings and thoughts, thereby reducing the scope of verbal disclosure and the intensity 
of personal involvement and adopting a passive defense approach (e.g., silence, withholding contradictory opinions) in threatening interpersonal situations. Americans, in contrast, should desire to express and share a larger proportion of their inner experience, and therefore prefer more spontaneous form of communication, cultivate both verbal and nonverbal expressiveness, and favor more aggressive solutions to threatening encounters. Those predictions were later supported by examination of a "Role Description Checklist," where subjects were asked to read the entire list of thirty adjectives and then select the five words that "best describe what Americans are like in talking to each other" and "best describe what Japanese are like in talking to each other." (The subjects consisted of a total of one hundred and twentytwo Japanese college students and total of forty-two American college students enrolled in classes in Japan.) Stereotypical as they may be, the Japanese described themselves and were described (in nearly complete agreement in the relative ordering of the terms between the two sets of respondents) as "reserved," "formal," "silent," "cautious," and "evasive." By the same token, Americans described themselves and were described as "self-assertive," "frank," "spontaneous," "informal," and "talkative." 
Barnlund (1975) notes that those cultural characteristics are not merely different attributes, but constitute "the polar extremes along a single set of attributes" ( $p .55)$. That is, "the qualities that one society nurtures -- reserve, formality, and silence in one case, and self-assertion, informality, and talkativeness in the other -- are the same qualities the other society discourages" ( $p$. 57). As Barnlund (1975) says, it may be that "most human tendencies are present, in at least latent form, in all peoples .... differences between cultures are matters of degree and relative frequency, not differences of kind" (p. 65). Yet the attribution of meaning certainly varies from one culture to another. Furthermore, it is also important to note that "agreement on a cultural profile" (suggestions) should not be confused with "the validity of that same profile" (truth) (Barnlund, 1975, p. 65). In other words, those cultural attributes are presented not as "static, 'either-or' descriptions of all Japanese or all American," but as "orientations which members of both cultures may fight against, strive for and certainly out of which they grow and change" (Ramsey and Birk, 1983, p. 239 -- see Table VI and also Table VII).

Again, these cultural generalizations are not intended to stereotype the characteristics of the two cultural groups. The real purpose of cultural contrast, which will be dis- 


\section{TABIE VI}

COMPARISON OF COMMUNICATION STYLES: USA VS. JAPAN

U.S.A.

SELF: Individualistic

REALTIY: Objective

Interaction:

2. Code Preference

3. Interaction Format:
Persuasive

Quantitative

Pragmatic

\section{JAPAN}

Interpersonal

Subjective

Nonverbal (and verbal)

Harmonizing

Holistic

Process

Oriented

Source: Ramsey and Birk, 1983, p. 240. 
TABLE VII

COMMUNICATION AND MANAGEMENT STYLES

Theme U.S. pattern Japanese pattern

Communica- explicit, verbal presentation style tion of information, requests, instruction, etc.

vagueness and ambiguity in communication irritating

emphasis is on expressive forms - speaking and to a lesser extent writing; speech style associated with leadership qualities

meaning always close to surface of words "Say what do you mean, and mean what you say"

Conflict and confrontation regarded as inevitable though not necessarily desirable; problems should be dealt with directly and frankly implicit, nonverbal

(through observation of others and of the situation) and some verbal presentation

vagueness and ambiguity may be positive in giving latitude in interpreting situation and in avoiding conflicts

emphasis is on perception, receptiveness, observation skilis; listening and reading and writing skills valued over public speaking ability

meanings often reside in the situation or context, or are to be read "between the lines" or in what is not said.

conflicts and confrontations are to be avoided if at all possible; harmony in interpersonal relations a primary goal; conflicts may be dealt with indirectly 
TABLE VII

(continued) conflict management important to deal with issues as they arise

Decisionmaking top down; relatively fast; where necessary, decision by vote; consensus, though desiraable, is not expected and sought. through an intermediary, or informally in "after hours" socializing agreement management is important, to prevent problems from occurring; good manager is aware of problem before it is openly presented

upward (from middle or bottom of organization), relatively slow; consensus through lengthy discussion, informal as well as formal, is expected and sought.

Source: Condon, 1984, pp. 64-65. 
cussed in detail later, lies in overcoming our natural cultural blindness, in other words, in gaining a better understanding of where we came from and where they came from that aids us in recognizing (and diagnosing) communication problems before/when they arise. Any generalization allows for a countless number of variations and exceptions.

Nevertheless, there seems to be an almost complete consensus on the basic cultural profiles of the Japanese in contrast to those of Americans (as seen in Tables III, VI, and VII ) between professionals in two fields; specialists in the field of intercultural communication (e.g., Barnlund 1975; Condon and Yousef 1981; Ramsey and Birk 1983) and authors of "doing-business-with-the-Japanese" books (e.g., Glazer 1968; Van Zandt 1970; Norbury and Bownas (eds.) 1974; Richardson and Ueda (eds.) 1981; Graham and Sano 1984; Tung 1984; Zimmerman 1985) or those of Japanese management (e.g. Ouchi 1982; Pascale and Athos 1982; Lee and Schwendiman (eds.) 1982). Many prescriptive works specifically echo Japanese cultural inclination toward reluctance to say "no," ambiguous responses, subtle power plays, self-contained non -verbal behavior (e.g., long periods of silence, fewer negative facial expressions) and so forth as contributing factors to communication difficulties for American.

\section{2}

However, Pascale and Athos (1982) provide a perspective on the effectiveness of ambiguity, uncertainty, and imperfection in communication, which coincides with some of the negotiation tactics advocated by many negotiators (e.g., Nierenberg, 1971; Ikle, 1985). 
Japanese Mentality: The Concept of "Amae"

Definition One useful way of understanding many of the aforementioned Japanese characteristics would be to examine the concept amae. Doi (1973a) singles out the Japanese term amae as "a key concept for understanding not only the psychological makeup of the individual Japanese but of the structure of Japanese society as a whole" (p. 28). Although there is no exact English equivalent of the word amae or amaeru (the verb; amae is its noun form), amaeru can be translated to mean to "depend and presume upon another's love" (Doi, 1982, p. 218). Originally the term amae refers to the psychology of the infant in its relationship to its mother, a sense of oneness between mother and child, the unwillingness to be separated from one's environment. The world of amae, where subject and object merge, enfolds everything, the good and the bad alike in a nondiscriminatory fashion. It is warm and the world of filial piety to the insider, but when viewed from the outside it is illogical, exclusivist, private, and even egocentric (Doi, 1973a, pp. 76-79).

At the conscious level, the word amae, associated with infantile mentality, does evoke negative connotations in the minds of the Japanese; children (and even adults) are often told not to amaeru too much. However, Doi's conception of amae goes beyond the simply negative nuances of the everyday usage of the word. Far more than they are 
aware, the amae mentality of the Japanese is so ingrained in their psyches that amae has become an almost underlying premise that is unconsciously operating (both positively and negatively) in the Japanese mode of interpersonal communication. For this reason, it would seem that Japanese interpersonal communication tends to rely heavily upon nonverbal means. "The psychological prototype of amae lies in the psychology of the infant in its relationship to its mother" (Doi, 1973a, p. 74). Implied by it is the psychology of the "nonverbal" baby (the amae-receiver) who expects the mother (the amae-giver) to be always sensitive enough to read its mind and respond to its needs and expectations with care. A good (sensitive) communicator in the Japanese sense thus has a great deal to do with the ability to perform this amae-giver's role; the ideal amae communication is the one where both parties constantly feel each other out to assure mutuality (another person's good will) by fulfilling simultaneously the role of both amae-giver and amae-receiver. This form of communication is often referred to as "haragei" (hara-[gut]-gei-[art]), which is interpreted to mean gut communication or "the art of guessing inner thoughts by nonverbal means" (Ramsaey and Birk, 1983, p. 246). It is regarded as the highest level of communication skill one can reach in Japan. Traditionally the Japanese have held verbali- 
zation in very low esteem, whereas they have always held reticence or taciturnity in very high esteem. Many Japanese proverbs are suggestive of the Japanese distrust of words. (See Ramsey and Birk 1983, p. 245.) As such, within Japanese communication, silence is more an acceptable and positive form with longer duration and more frequency than its American counterpart. Consequently in negotiation situations "a major difference between a U.S. and a Japanese negotiating team is the amount of time the Americans speak and the observance of long silence on the part of the Japanese" (Tung, 1984, p. 167). A similar observation is also provided by Graham (1981) and Zimmerman (1985) about the Americans' responses to (intolerance for) Japanese silence: either they make quite unnecessary concessions, or they do most of the talking, ending up with little understanding of the Japanese point of view. Although Japanese employment of silence may be a result of their inclination to adopt, in Barnlund's (1975) words, "passivewithdrawing defense to threats" as opposed to American "active-aggressive form of defense" against an unreasonable proposal or an unjustified attack, silence may be a simple

3

Ramsey and Birk (1983) also express a similar viewpoint on silence. "...non-Japanese must learn to become more comfortable in situations of silence and refrain from filling in the space with questions or small talk. It is also imperative to train oneself to be able to wait as long as a minute, after inquiring about understanding or asking for a suggestion, before assuming that no response will be forthcoming" ( $p .246)$. 
reflection of their cultural speech mannerism to which Americans are not accustomed.

Other-Directedness As has been seen, Japanese sensitivity, at the core of which the amae mentality lies, is closely related to their other-directed orientation and their inability (or unwillingness) to divorce themselves from the object (lack of objectivity). Other-directedness refers to an inclination to "respond with great sensitivity to the expectations and preferences of others" (Takeuchi, 1984, p. 56). On the negative side, the other-directed person is, therefore, disposed to say what others want to hear rather than what he/she wants to say. Inability to depersonalize objects (or words) from the individual certainly prevents any candid discussion from taking place. Doi (1973b) calls the Japanese psychological mechanism of interpersonal orientation "the Japanese 2-fold structure of consciousness"; omote (face) and ura (mind). Literally they refer to the fore and back sides of things. Omote means "the patterns one would show to others; ura, "those private and intimate thoughts which generally are not to be shown to others" (p. 258). They are connected to probably more familiar concepts tatemae (form) and honne (substance) respectively. In an universal sense, they are related to Barnlund's (1975) concepts of the public and private self discussed earlier, and they are certainly not exclusively Japanese traits, as Doe says. However, the reasons why the Japanese need to 
make much of the distinction between omote and ura are, first of all, according to Doi (1973b), related to psychology amae, which is also basically an universal trait, yet particularly prevails in Japanese society with its specific connotation, "a longing to merge with others" (p. 259). Thus, Doi (1973b) explains: "Omote or tatemae is a token that the mutuality of members of groups is preserved, while ura or honne which acknowledges the inevitable frustrations in amae is given free rein as long as it does not dispute the former. This is surely a very ingenious way of handing ambivalent feelings" ( .259 ). Another possible explanation for "the Japanese 2-fold structure of consciousness" would be that the distrust of words (verbalization) coupled with the value placed on interpersonal harmony has somehow confined the function of the verbal communication more on a ritualized and superficial level; consequently, Japanese are practically urged to allocate each of the operations of verbal and nonverbal means for a different purpose; verbal communication for omote (face) or tatemae (form) and a more sought and necessitated nonverbal form of communication (e.g., haragei) for ura (mind) or honne (substance). Again, mastery of the mechanism of omote and ura is, by and large, the basic nature of the socialization process in almost every human society. Yet a society like Japan where the harmonious integration of group is foremost seems to encourage this trait further 
as the necessary coping skills entailed by the social relationships.

Social Implications In Doi's (1982) words, "in Japan parental dependency is fostered and its behavioral patterns institutionalized into social structure" (p. 218). For instance, the peculiar relationship between employer and employee in Japan seems to bear some analogy with an alternative form of a parent-child relationship -- the relationship between an adoptive parent and an adoptive child. Unlike the American recruitment practices where people with practical work experience are taken on as the need arises, many Japanese companies (major firms in particular) recruit once a year only young rookies with no experience but high potential for a generalist position, just as many prospective adopted parents prefer to adopt newborn babies rather than adopt older children who have already been processed to some extent. Japanese companies aim at developing emotional ties (trust, commitment) with the employees by nurturing them in the long-running working relationships (e.g. investment in training employees along with career circulation within an organization, participatory decision-making, concern for the social and emotional needs of the employees such as company outings for the employees and their families, financal assistance for the purchase of construction of employees' homes, etc.). The employees who are indulged in such an amae treat, in turn, 
are obliged to repay the amae by their complete loyalty to the organization, which is the kind of amae the employer expects from his employees.

As such, Japanese experience frustration with an "insensitive" person who does not appreciate amae (or obligatory relationships) as much as Americans get frustrated and even furious with an "insensitive" person who in one way or other threatens their independence or individual rights or freedoms. (As Doi says, the Western concept of freedom depends on a rejection of amae as opposed to the Japanese concept of freedom which means a permission for amae. )

Implications for Negotiation

As mentioned earlier, predictions from Barnlund's (1975) notion of "public and private self" about a basic difference in interpersonal accessibility between Japanese and Americans are consistent with the observations of many authors on Japanese business and negotiation as well as with his own survey. Barnlund (1975) postulated that the Japanese would prefer a communication style in which "the public self" (the self accessible to others) is relatively small, while "the private self" (the proportion not disclosed) is relatively large. The opposite would be true of Americans. One of the difficulties facing American negotiators communicating with the Japanese is the Japanese concept of tatemae (form) and honne (substance), which 
is closely related to the Barnlund's concept of "public and private self." The Japanese "public self" tends to take the form of tatemae and their honne is more likely to be confined in "the private self." To take an example:

...Regarding the ambiguous responses of Japanese, the laboratory results indicate that informative and credible bargaining strategies of opponents have no effects on negotiation outcomes between Japanese. Apparently the Japanese negotiator follows the cultural double standard of tatemae and honne. Tatemae can be translated as "truthful," and honne as "true mind." It is important for Japanese to be polite and to communicate the tatemae while reserving the possibly offending, but also informative honne... Japanese often describe Americans as honest and frank, but to the point of discomfort for Japanese. Finally, eye contact is much less frequent during Japanese negotiations, thus limiting leakage of potentially offending feelings and keeping intact the honne. To the American point of view the distinction between tatemae and honne seems hypocritical indeed. $\overline{\text { However }}$, the discrepancy is borne by Japanese in good conscience. (Graham, 1981, p. 7 -- also see Table I)

Doi (1973b) calls this so-called cultural double standard "the Japanese 2-fold structure of consciousness" ( $p$. 258). The value of maintaining harmoneous interpersonal relationships may be a major contributing factor for that. But it would also seem that a culprit of the Japanese heavy emphasis on communicating the tatemae as a face-saving device is their inability to depersonalize objects (e.g., criticism) from the individual. It is, again, rooted in the amae mentality, where subject and object merge, a sense of oneness between mother and child, and the unwillingness to be separated from one's environment. Conversely, 
Americans' directness and confrontiveness in communication stem largely from their ability to impersonalize a part of the person from his/her whole personality. Although face-saving is important in any culture, as Tung (1984) says, "the difference is in the level of sensitivity and the ability to cope with it" (p. 143). In general, Japanese are more sensitive in this area and are less capable of coping with affronts than Americans. Hence, Tung (1984) suggests that "in negotiation the Americans should never back the Japanese partner into a corner but should always give the other side sufficient room to maneuver and change positions without a loss of face" $(p \cdot 60)$.

\section{DIFFERENCES IN DECISION-MAKING PROCESSES}

Conception of Decision-Making

Peter F. Drucker (1974) pointed out that a critical difference between Japanese and American decision-making is the difference between the emphasis on "defining the question" and the emphasis on "giving an answer":

In the West, all the emphasis is on the answer to the question. Indeed, our books on decision-making try to develop systematic approaches to giving an answer. To the Japanese, however, the important element in decision-making is defining the question. The important and crucial steps are to decide whether there is a need for a decision and what the decision is about. And it is in this step that the Japanese aim at attain- 
ing consensus. Indeed, it is the step that, to the Japanese, is the essence of the decision. The answer to the question (what the West consider the decision) follows from its definition. (p. 467)

To take a specific example of this holistic Japanese approach to decision-making:

I once watched a Japanese company work through a proposal for a joint venture received from a well-known American company, with whom the Japanese had done business for many years. The Orientals did not even discuss the joint venture at the outset. They started out with the question "Do we have to change the basic direction of our business?" As a result, a consensus emerged that change was desirable; management decided to go out of a number of old businesses and start in a number of new technologies and markets; the joint venture was to be one element of a major new strategy. (Drucker, 1974, p. 469)

The key to this Japanese approach is that the whole process is focused on "finding out what the decision is really about, not what the decision should be," as a result, "the focus is on alternatives rather than on the 'right solution" (pp. 469-470). Interestingly enough, this seems to be a complete account of Barnlund's (1975) remark that "if an American cannot understand why he gets such puzzling answers to such simple questions, the Japanese cannot understand how anyone can give such simple answers to such puzzling questions" ( $p$. 134).

The Locus of Decision-Making Authority

If the first managerial skill in the West is the making of effective decisions as the issuer of edicts (the 
top-down style of decision-making), the most crucial managerial skill in Japan is coordination skills as the facilitator of decision-making (the bottom-up style of decisionmaking). In other words, where the Western decision-making process largely revolves around the responsibility of a specific decision-maker (mainly senior management), the decision-making process in Japan is normally based on building a consensus by "maximum consultation" (Nakane, 1970, p. 145) among the individuals who will be involved in the execution. (The other side of the coin is that in this way the system protects a particular individual from "losing face.") As a result, what is arrived at is "a consensus for execution," not "a decision 'on command" (Ballon, 1974, pp. 106-107). Consequently, the process eliminates selling a decision. The point West calls a decision is already the commencement of the execution in the Japanese system. Predecision delay of the Japanese decision-making is, thus, offset by swift implementation after the decision, whereas the reverse time allocation is typical of the American system.

Communitarian Sentiment in The Japanese Decision-Making Process

Tsurumi (1981a) explains how the process of building a consensus operates in Japanese firms as follows:

The commitment of individual employees to the widely accepted goals of their firm has produced an often mentioned decision-making 
system in Japanese firms that is called ringi seido. Observers of this decisionmaking process will note that new proposals --marketing or investment decision, for example--are often initiated at the lower or middle echelons of the firm. These proposals are passed along through the hierarchy, collecting seals of approval or undergoing minor revisions, on their way up to the president. The initiators or collaborating parties of such proposals are busily engaged on an informal basis in pinpointing key personalities whose support is needed. Some proposals fade away or die on their journey to the top echelon. But those proposals that do survive cannot be attributed solely to their initiator(s). By the time a proposal is accepted by the top management, there will be a corporate consensus concerning its feasibility. (pp.9-10)

The advantage of this seemingly inefficient Japanese decision-making process is that it almost guarantees the commitment of the individuals involved to action and results. Drucker (1974) calls such a Japanese decisionmaking process as participation in "decision-thinking" (or genuine participation in responsibility), not participation in decision-making (p. 258). Nakane (1970), on the other hand, terms it as a kind of "communitarian sentiment, with as major premise, a high degree of cohesion and consensus with the group" (p. 147). That is, the undercurrent of feeling is that "after all we are in the same boat, and we should live peacefully without leaving anyone behind as a stranger." And she thinks that in Japan this sort of sentiment has made it possible for authoritarian power to be exercised in the name of 'democracy,' 
which in the Japanese sense is identified with consensus decision-making on the basis of maximum consultation, not of a truly democratic discussion. (The reason why it is extremely difficult for the Japanese to engage in a truly democratic discussion is attributable to their vertical interpersonal relationships, which will be discussed in the following section.) A consensus in Japan, thus, means acceptance rather than agreement. The power-exercise of a Japanese leader is much restricted by and heavily relies on his subordinates' acceptance.

The Japanese organization, in fact, is more autocratic than its American counterpart in the sense that interpersonal relationships are built along hierarchical orientation that characterizes the structure of Japanese society itself. Yet the power relationship between superior and subordinate is counterbalanced by "informal contacts which give the subordinate men a feeling of being 'in the same boat'," namely, "emotional security" (amae), which is "the foremost requirement for a Japanese engaged in co-operative work" (Nakane, p. 80, p. 147). It is the essence of a vertical relationship known as oyabun-kobun (leader-follower) relationship in Japan. it seems to be the reason why "authority from the top is always matched by responsibility from the bottom up," which Drucker (1974) defined as the real meaning of "consensus decision," despite many contradictions involved in the Japanese decision-making process and group dynamics. 
Implications for Negotiation

Concensus-building practices in the Japanese decisionmaking process can cause irritation to Americans. First, the process of building a consensus is time-consuming. American negotiators often complain of the length of time it takes their Japanese counterparts to reach decisions. It might make Americans wonder whether a decision was made at all or who holds power in Japanese companies. Second, building a consensus among those who will be affected by a decision means that Japanese negotiators have to carefully build a foundation of support from everyone involved. Consequently, Japanese representatives "review and re-review the facts" (Zimmerman, 1985, p. 122) and "ask endless questions" during information exchange (Graham, 1981, p. 7 -- see Table I). Pascale and Athos (1982) note that "frequently, we hear stories of perplexed American firms receiving and briefing a delegation from their Japanese business partner only to receive a follow-up delegation two weeks later which requires the same briefing" ( $p$. 175). (All of this seems to be indicative of "defining the question" (Drucker, 1974) discussed earlier, too.) Furthermore, building acceptance is usually undertaken informally before the formal ringi seido begins to maintain harmony in the actual meeting. Such informal communication is called nemawashi (preliminary groundwrok) in Japanese. Hence, 
Graham (1981) comments: "for Japanese the negotiation is more a ritual, with actions predetermined and outcomes prespecified by status relation" (p. 8).

A possible explanation for this Japanese inclination toward nemawashi and to spend much time trying to understand the situation and associated details of one another's bargaining position is that it is not only because Japanese place more value on maintaining harmoneous relationships than on being frank and open, but also in terms of Hall's (1977) concept of "high and Iow contexts" because they feel uncomfortable without any firm context to belong to (high-context culture). They, in turn, seem to let the context they have programmed pass through a decision-making process.

Another potential problem area in the decision making would be a difference in a Japanese "holistic" approach versus an American "quantitative" approach (Ramsay and Birk, 1983 -- see Table VI ). Americans' needs to quantify an object in numbers and percentages, not just perceiving it in "feelings," again, have to do with their preference for fragmentization of an object rather than dealing with it as a whole. For example, such an decision-making system as "breaking down the decision into component parts and assessing risk at each stage of the project" is a familiar technique to many American managers, Zimmerman (1985) says in retrospect, "the Japanese 
executive had a great deal of trouble understanding the whole concept...mainly because the decision-making system ...was so alien to their own corporate situation and experience" ( $p \cdot 121)$. Consequently, the difference tends to manifest itself in the negotiation situation as follows:

Regarding the fourth and final stage of business negotiations, Americans tend to make concessions throughout, settling one issue, then proceeding to the next. Thus, the final agreement is a sum of the several concessions, and progress can be measured easily. The Japanese tend to make concessions at the end of the negotiation and agreements are concluded rather abruptly from the American point of view. (Graham, $1981, \mathrm{p} .7$ )

DIFFERENCES IN SITUATIONAL CONSTRAINTS AND STATUS RELATIONSHIPS

Situational Constraints, the Role of the Negotiator

Graham's (1981, 1983) studies of cross-cultural business negotiations examined the impact of a situational constraint, the role of the negotiator (buyer and seller) on individual profit levels. In his samples of three cultural groups -- Brazilians, Japanese and Americans, buyers in general did better than sellers in the simulated business negotiations. Yet, the role of a player was the key variable only in negotiations amongst Japanese, where buyers consistently achieved higher profit solutions than sellers. In American and Brazilian samples the relations between role and individual profit levels lacked statistical significance. When Americans are negotiating with 
other Americans, a representational (problem-solving oriented) bargaining strategy was the most important variable. But in negotiations amongst only Japanese, the representational bargaining strategy had no influence on the player's performances. "For Japanese, the negotiation is more a ritual (tatemae and amae are foremost), with actions predetermined and outcomes prespecified by status relations (minds are changed 'behind the scenes')" (Graham, 1981, p. 8). Further, the degree to which Japanese bargaining behaviors are constrained by status relations was observed by Graham (1981) through videotaped business interactions: "Japanese, like Americans, do use aggressive persuasive tactics. However, in Japanese negotiations, threats, warnings and like tend to be used only by the buyer and in the later stages of the negotiations (when all else fails)" (p. 8).

Status Relationships: Horizontal vs. Vertical

The horizontal relationship between American buyer and seller as opposed to the vertical relationship between Japanese buyer and seller is, in fact, one of the most interesting (and impressive) cultural differences the author (a native Japanese) has perceived in her everyday experience in the United States. However, this difference in interpersonal relationships is not, of course, con- 
fined to commercial aspects of the both societies; rather it is a manifestation of the fundamental differences in social relationships between the two cultures. American culture attaches high value to equality in social relationships. Although ironically the emphasis on the "value of individualism and freedom" sometimes creates problems of "inequality and discrimination in social relationships with persons of different racial and ethnic groups" (as a result of "the freedom to decide who to relate with, what groups to join, and how to conduct social relationships"), yet the basic interpersonal equality is espoused as the cultural premise (Samovar et al., 1981, pp. 78-79). Even when different hierarchical levels exist between two persons their interactions tend to be conducted in such a way as to establish equality. By contrast, in Japanese society the basic social relationships are formed by "multiplication of a vertical relation between two individuals" (Nakane, 1970, p. 44). The bases for vertical relationships are age, sex, rank (in and of an organization), roles and so on. (It should be noted that the vertical relation in Japan is not based on the inherited class stratification as seen in England or India.) The codes (both verbal and nonverbal) that differentiate appropriate situational behavior for Japanese are much more complex and delicate than their American counterparts. The Japanese language cannot be spoken appropriate- 
ly without status and age considerations, which determine "the degree of honorific content and politeness." ${ }^{4}$ Even a one-year age difference between two persons requires the younger (thus the lower in the status position) to use a certain amount of honorifics towards the older unless they are very close friends. Thus, the Japanese language and the consciousness of status are interlocked with one another. The Japanese language, as a product of the value of status difference, seems to be functioning as the biggest reinforcer of the ranking consciousness in Japanese society.

Nakane (1970) claims the "the consciousness of rank," namely, "the lack of a discipline for relationships between equals," has prevented the Japanese from developing a logical procedure of the basic steps of reasoning (pp. 34-35). Open expression of opinions is curbed by ranking order. A bold negative expression is rarely employed by a junior for fear of hurting the feelings of a superior or even for fear of being cast out from the group. Freedom to speak out in a group is, thus, determined by a man's place in it; self-expression has to be sought within the framework of the group. As a result,

4

Status differences not only determine correct prefixes and suffixes to be used but differentiate an appropriate word to be used from many synonyms. For instance, there are more than ten status-related synonyms in Japanese that correspond to the first personal pronoun "I" in English. 
in negotiation situations "the chief negotiator on the Japanese team would do most of the talking; the others are generally silent observers... while Americans tend to give the floor to whoever the expert is" (Tung, 1984, p. 167). This view is shared by Barnlund (1975) saying that "the lack of complicating status considerations may ease communication, make for greater approachability with strangers, and encourage greater consistency in verbal, nonverbal, and defensive messages" ( $p .164)$.

\section{Implications for Negotiation}

Hence, given the horizontal relationship between American negotiators and the vertical relationship between Japanese negotiators, what would happen in negotiations between the two cultural groups? Here is Graham's (1981) postulate: "A Japanese seller and an American buyer will get along fine, while the American seller and the Japanese buyer will have great problems (p. 9). That is, the Japanese seller coming to the U.S. to market his products "naturally assumes the lower status position and acts accordingly" (he adjusts his business and negotiation practices to fit the American system), and a sale is made. On the other hand, "the American seller expects to be treated as an equal and acts accordingly; the Japanese buyer is likely to view this rather brash behavior in a lower status seller as inappropriate and lacking in respect." Consequently, a 
sale is much less likely.

\section{CONCLUDING REMARKS}

Factors for success or failure of U.S. and Japanese business negotiations are numerous (see Tables IV and v). Economic considerations must be a foremost motivation to agree on a joint participation. However, cultural understanding could lead to an increased ability to accommodate nehavior necessary for successful business negotiations. From this point of view this chapter attempted to demonstrate the degree to which cultural (unconscious) factors condition negotiating behavior in five areas: cultural assumptions and values; philosophies of negotiating; communication styles; decision-making processes; and situational constraints and status relationships. In the following chapter we will discuss some of the intercultural communication principles that provide a theoretical framework for a better understanding of such unconscious, cultural factors. 


\section{CHAPTER IV \\ INTERCULTURAL COMMUNICATION PRINCIPLES}

\section{INTRODUCTION}

Major purposes of the literature review on the concepts of intercultural communication principles in this chapter are based on the following assumptions on negotiation:

negotiation: 1) all negotiations (all human interactions) are interculturally loaded;

2) negotiation is a process of cultural synergy between two or more differing entities.

This chapter, therefore, is intended to provide a theoretical framework that helps understand and address culture-biased communication problems in business negotiation, thereby lending some insight into the applicability and usefulness of intercultural communication perspective in enhancing negotiating skills. The research question (\#3) to be asked in this chapter is: What are some relevant intercultural communication principles, and what is the applicability and usefulness of an intercultural perspective in enhancing negotiating skills? 


\section{DEFINITIONS}

\section{Culture}

definitions: 1) the deposit of knowledge, experiences, beliefs, values, attitudes, meanings, hierarchies, religion, timing, roles, spatial relations, concepts of the universe, and material objects and possessions acquired by a large group of people in the course of generations through individual and group striving (Samovar et al., 1981, p. 24.).

2) objective and subjective culture objective culture: either artifacts and technologies that produced them (potsherds, tools, habitations, transports, paintings, and so on) or observable human activities (norms of behavior generally, interpersonal roles, childrearing practices, institutional structures, etc.)

subjective culture: human cognitive processes, either non-linguistic (perceptual styles, motivational patterns, and skills) or linguistic (meanings, beliefs, and the linguistic structures which express them) (Osgood et al., 1975, p. 335).

3) culture 1, the recurring patterns which characterize a community as a homeostatic system, and culture 2, people's standard for perceiving, judging, and acting. Culture 1, moreover, is an artifact or product of the human use of culture $2 \ldots$ individuals can be said to possess culture 2 but not culture 1, which is the property of a community as a social-ecological system (Goodenough, 1961, p. 522).

functions: 1) the provider of the skills, knowledge, customs, traditions, material objects, and social organization that make living in groups impossible; 
2) the medium through which a society survives and perpetuates itself by the survival, reproduction, and training of the individuals who comprise the society; and

3) the basis of the structure, stability, and security that both individuals and a society must possess if they are to maintain themselves (Samovar et al., 1981, p. 26).

the nature: dynamic (processual), persistent, enduring, omnipresent, and riddled with contradictions and extremes (Samovar et al., 1981, p. 18, pp. 23-27).

This study is concerned primarily with subjective culture (in the sense of culture 2) possessed by "an aggregation of people (a community's members, collectively)" (Goodenough, 1961, p. 522) rather than with subjective culture of each individual. The term culture used in this study, therefore, refers to subjective culture of people in the collective sense. However, this does not mean to undermine the importance of individual meanings. Rather, the basic stance of this study lies in the view that all human interactions are interculturally loaded in that differing cognitive and perceptual orientations of each individual result in his/her own unique way of creating reality, or subjective culture. Thereby, although this is not intended to equate the complexities and intensities of communication between people of different nationalities with those of communication between individuals of the same nationality, this study takes the view that employment of an intercultural communication perspec- 
tive is an indispensable prerequisite for effective human communication of any sort to take place.

Intercultural Communication Principles

Frequently the terms "cross-cultural communication" and "intercultural communication" are used interchangeably. However, a distinction is sometimes made between them. For example, Prosser (1978) defined intercultural communication as opposed to cross-cultural communication as follows:

Intercultural communication... is defined as the interpersonal communication which has the added characteristics of similarities and differences in language, nonverbal cues, attitudes, perceptions, norms, values, and though-patterning. It is subsumed in the cultural level of the hierarchical model and is related to such subsets as intra/interracial, intra/interethnic, countercultural, and intracultural communication. While intercultural communication is seen as much more spontaneous and unplanned with a relatively small number of persons, cross-cultural communication is considered the interaction on a much more formal, planned, and routinized basis. Intercultural communication is considered much more two-way communication, while cross-cultural communication is considered oneway, from a small group to a larger group. (p. 299)

In this study, however, the terms intercultural communication and cross-cultural communication are employed synonymously. In its simplest sense intercultural communication is understood as communication between people from different cultural backgrounds, where "a message encoded in one culture must be decoded in another" (Samovar et al., 1981, p. 27). A message means any verbal and non- 
verbal behavior to which meaning is attributed. Behavior may occur consciously or unconsciously, intentionally or unintentionally. The fact that the decoder (a message receiver) does not share the same cultural meanings with the encoder (a message producer) means that the meaning intended by the encoder is modified under the influence of the decoding culture when the message is processed. Many of the difficulties inherent in intercultural communication stem from such culturally differing attributions of meaning in the coding processes of communication. Both encoding and decoding are internal perceptual operations in the sense that a message is created or processed in light of the encoder's or the decoder's perceptual frame of reference. Although perception is a highly personalized process, the framework of it is primarily a product of culture.

The significance of learning an intercultural communication perspective lies in the fact that much of the cultural implications are outside our awareness. It is due largely to the elusive nature of culture and of its influence upon us. The elusive nature of culture manifests itself, in Singer's (1982) terms, in "shared, often unarticulated, and sometimes unarticulatable patterns of perception, communication, and behavior," which are, in fact, referred to as "a culture" ( $p$. 58). 
The term "intercultural communication principles" here is used in a generic sense to refer all the concepts that help examine variables in intercultural communication processes and provide directions of improvement in communicative behavior in intercultural transactions. Specifically, in this chapter, the following concepts will be explored: awareness of cultural contrast, empathy, and ethnorelativism.

\section{AWARENESS OF CULTURAL CONTRAST}

Awareness of cultural contrast can be seen to include three types of cultural dimensions suggested by Samovar et al., (1981): 1) an awareness of the cultural patterns that influence upon our own perception, thinking, encoding and other communication behaviors (cultural self-awareness); 2) an awareness of the cultural patterns influencing the communication behavior of people from other cultures (an awareness of other culture); and 3) identification of cultural differences and their effect on communication (an awareness of cultural value conflict) ( $p$.60). In this section the discussion will be centered around the first two dimensions, i.e., cultural self-awareness and an awareness of other cultures -- ethnocentric awareness. 
Cultural Self-Awareness

As long as our way of perceiving the world... on which our communication styles and behavior patterns are based... is "out of awareness" it is not accessible to being deliberately changed, managed, or influenced. (Hoopes, 1979, p. 16)

The Significance of Cultural Self-Awareness The significance of cultural self-awareness can be drawn from a few interrelated terms that all stem from the nature intrinsic to culture and to its members as cultural beings: low level of cultural self-awareness (Samovar et al., 1981); projected cognitive similarity (Kraemer, 1973); and a self-reference criteria (Lee, 1966).

One of the major contributing factors to the low level of cultural self-awareness is our internalization of our own cultural patterns in the course of socialization, which results in burying the most of the influences of culture below the level of our consciousness and blurs the demarcation between the culturally-programmed conscious/ unconscious mind and the culturally influenced and yet unconstrained one (one's personality predisposition). The influences that culture has had on us usually remain unquestioned until our first encounter with people of the other culture. In other words, to the extent that our cultural experiences are limited mainly to the sphere of our own (resulting in the lack of experience to learn to exercise multiple perspectives), we are most likely to subject our- 
selves to the assumption that under the similar circumstances everyone thinks in the same way (projected cognitive similarity). However, projected cognitive similarity or a self-reference criterion (the unconscious reference to one's cultural values in judging situations in a new cultural environment) is by nature an unconscious emotional operation in which even those who are well equipped with intercultural communication skills often find themselves entrapped. Cultural self-awareness is, in this sense, to come to grips with the emotionality of ourselves, i.e., "awareness of emotional self" (Gudykunst and Hammer, 1983, p. 140) and our inherent problems as cultural beings (the unconscious nature of our perception) separate of the degree of our intelligence.

Developing cultural self-awareness is a process of the individual's "becoming more 'functionally aware' and having more knowledge of the degree to which his perception and his behaviors are culturally conditioned" (Hoopes, 1979, p. 13, p. 16). By "functionally aware" Hoopes means "with an awareness that translates into an ability to alter or manage our behavior in intercultural contexts." It is true that cultural self-awareness can be learned both at the cognitive and the affective levels. However, cognitively-learned cultural self-awareness cannot be consummated or validated if not accompanied by the emotional affirmation through affective learning which in- 
volves actual, and usually painful experience in real-life intercultural settings. On the other hand, affective learning that lacks a solid conceptual basis is prone to have weaknesses in its limited application ( $J$. Bennett, 1986, p. 118). Also equally true, however, is that no amount of one's knowledge or awareness can guarantee that one would act out the appropriate patterns of behavior in a given situation. As such, developing cultural self-awareness, i.e., becoming "functionally aware," should be a continual conscious endeavor toward the integration of three levels of communication skills: cognitive, affective, and behavioral. Benefits of Cultural Self-Awareness Probably the most valuable asset we can gain from increased cultural selfawareness is enhanced objectivity in intercultural perspective, i.e., "objectivity in appraising ourselves as well as in evaluating our counterparts" (Samovar et al., 1981, pp. 62-63). Among the reasons: 1) Understanding of the degree to which our perceptions and our behaviors are culturally conditioned allows us to diagnose difficulties in intercultural communication "from the point of view of discovering what cultural aspects of our own thinking may have caused the difficulty," which in turn predisposes us to observe the communication behavior of people from other cultures in their contexts, not in our own.

2) The knowledge acquired by understanding our own cultural patterns (i.e., the knowledge of conceptualiza- 
tion or categorization of cultural patterns) provides us with "a perspective or a frame of reference for identifying cultural similarities and cultural differences between ourselves and others involved in an intercultural encounter."

3) Increased cultural self-awareness leads to "greater awareness of our ignorance of other cultures and a corresponding increase in motivation to learn more about them." Many of the misunderstandings and the difficulties in intercultural (or any type of) communication often stem from our simple ignorance of the other (culture) as well as of ourselves.

For all these reasons awareness of our own culture serves as an essential stepping stone toward awareness of other cultures.

Awareness of Other Cultures; Ethnocentric Awareness

Perception Cultural difference is natural and intrinsic. Yet, we are so accustomed to our own perception of reality that we often find ourselves facing a mental block against accepting different but, equally valid patterns of thought and perception in other cultures. A part of the reason is that our psychological mechanisms are programmed to act on the defensive against any deviation that is incongruent with our identity so as to maintain a certain internal consistency. 
The implied problems here is that our perceptions about other people or other cultures are largely our subjective images (screened out and colored by our own assumptions and values) of those people or those cultures. In its simplest sense perception is understood as a combination of two fundamental internal operations: the physical (organizing stimuli) and the psychological (interpreting data) dimensions (Samovar et al., 1981, p. 109). In short, perception is a creation of "internal mental images" out of the external stimulation. The outcome of perceptual process is, thus, much more influenced by our psychological dimension, the basic framework of which is provided by culture, than by the capacity of our physical apparatus. As such, distortion of our perception of reality and negative stereotyping occur when our experience does not fit into our categories of meaning, thus being forced into an inaccurate category to somehow eliminate ambiguity and uncertainty (Hoopes, 1979, p. 15). Ethnocentrism Ethnocentrism is defined as "the tendency to interpret or judge all other groups, their environments, and their communication, according to the categories and values of one's own culture" (Ruhly, 1976, p. 22) with its implicit assumption of the supremacy and universality of one's own culture. Consequently, it ignores or disvalues the importance of culturally different views of the world in one way or another. 
The most sensitive aspect of ethnocentrism lies in very pervasive human emotionality in the sense that one's cultural identity is a significant part of one's self-concept and self image. In Katz's (1971) words, "national identity... is an anchoring frame for the individual's conception of himself" ( $p$. 424). The socialzation process includes the development of an individual's "self-identity not only as a unique personality but as an individual belonging to an in-group showing the same values and orientations in contrast to foreign out-group" (Katz, 1971, p. 424). In this respect one can argue that the socialization process is the one where a society encourages its members to be ethnocentric for its own survival and stability. This is one of the reasons why cultural sensitivity is so important in any intercultural transaction.

Intercultural learning (the learning of other cultures) suggested by Hoopes (1979), for instance, goes through a progression of seven stages on the learning continuum with ethnocentric awareness as a starting point: ethnocentrism -- awareness (an awareness of other cultures) -- understanding -- acceptance/respect -- appreciation/valuing -- selective adoption -- assimilation/ adaptation/biculturalism/multiculturalism (p. 18). This basic notion is shared by Bennett's (1984) "Developmental models of intercultural sensitivity" that demonstrates 
various processes of a learner's acquisition of intercultural sensitivity. By "intercultural sensitivity" Bennett (1984) means "a person's perceptual relationships to cultural difference" ( .5$)$. The model describes the developmental states from the ethnocentric states (denial, defense, minimization) to the "ethnorelative" states (acceptance, adaptation, integration) with subdivided stages of development within each state.

All varieties in ethnocentric (and ethnorelative) states in Bennett's (1984) model may be found among people in any one single culture or even within an individual with change in his/her perception of cultural difference.

To summarize (pp. 9-30):

I. Denial

- denial of the existence of cultural difference

- the most naive and parochial position

- "...a purely ethnocentric person feels that all people in the world share his or her beliefs, attitudes, behavioral norms, and values."

A. isolation: lack of a category for cultural difference due largely to circumferential physical isolation "Cultural difference is not experienced at all. It simply has no meaning."

B. rejection: "the intentional erection of physical or social barrier to create distance from cultural difference" (e.g., racially distinctive neighborhoods and ethnically-selective clubs) 
II. Defense

- cultural differences are "overtly acknowledged" and yet perceived as "threatening"

- "...strategies are now sought to fight the differences directly in an effort to preserve the absoluteness of one's view."
A. denigration: "negative stereotyping" i,e., nega- tive evaluation of difference in race, religion, age, gender, etc.
B. superiority: "the positive evaluation of one's own cultural status, not the overt denigration of other groups" (e.g., black pride, and some manifesta- tion of nationalism)
C. reversal: "a denigration of one's own culture
and an attendant assumption of
superiority of a different culture"

III. Minimization

- cultural difference is "overtly acknowledge" and "not negatively evaluated", however,

- cultural difference is "trivialized" under the weight of cultural similarities.

A. physical universalism: "...human being in all cultures have physical characteristics in common that dictate behavior which is basically understandable to any other human being."

B. transcendent universalism: "... all human beings, whether they know it or not, are products of some single transcendent principle, law, or imperative" (e.g., religion, the Marxist notion of historical imperative).

Japanese Ethnocentrism; Its Historic Changes If any generalization is allowed about ethnocentrism found among Japanese and Americans, it appears that typical Japanese ethnocentrism takes the form of "polycentric ethnocentrism," whereas typical American ethnocentrism is operating in the direction of "minimization" (minimizing the importance of difference, Bennett, 1984) due largely to the pervasiveness 
of American culture reinforced by the nation's linguistic, economic and military super power in international affairs. The term "polycentrism" refers to the state where one "is overwhelmed by the difference, real and imaginary, great and small, between its many operating environments" (Thorelli, 1966, p. 5). In such a state cultural difference is "overtly acknowledged," and yet perceived as "threatening," which is characteristic of the "defense" state in the aforementioned Bennett's (1984) model. (Implications of these differing forms of ethnocentrism for cultural adaptability in international business will be discussed in detail in chapter VI.)

For a number of reasons Japan as a nation seems to have been caught up in very ambivalent foreign and cultural consciousness. Environmentally, on the one hand, Japan is most likely to be subject to "isolation" (i.e., cultural difference is not experienced at all) due to the almost complete racial homogeniety and the geographical isolation as islands. But on the other hand, a small country with virtually no natural resources required by modern industry is forced to be totally dependent upon imported energy for its survival, thereby fostering a strong sense of helplessness or vulnerability deep inside (although since the first and second oil crises energy-conservation along with the development of alternative energy such as nuclear energy has been promoted). 
Historically, although Japan had formed the foundation of its own culture under the heavy influence of Chinese culture, contacts with China were interrupted by the end of the 9th century. During the Tokugawa Shogunnate (16031867) the Government overtly practiced "rejection" (keeping distance from foreigners) by embarking on an isolation policy (1639-1853). This was a drastic defensive strategy against a potential threat of Western colonialism due to a steady increase in the numbers of converted Christians in the country. "Denigration" (negative stereotyping) of European missionaries was employed to justify the policy. It resulted in the expulsion of all foreigners except for a handful of Dutch and Chinese "traders" confined to the small island of Dejima at Nagasaki, by whom the Government was, in fact, kept informed, if not fully, on what was going on in the West. However, the Meiji Restoration of 1868, in turn, triggered an extreme "reversal" phenomenon (Western cultures are superior to all others) that propelled the nation's radical and instant "catch-up" modernization during the era. But the "reversal" was soon replaced by "superiority" with the advent of imperialism that led to war with China (1894-1895) and Russia (1904-1905), and further military aggression eventuated in plunging the country into the Pacific War (1941-1945) in vain. As a consequence of the surrender to the Allied Powers in 
1945, the pendulum swung back once again from "superior" to "reversal" as may have been expected (for Japan, the process of modernization was always a process of Westernization). At present, when already 41 years have passed since the end of World War II, it would seem that the deep-rooted "reversal" complex, along with the "rejection" residues, is somewhat being balanced with the resurgence of confidence and cultural pride backed by the nation's remarkable postwar economic recovery that built the world's second-largest industrial economy. However, on the other hand, some Japanese are beginning to be concerned about the growing Japanese arrogance observed both at home and abroad (e.g., Kunihiro, 1984, pp. 41-51; Hara, 1984, pp. 30-33; Hiraiwa and Okawara, 1985, pp. 8-9). Prime minister Nakasone's recent (September, 1986) racist remarks on minorities in the United States (minorities lowered the literacy level in the United States) would be one of the worst possible examples of Japan's present leader's "big-power chauvinism," (Kunihiro, 1984) which, in fact, revealed the low level of his own international sensitivity and perspective. In his article Kunihiro (1984) had already castigated Nakasone for his international insensitivity and his "narrow nationalism of a homogenous race," i.e., "racial homogeneity as a source of superiority ." 
Basically, superiority complex and inferiority complex are synonymous in the sense that both are the products of fear or insecurity. Considering the nature of past U.S.-Japan relationships, the growing arrogance exhibited by some Japanese toward the United States could be a repercussion of their deep-rooted inferiority complex toward the United States, which is like the bursting of a dam behind which has accumulated frustration of a century. On the other hand, however, there also could be a possibility that in some cases increasing assertiveness (not only economically but also verbally) on the part of a good old "teacher's pet" is perceived as extremely arrogant by some Americans.

In general, the Japanese are so conscious and perhaps so overly cautious of cultural difference that they are, in fact, imprisoned in their own paranoiac ethnocentric frame. It is associated with their latent xenophobia, which has rendered Japan as homogenous as it is today, and their pessimistic conviction of the uniqueness of Japanese culture that non-Japanese can never comprehend Japanese culture. Xenophobia is based on a fear of losing one's own cultural identity. Despite the fact that over

1

This obviously forms a striking contrast to the basic fabric of American society and to typical American ethnocentrism, i.e., American values are universal. However, there also seems to be quite a number of Japanese who confuse internationalization with Americanization. 
the centuries the Japanese have shown an enormous appetite and a unique aptitude for assimilating elements of foreign cultures, their acquaintance with foreign cultures has never really centered on the most direct form of face-toface interaction with people of other cultures. Suzuki (1985) explains:

Throughout history the medium of almost all Japan's contact with other cultures has been documents and objects rather than personal interaction. The Japanese have very little experience of the most direct form of cultural contact, confrontation with people of other cultures in the course of daily life.... the Japanese never developed the strong sense of identity characteristic of continental peoples, whose countries are contiguous to other countries. ( $p .84$ )

Consequences of Japanese Ethnocentrism The most

damaging consequences of Japanese ethnocentrism for the Japanese themselves are manifested in "an extreme imbalance in the flow of information and opinion, with a heavy flow into Japan but almost no flow the other way," which has exacerbated frustration and tensions arising from trade friction with other nations (Takashina, 1985, p. 78). The Japanese are zealous in exporting products, which have penetrated all over the world, but make little effort to export information about themselves, their values and premises to the rest of the world. A few factors serve to explain the situation. First of all, it is attributable to Japanese parochialism. As has already been discussed, historically, Japan has always been overwhelmingly an importer of foreign cultures in order to catch up with 
advanced nations. In ancient times China was an absolute teaching model for Japan; so have been western countries since the Meiji Restoration of 1868. In other words, Japan has never been in a position to commit itself to fulfill its full international responsibilities as a major power. Culturally, dread of confrontation and distaste for explicit verbalization result in their apparent lack of verbal skills in international contexts, even if those traits are valued and work perfectly in the Japanese 2 context.

Awareness of Cultural Value Conflict

In general, the effectiveness of communication depends largely upon similarities between communicators. Yet in intercultural contexts similarities cannot be relied on. Thus, the key to effective intercultural communication is not to expend most of our energies in the direction of assuming similarities, but to identify and deal with our incompatibilities by creating some commonalities between ourselves and others. Differences and similarities can be identified in such categories as 1) cultural assumptions and values (basic conceptualizations of the self, family, society, and the

\section{2}

There are also a few other obstacles that impede Japan from disseminating information to the rest of the world: the Japanese language as a language in isolation and the Japanese people's negative attitude toward their own language (Suzuki, 1985, pp. 79-84). 
universe), 2) patterns of thought (inductive vs. deductive, linear vs. circular), and 3) communication styles (verbal and nonverbal processes, including such concepts as time and space). For the purposes of this study some of the cultural value discrepancies between the United States and Japan have already been discussed in the previous chapter. Now, a question is: How to deal with differences, which is the main focus of the next section.

\section{EMPATHY}

Empathy and Sympathy

The philosophical assumption essential to empathy is "multiple-reality" (the relativity of frame of reference). It is based on the assumption of perceptual variance; what is perceived is not the same for all people. The alternative to this stance is the assumption of similarity (similarity in our perceptions, given similar circumstances), on which sympathy is based.

The term empathy is contrasted to sympathy and defined as "the imaginative intellectual and emotional participation in another person's experience," while sympathy is "the imaginative placing of ourselves in another person's position" (Bennett, 1979).

In empathy, we "participate" rather than "place," and we are concerned with "experience" rather than "position." Placing 
ourselves in another person's position assumes essential similarity of experience with the other, making it sufficient to merely change places with him or her. In contrast, participation in another's experience does not assume essential similarity. The other's experience might be quite alien, even if his or her position is similar. Thus, we need to do more than merely change places, or stand in the other person's shoes. We need to get inside the head and heart of the other, to participate in his or her experience as if we were really the other person. (Bennett, 1979, p. 418)

Bennett (1984) identified the difference between sympathy and empathy as the difference between "a shift in assumed circumstance" (where one imagines how one's self would feel in another person's position) and "a shift in the frame of reference" (where one temporarily suspends one's own world view in order to experience another), thereby sympathy can be seen as ethnocentric, whereas empathy is ethnorelative (p. 42). In this respect, sympathy could be egoistic even with the best of intentions, whereas empathy is altruistic to the extent that it is exercised constructively for beneficial purposes, not for unethical manipulation.

However, "there is nothing intrinsically 'good' about empathy" (Bennett, 1979, p. 421). By the same token, there is nothing intrinsically bad about sympathy, either. Sympathy is "easy," "credible," "often accurate," and "may be comforting" (Bennett, 1979, pp. 413-414). Yet, "in the face of difference" a sympathetic approach 
does not practically work. it can work best only with extremely similar people with truly similar experiences. Again, the assumption that underlies sympathy is that "all people are basically the same; thus other people want to be treated in the same way we would like." In the face of difference, however, it is so "patronizing" that it could even risk leading to misattribution of motives. To provide a specific example:

The Japanese, with the best of motives, wants to show kindness or respect to the visiting American. So he showers him with attention, plans his itinerary, escorts him to every attraction, supervises each photograph, selects a menu for him, chooses his souvenirs, and honors him with farewell gifts. The intent is constructive, but the American may interpret this as "coercive hospitality" at best, or at worst as "damned interference." He may appreciate the motive, but prefers to select his own itinerary, move at his own pace, choose his own restaurant, and spontaneously change plans according to his mood at the moment. After exhaustion has taken over he may feel more anger than gratitude for the "hospitality" he received. (Barnlund, 1975, p. 42)

Given the fact that culture is the major supplier of values and beliefs, it is highly unlikely that people from different cultures share truely similar perceptual frames of reference. It is, therefore, a safe and more realistic assumption that the reality we experience may not be the same reality being expressed by a person from another (or even in the same) culture. In intercultural communication where difference is inevitably encountered, the key is the ability to shift cultural 
frames of reference when and where necessary, that is empathy •

\section{Developing Empathic Skills}

In order for empathy to occur successfully in intercultural contexts several preconditions need to be considered:

1) a sincere desire for effective communication across cultural boundaries;

2) appreciation of cultural differences and a willingness to make a conscious effort to manage differences;

3) a sufficient knowledge and understanding of cultural factors subject to perceptual variance (as for business negotiation implications, in addition to culture-specific negotiation and management styles, company-specific negotiation styles need to be taken into account); and

4) sufficient flexibility that disallows stereotypes from interfering with judgment.

Specifically, empathic skills can be developed systematically by following six steps suggested by Bennett (1979, pp. 419-421): assuming difference -- knowing self - suspending self -- allowing guided imagination -- allowing empathic experience -- reestablishing self.

Developing empathic skills assists us not only in becoming more sensitized to the values and needs of other people but also in reexamining our own values and expectations. If empathy is exercised mutually, and that 
accompanied by mutual feedback from time to time, the accuracy and effectiveness of empathy will be greatly enhanced. (Conversely, without feedback empathy could be a mere guessing game.)

\section{ETHNORELATIVISM}

Definition

Ethnorelativism is a term coined by Bennett (1984) asn an appropriate opposite to ethnocentrism. It can be considered synonymous with the term cultural relativism in the following views:

1) "Culture can only be understood relative to one another."

2) "There is no absolute standard of 'rightness' or 'goodness' that can be applied to cultural behavior."

3) "Cultural difference is neither good nor bad, it is just different," thus, the position does "not imply an ethical 'agreement' with all difference nor a disapproval of stating (and acting upon) a preference for one world view over another" as long as it is "made on grounds other than the ethnocentric protection of one's own world view or in the name of absolute (true) principles" ( .31 ).

An important point to note is that a substantial change in "the meaning attributed to difference" occurs in the ethnorelative states. Unlike in the ethnocentric states where cultural difference is experienced as "threatening" (either explicitly or implicitly), the 
ethnorelative experience of difference is "nonthreatening," rather "enjoyable." Cultural difference is "both acknowledged and respected," yet "rather than being evaluated negatively nor positively as a part of a defensive strategy, the existence of difference is accepted as a necessary and preferable human condition" (Bennett, 1984, p. 33). Basically it is a nonevaluative, sober attitude toward difference which is taken as a matter of course in life.

\section{Ethnorelative States and Their Stages}

The ethnorelative states consist of a progression of three states with two stages of development within each state: acceptance (behavioral relativism, value relativism); adaptation (empathy, pluralism); and integration (contextual evaluation, constructive marginality). In a state of acceptance value difference is understood "in a processual context" (Bennett, 1984, pp. 37-38). That is, valuing (or culture itself) is seen as a process of reality construct with both great external variation and internal variability rather than being reified into values that are perceived as "things" intrinsic to one's identity. Therefore, "other cultures" different valuing is worthy of respect, not censure." Cultural variation in values and behavior is acknowledged and respected as inevitable and 
enjoyable. (It is associated with cultural self-awareness.)

The adaptation state of intercultural sensitivity is characterized by "the emergence of ability to use acceptance of cultural difference for relating and communicating with people of other cultures" (Bennett, 1984, p. 40). By adaptation Bennett means the ability to "shift" cultural frame of reference for the purpose of effective communication, and it should not be confused with assimilation that implies absorption into a new culture. Thus, it allows for shifting back into one's own cultural frame of reference, which has been temporarily suspended for the purpose of communication with people of other cultures. In other words, in the empathy stage of adaptation "such shifts are intentional and temporary." In pluralism, a more advanced stage of adaptation, however, "the shifts may be more unintentional and tied to permanent frames of reference" ("the existence of two or more internalized cultural reference" is characteristic of all pluralism) (Bennett, p. 41). As such, experience of difference in the stage of empathy is more limited than in the stage of pluralism in that "a different world view is still 'outside' self before and after the act of empathy" (Bennett, p. 46). Yet pluralism itself also has possible limitations -- "nongeneralizability and nonprocessual 
orientation" (Bennett, p. 48) unless accompanied by "a conscious assumption of ethnorelativism." In other words, multiple frames of reference in such nondevelopmental pluralism lack an awareness of systematic development of cultural sensitivity. They are more a simple collection of multiple cultural perspectives with which one can identify, but which one is unable to extend into the general adaptation to cultural difference beyond the cultural spheres one is familiar with.

In the state of integration, the final state of ethnorelativism suggested by Bennett (1984), the person is not only pluralistic (sensitive to many different cultures) but also capable of incorporating difference as an integral part of his ever evolving identity process free from any particular cultural constraints. This type of person is what Adler (1982) calls "multicultural man." His essential identity is inclusive of life patterns different from his own and who has psychologically and socially come to grips with multiplicity of realities" ( $p$. 390). A key ingredient in such multicultural mentality seems to be a strong motive for selfreconstruct (or self-expansion) toward a new identify. It is accompanied by a thirst for knowledge and perpetual psychological quests as well as great flexibility and tolerance for ambiguity. Adler (1982, pp. 394-396) described the multicultural identity as 
follows :

1) The multicultural person is psychologically adaptive... The multicultural identity is premised, not on the hierarchical structuring of a single mental image but rather on the intentional and accidental shifts that life's experiences involve.

2) The multicultural person is ever undergoing personal transitions. He moves through one experience of self to another, incorporating here, discarding there, responding dynamically and situationally.

3) Multicultural man maintains indefinite boundaries of the self. The parameters of his identity are neither fixed nor predictable, being responsive, instead, to both temporary form and openness to change.

4) No culture is capable of imprinting or ingraining the identity of multicultural man indelibly; yet, likewise, multicultural man must rely heavily on cultures to maintain his own relativity.

Hence, implied by such multicultural identity is "the ability to analyze and evaluate situations from one or more chosen cultural perspectives" -- "contextual evaluation" (Bennett, 1984, p. 52). However, several potential pitfalls are also associated with such dynamism (Adler, 1982, pp. 400-402):

1) multicultural man is vulnerable;

2) multicultural man can easily become multiphrenic ("diffused identity");

3) multicultural man can very easily suffer from a loss of the sense of his own authenticity; 
4) multicultural man can very easily move from identity experience to identity experience without commiting himself or his values to real-life situations;

5) the multicultural person may take ultimate psychological refuge in an attitude of existential absurdity, mocking the patterns and lifestyles of others who are different from himself, reacting, at best in a detached and aloof way, and at worst as a nihilist who sees negation as a salvation for himself and others.

Adler, however, pointed out that these "stresses and strains" are basically different in nature from the tensions and anxieties usually associated with cross-cultural adjustment as seen in culture shock. A possible explanation for this in terms of the nature of identity would seem that culture shock may be caused by the clash of conflicting cultural identity patterns while one has had a relatively stable form of self process. Psychocultural dynamism and marginality characteristics of the multicultural person are two sides of the multicultural identity coin. A fluidity of self (or marginality) may give rise to stresses and strains; those tensions are the very basis of the dynamics of the multicultural style of identity. Yet, as Adler also says, the multicultural person does not necessarily have to entertain all those difficulties. In fact, when marginality is consciously used as "a constructive force" based on the awareness of marginality as "a natural out- 
growth of highly developed sensitivity to cultural relativity," it becomes what Bennett (1984) calls "constructive marginality" that "can be the most powerful position from which to exercise intercultural sensitivity" (p. 57).

THE APPLICABILITY AND USEFULNESS OF AN INTERCULTURAL PERSPECTIVE IN ENHANCING NEGOTIATING SKILLS

The Assumption of Perceptual Variance

As obvious from the literature review on the concepts of intercultural communication principles in the previous section, an intercultural perspective does not simply mean a mere awareness of or familiarity with cultural differences. It is an ability to understand and appreciate the reasons for the differences (e.g. the underlying reasons that motivate people to behave in a certain way). It is a person's "nonthreatening," "nonevaluating," and rather positive perceptual relationship to differences ("ethnorelativism"). Associated with this trait are self-awareness, mental flexibility, tolerance of ambiguity, empathy if not more sophisticated "contextual evaluation" i.e., "the ability to analyze and evaluate situations from one or more chosen cultural perspectives" (Bennett, 1984, p. 52), which can be possible by internalization of multiple cultural frames of reference. 
Negotiation here again is defined as "a process in which two or more parties, who have both common interests and conflicting interests, put forth and discuss explicit proposals concerning specific terms of a possible agreement" (Ways, 1985, p. 20).

The assumption of perceptual variance -- what is perceived is not the same for all people -- plays an important role in the negotiation process for the following reasons: Firstly, it should be acknowledged that perceptual and value discrepancies between the parties can become major variables affecting the course of the negotiation. Perceptual difference, however, has ambivalent effects in conflict. On the one hand, it can be a cause of conflict. In many cases perceptual differences (differences in subjective reality, not in objective reality) generate conflicts in the first place. What you perceive to be reasonable is not necessarily what the other party perceives to be reasonable, for instance. On the other hand, agreement can often be reached because of differing perceptions between the parties by "dovetailing differences" in interests, priorities, beliefs and so on (Fisher and Ury, 1983).

Secondly, empathic skills (or a person's nonevaluating perceptual relationship to difference) are considered as a prerequisite to conflict management for the following reasons: 
1) Empathic skills allow for objectifying the problem, wherein the problem is viewed from a common ground in an objective way. For instance, empathy is employed in Lee's (1966) four-step cultural analysis in business adaptation that is designed to check the influence of self-reference criterion (SRC) -- the unconscious reference to one's own cultural values:

$$
\begin{aligned}
\text { Step } 1 \text { - } & \text { Define the business problem or goal } \\
& \text { in terms of the American cultural } \\
& \text { traits, habits, or norms. } \\
\text { Step 2 - } & \text { Define the business problem or goal } \\
& \text { in terms of the foreign cultural } \\
& \text { traits, habits, or norms. Make no } \\
& \text { value judgments. } \\
\text { Step } 3 \text { - } & \text { Isolate the SRC influence in the } \\
& \text { problem and examine it carefully } \\
& \text { to see how it complicates the prob } \\
& \text { lem. } \\
\text { Step } 4- & \text { Redefine the problem without the SRC } \\
& \text { influence and solve for the optimum } \\
& \text { business goal situation. (p. 110) }
\end{aligned}
$$

However, there are some people who tend to interpret empathy mainly from the emotional side of it and argue the costs of empathy in the negotiation process, that is, the costs of oversensitivity and excessive reactiveness to the other's needs and wants in the negotiating outcomes (e.g., Kelle and Schenitzki, 1972; Rubin, 1983; Raven and Rubin, 1985). Moreover, a number of studies on the impact of the bilateral focus perspective (role reversal) vs. self-representation in simulated debates show that "bilateral presentation per se did not lead to more 
frequent attainment over self-representation" (Lewicki and Litterer, 1985, p. 287). Yet this is due to the fundamental function of bilateral focus or empathy, which is to uncover the goals of both parties, i.e., to reveal whether or not actual compatibilities in objectives exist between the parties. According to Lewicki and Iitterer (1985), only under the following circumstances did role reversal tend to enhance objective understanding of the other position:

1. The role reversers performed well, that is, they were skillful effective role reversers.

2. The positions they were advocating were actually compatible. Bilateral focus did not increase agreements when the negotiators' positions were actually incompatible. When positions are incompatible, bilateral focus may serve to sharpen the areas of incompatibility and inhibit progress rather than promote it.

3. One party actively proposed compromises to reconcile any incompatibilities that may be recognized. (p. 287)

Thus, Lewicki and Litterer (1985) say, "...if the use of bilateral focus reveals that the parties' goals are actually incompatible, integral bargaining is impossible, and the sooner that is discovered, the better" (p. 288). In short, empathy should be an operational tool for the need of objectivity in negotiation.

2) Conflict (or difference) needs to be viewed as a natural and a more necessary condition to creative solutions; in other words, a creative decision benefits from the differing points of views and strengths of each the dynamics of competition and collaboration (a win-win 
situation). In his painstaking review of conflict literature Thomas (1976) observed an emergence of a more general recognition of positive effects of conflict in the United states. A balanced view of conflict recognizes that "conflict itself is no evil but rather a phenomenon which can have constructive or destructive effects depending upon its management" ( $p$. 889). The emphasis has shifted from the elimination of conflict to management of conflict over the past thirty years. Thomas (1976) notes some recurrent themes in discussion of positive effects of conflict as follows:

- A moderated degree of conflict may not necessarily be viewed as a cost by the parties involved;

- The confrontation of divergent views often produces ideas of superior quality;

- Aggressive behavior in conflict situations is not necessarily irrational or destructive (suppression of conflict may have the effect of impeding progress and maintaining the status quo). (pp. 891-892)

Needless to say, those views are culture-bound. They are American views of conflict and its management. Yet given the improbability of complete elimination of conflict in human interaction, it appears that the essence of the argument -- the importance of viewing differences as positive diversity -- has universal validity even if conflict may or should be managed in a culturally determined way in a given cultural context. 
Synergistic Conflict Resolution

One of the crucial negotiation skills suggested by Stepsis (1974) is the ability to determine the nature of the conflict, that is, the ability to diagnose "whether the conflict is an ideological (value) conflict or 'real' (tangible) conflict -- or a combination of both" (p. 140). Value conflicts are extremely difficult to negotiate and often unnegotiable. Stepsis (1974) explains:

A difference of values, however, is really significant only when our opposing views affect as in some real or tangible way. If your stand on women's place in society results in my being denied a job that I want and I am qualified to perform, then we have a negotiable conflict. Neither of us needs to change his values for us to come to a mutually acceptable resolution of the "real" problem. For example, I may get the job but, in return, agree to accept a lower salary or a different title or not insist on using the all-male executive dining room. If each of us stands on his principles -- maintaining our value conflict -- we probably will make little headway. But if, instead, we concentrate on the tangible effects in the conflict, we may be able to devise a realistic solution. (p. 140)

In other words, "focus on interests, not positions" (Fisher and Ury, 1983) or focus on "problems rather than our demands" (Nierenberg, 1971). It is clear from the above example that first of all "our demands are only a one-solution approach to the problem" (Nierenberg, 1971, p. 12). To put it another way, "for every interest there usually exist several possible positions that could satisfy it" (Fisher and Ury, 1983, p. 43). Second 
of all, "as more attention is paid to positions, less attention is devoted to meeting the underlying concerns of the parties" (Fisher and Ury, 1983, p. 5). However, it does not suggest that we should totally ignore positions and concentrate only on interests. The implication is that focus should be on identifying underlying interests of the parties while taking into account a specific position of each as a reflection of the underlying interests. Neither position needs to be given up, although it is possible that in the course of a negotiation new circumstances lead to a change in the position of one or the other party.

Intercultural implications of this point are important. It would be almost impossible to resolve any international conflict if the negotiation centers around the argument over the fundamental ideological differences between the parties, and not directed toward resolution-seeking endeavors for mutual gains if and whenever possible. The essence of intercultural communication principles is a creation of common meaning between the differing cultural entities. Based on the appreciation of cultural difference, commonality is established by both promoting shared meaning and resolving conflicting one. What should be dealt with, however, is not cultural difference per se, which exists for good reasons, but the problems caused by the effects 
of difference on communication behavior of the people involved.

The following definitions of cultural synergy by Moran and Harris (1982, p. 5) may serve to explain the nature of integrative bargaining -- a win-win approach to negotiation - Lewicki and Litterer, 1985):

1. It represents a dynamic process.

2. It involves two, often opposing views.

3. It involves empathy and sensitivity.

4. It means interpreting signals sent by others.

5. It involves adapting and learning.

6. It means combined action and working together.

7. Synergy involves joint action of discrete agencies in which the total effects greater than the sum of their effects when acting independently.

8. It has the goal of creating an integrated solution.

9. It is sometimes related by the analogy that $2+2=5$ instead of 4 , but given the various cross-cultural barriers, cultural synergy may be the equation $2+2=3$. If the cultural synergy sum is not negative, progress has been made.

10. For two prospective synergists to synergize effectively, true and complete understanding of the other organization and especially of the culture is necessary.

11. Cultural synergy does not signify compromise, yet in true synergy nothing is given up or lost.

12. Cultural synergy is not something people do, rather it is something that happens while people are doing something else that often has little to do with culture.

13. Cultural synergy exists only in relation to a practical set of circumstances and it takes place by necessity when two or possibly more culturally different groups come to the mutual conclusion that they need to unite their efforts in order to achieve their respective goals.

\section{CONCLUDING REMARKS}

In this Chapter based on cultural awareness the usefulness and applicability of an intercultural perspective in business negotiation was discussed. However, in real-life 
business negotiation situations, a mere awareness or recognition of the usefulness of an intercultural perspective is not necessarily sufficient to motivate people to act it out. There are many factors affecting the use of an intercultural perspective. The following chapter will examine some of the factors affecting the use of an intercultural perspective in cross-cultural business negotiation. Some specific examples of cultural synergy in negotiation will also be discussed. 
CHAPTER V

ANALYSIS OF THE FACTORS AFFECTING THE USE OF AN INTERCULTURAL COMMUNICATION PERSPECTIVE IN CROSS-CULTURAL BUSINESS NEGOTIATION

\section{INTRODUCTION}

In this chapter we shall explore some of the factors affecting the use of an intercultural perspective in crosscultural business negotiation and the degree to which they are manifested in U.S.- Japan business negotiation (research question \#4). While there are many such factors, the discussion will be concerned with two interrelated factors -- motives and power relations between parties.

The chapter consists of five main sections: the assumption; the approach; motives; power relations; and cultural accommodation as negotiating power. Although findings and theory to be presented are sketchy, two of the U.S.-Japan business negotiations case studies (from the literature review) will be used to demonstrate, first, the impact of motives and power relations between parties on the degree of their cultural accommodation in two opposite contexts, and second, conversely, the impact of parties' cultural accommodation on their negotiating power. While power in the first case refers to 
the one shaped by environmental conditions, power in the second case means strategic negotiating power.

The section of "power relations," however, will address a rather general discussion of the impact of U.S.-Japan power relations on cultural adaptability of the two cultural groups. Specifically the discussion will center around the question of why in general the Japanese tend to be more willing to accommodate themselves to cultural differences than their American counterparts in their interaction. A feasible reason would be: "the reality of living with Western domination" (Yamazaki, 1986, p. 59). 


\section{THE ASSUMPTION}

Two issues are of importance here that affect the use of an intercultural communication perspective in cross-cultural business negotiation. The first one is "motives to cooperate" (Tung, 1984, p. 115) that lead to the entry decision and commitment. The second one deals with power, i.e., the ability to influence favorably the decision of others. The main assumption here is that the degree of a willingness (or unwillingness) to use an intercultural perspective in crosscultural business negotiation often has more to do with the impact of the motives and power relations between the parties involved on their negotiating behavior than with the recognition of the importance of bridging cultural gaps per se. In other words, motives to cooperate and power relations of the parties tend to dictate who accommodates behavior more, thus who is more willing to use an intercultural communication perspective in crosscultural business negotiation.

A willingness to use an intercultural communication perspective has three aspects: 1) a willingness to understand cultural differences (cognitive); 2) a willingness to appreciate cultural differences as a viable alterna- 
tive (affective); and 3) a willingness to engage in interculturally appropriate behavior (behavioral). While in the previous two chapters we have emphasized the cognitive and affective aspects, what we are concerned with here is the behavioral aspect. A willingness to understand or appreciate cultural differences does not necessarily go hand in hand with a willingness to act out interculturally appropriate patterns of behavior. Cultural adaptation demands motivation. While there are a number of conditions that produce motivation, attention will be restricted to motives (some specific factors, e.g., incentives) to cooperate and power relations of the parties in business negotiation situations.

\section{THE APPROACH}

Basically the approach this study employs (not only this particular chapter but this entire paper) falls into a category which Thomas (1976) calls a "structural model" of conflict. Thomas synthesized two general models of conflict from his extensive literature review on conflict and conflict management -- a process model and a structural model (pp. 892-894):

Process model: - focuses on the internal dynamics of conflict episodes;

- the objective is to identify the events within an episode such as the frustration of one party, his behavior, the reaction of the other party and 
the final agreement or lack of agreement. Having identified those events, the model is then concerned with influence of each event upon the following events -- for example, how does the party's conceptualization of the issue influence his behavior, how does his behavior influence the other's, and how is the form of the final agreement influenced by their behavior;

- useful for managing an ongoing system and helps one cope with crises.

Structural model: - focuses on the conditions which shape events;

- the objective is to identify parameters which influence conflict behavior, i.e., identifying the pressures and constraints which bear upon the parties' behavior -- for example, social pressures, personal predispositions, established negotiation procedures and rules, incentives, and so on. Furthermore, the structural model attempts to specify the effects of these conditions upon behavior for example, in what way do peer pressures influence behavior, how does frequency of interaction influence conflict behavior, and how do various personal motives shape one's conflict behavior?;

- helpful in altering variables to produce long-run changes in conflict-handling behavior in a situation.

Thomas (1976) claims that the two models complement each other in that "the structural variables constrain and 
shape the process dynamics, while knowledge of the process dynamics helps one predict the effects of structural variables" (p. 894).

While the process model is concerned with a party's conceptualization of issues as a determinant of his behavior, the structural model is concerned with the effects of conditions (e.g., personal predispositions, rules, procedures, incentive, organizational norms, constituent pressures, etc.) upon emergent behavior. Cultural values and norms are considered as one such variable shaping ambient social pressure in terms of proper conflict behavior. Hence, what we are concerned with here is the effect of two particular variables -- motives and power relations between parties -- on their negotiating behavior regarding cultural adaptability.

In fact, the concept of negotiating power involves an infinite number of factors about the negotiating process. Bases of power, therefore, are identified variously. For instance, French and Raven (1959) categorized power into five factors: reward power, coercive power, legitimate power, expert power, and referent power. Lewicki and Litterer (1985) added to them the power of information as a sixth base. Fisher (1983), on the other hand, identified six kinds of power: the power of skill and knowledge, the power of a good relationship, the power of a good alternative to negotiating, the power 
of an elegant solution, the power of legitimacy, and the power of commitment. Moreover, negotiating power between parties are subject to change with a constant shift of circumstances (both internally and externally) developing during the course of negotiation. One's negotiating power can dissipate easily; the negotiating momentum swings from the one side to the other in a moment. However, our main concern is with negotiating power affected by the relatively fixed underlying conditions (sociocultural environment), and not with negotiating power shaped by the moment-to-moment process of various conflict behavior patterns or negotiating strategies and tactics, which, however, will be touched on briefly regarding the issue of cultural accommodation.

\section{MOTIVES}

Referring to Kapoor's (1975) study on international business negotiation, Tung (1984) claims:

$$
\begin{aligned}
& \text {...to capture the dynamics of an interna- } \\
& \text { tional business negotiating situation, it } \\
& \text { is necessary to understand either partner's } \\
& \text { motives to enter into a cooperative agree- } \\
& \text { ment. An accurate gauging of the motives } \\
& \text { will assist in the projection of how accom- } \\
& \text { modating or non-accommodating a particular } \\
& \text { partner to the negotiation will be. If one } \\
& \text { party needed the agreement badly enough, } \\
& \text { it would bend over backward to meet the } \\
& \text { terms and demands of the other partner. } \\
& \text { (p. 115) }
\end{aligned}
$$

In other words, if there is strong enough motive, there may be a willingness to accommodate in order to attain 
negotiating objectives. It seems that a willingness to accommodate to cultural differences becomes an integral part of a whole package of accommodating to the needs of the other party. One of the Tung (1984) case studies, which dealt with a joint program in aircraft production between Boeing and the Civil Transport Development Corporation (CTDC), a quasi-Japanese government entity, shows how accommodating the Japanese could be in industries where Japan is deficient and which are vital to the national interest (pp. 109-129). The Japanese partner was very accommodating "not only in the area of terms agreed to,....but also in its willingness to accept the U.S. style of confrontation in the negotiation process" (Tung, 1984, p. 115). The Kapoor (1975) case study on the MitsubishiChrysler joint-venture negotiation, on the other hand, provides an example of how accommodating and flexible Americans could be in adjusting to cultural differences as well as in seeking terms in the situation where the U.S. company was very anxious to enter the Japanese market (pp. 93-152).

The following are major underlying conditions, including motives, behind such accommodating behavior of the parties in the two case studies (the conditions basically formed a power structure between the parties).

In the case of the Mitsubishi-Chrysler joint-venture negotiations: 
1. The American IC (Chrysler) is smaller than the Japanese IC (Mitsubishi) it was negotiating with.

2. The American company was very anxious to enter the Japanese market and therefore the terms of entry it could seek were different than if it were negotiating with a venture in developing countries, which generally seek foreign investment.

3. The necessity of recognizing and meeting the requirements of the Japanese government in order to gain approval of the joint venture required specific skills and intimate sensitivities in relation to Japanese business-government relations, which greatly enhanced the negotiating position of the Japanese company vis-a $\mathrm{v}$ is the American partner. (Kapoor, 1975, p. 15)

In contrast, main characteristics of the negotiations for the production of Boeing's 767 between Boeing and CTDC were:

1. The Japanese lag considerably behind the United States in aircraft technology; the role of the Japanese is a participant, rather than full-fledged partner.

2. The aerospace industry has been designated by the Japanese government as a growth industry for the rest of the twentieth century. CTDC is a quasigovernment agency created under the sponsorship of the Japanese government, whose working entities are three giant multinationals - Mitsubishi Heavy Industries, Ltd.; Kawasaki Heavy Industries, Ltd.; and Fuji Heavy Industries, Itd.

3. Because of the unique characteristics of the aircraft industry, there is virtually no viable route for Japan to follow except for joint cooperation with foreign manufacturers. (Tung, 1984, pp. 109-112) 
The term "accommodating" will be qualified in detail later with more about these two case studies. But in the meantime the following section will shift attention to a discussion of a more general and broader impact of structurally influenced power relations between the United States and Japan on cultural adaptability of the two groups.

POWER RELATIONS

In the last section of Chapter III, based on the Graham (1981, 1983) studies we discussed the vertical relationship between Japanese buyer and seller as opposed to the horizontal relationship between American buyer and seller and its implications for U.S.-Japan business relations. It was predicted that a Japanese seller coming to the U.S. to market his products "naturally assumes the lower status position and acts accordingly" (he tailors his business and negotiating practices as well as his products to fit the needs of the American context); thus a sale is made. On the other hand, an American seller who assumes the equal status position with his Japanese buyer's tends to be viewed as "inappropriate and lacking in respect" (it may be most reflected in product adaptation); consequently the sale is less probable. 
This is an example of power relations between buyer and seller based on situational constraints and their impact on the behavior of the negotiators. Different degrees in perceptions of power relations between Japanese buyer and seller and American buyer and seller manifest their impact on the negotiators' behavior in different ways. An irony about it in terms of cultural adaptability is that the very usage of the Japanese way of conducting human interaction in international businesss coincidently leads the Japanese seller to be naturally adaptive to the host country or firm he aims at negotiating with.

Circumstantially, it would seem that the United States has been in one of the most disadvantageous positions to become empathic (but in one of the best positions to be sympathetic) toward other nations in the international arena, no matter how culturally pluralistic its own society is, because of the nation's power in every aspect of the international affairs coupled with the pervasiveness of its culture. If there is any truth to the statement that the Japanese have usually been the ones who are more willing to adjust to cultural difference in overall U.S.-Japan relations, it may be probably due to the power relations that have existed between the two nations.

The Reality of Iiving With Western Domination

- Our own great American achievement has somehow 
become a positive psychological handicap. The United States has been a vast and successful working machine for converting into ourselves persons from every nation of the world. We cannot make ourselves over, even imaginatively, into other people.... Our thoughtlessness is caught in our assumptions that what we do is never chauvinistic or nationalistic, though what others do may well be. Thus for British missionaries to teach cricket or Canadian missionaries to teach lacrosse would be chauvinistic, but for American missionaries to teach baseball is not spreading American culture but merely enabling the benighted nations to be human beings. (Ong, quoted in Cleveland et al., 1960, p. 131)

- Business people on both sides of the Pacific have learned to manage... differences in negotiating styles. The Japanese have been better at making adjustments. (Christopher, 1984, p. 31)

- An important aspect of the Japanese style of business negotiation includes adapting bargaining behaviors to those of the host country or firm. (Graham and Sano, 1984, p. 17)

- Most U.S. companies that are international still have a basic strategy that is oriented toward the American market. They are simply not interested in foreign markets. (an American business executive, quoted in Hall and Hall, 1987, p. 151)

In the early years after World War II the United States was the provider of technical expertise and Japan was its recipient. It is true that the economic relations between the two countries have drastically changed ever since. Since the early 1980s Japan's visible (merchandise) trade surplus with the United States has grown rapidly and totaled about $\$ 50$ billion in 1987 (Wall Street Journal, Jan. $6,1988, \mathrm{p} .14)$ and it has been adversely affecting U.S.- 
Japan economic relations. Moreover because of the continuing decline of the U.S. dollar's value against the yen since 1985 (down 54\% from its 1985 heights), which could produce a significant improvement in the trade gap, Japan's direct investments in the U.S. real estate and corporations have been building up very rapidly and reached $\$ 23.4$ billion at the end of 1986 , from just $\$ 4.7$ billion in 1980 .

Furthermore, because of the change in economic relations, a psychological shift in their perceptions of one another has been taking place. American business people have been showing, for the first time, their serious interest in learning Japanese management and business practices and reassessing their own systems; Japanese people have begun to exhibit their "big-power chauvinism" both at home and abroad (e.g., Kunihiro, 1984, pp. 141-151). However, what has not changed and what seems, at least to the author, to be likely to remain the underlying reason for the Japanese people's willingness to adjust to cultural differences in their interaction with Americans is this undeniable reality -- "the reality of living with Western domination" (Yamazaki, 1986, p. 59). Take a simple example: When American and Japanese business people or and Britain ( $\$ 51.4$ billion), according to Time, Sept. 14, 1987, p. 55 . 
politicians meet in Japan, do they bow to each other as a form of greeting? Of course, not. They shake hands, instead. Yamazaki (1986) explains two basic reasons for what he calls "Western domination of world culture":

1) Western culture has a 400 year history of global expansion, beginning with the emergence of the European nation-states;

2) Western culture gave birth to industrial society and so became the purveyor of an asset of universal value: material wealth. (pp. 59-60)

Thereby Yamazaki goes on to say what internationalization for Japan (or any non-Western nations) means:

First, it must be recognized that the world today is the world that was discovered by the West from the sixteenth century on. Accordingly internationalization for Japan means adapting to the Western order. Internationalization thus involves not a peculiar culture adapting itself to a more universal culture but rather one set of peculiarities adapting themselves to another set. Just as "standard" Japanese is not a synthesis of diverse dialects but an expanded version of a particular Tokyo dialect, so the standard language of international relations -- both literally and figuratively -- is merely an extension of Western idiom. ( $p$. 59)

To almost an amazing degree, Japan has been showing an enormous appetite and a unique aptitude for incorporating elements of "advanced Western cultures into its own in order to survive and succeed in the international arena, as discussed in the previous chapter.

However, it must be added that Buddhist fatalism ("the Buddhist virtue of passive acceptance of destiny, 
rather than an active modification of it" $)^{2}$ is considered as another reason why the Japanese are inclined to accomodate themselves as a virtue to the external realities. The word "full" (rather than "sufficient") understanding is almost unrealistic in intercultural settings. The argument in this section that the Japanese are more willing to adjust to cultural difference than their American counterparts in their interaction with one another is not meant to say that the Japanese have a better understanding of what makes the other side of the Pacific tick. Rather it is simply to say that the presumably better cultural accommodation on the part of the Japanese, which is confined largely on the exteria, is a mere result of their playing by the rules in the international community run on Western principles. Both Americans and Japanese still have a long way to go in even having a "sufficient" understanding of each other's cultural premises that influence them differently. Even though billions of dollars of business have been transacted between the two countries and no doubt it will continue to increase in the future, what we are seeing now is increased and probably deep-seated mistrust between these two countries. (See Japan Echo: vol XI, No. 3, 1984, pp. 25-33; vol XII, No. 3, 1985, pp. 7-37; vol

In other words, the value of "man in harmony with nature" as opposed to the value of "man dominating nature" -- see Table 3.1. and Haglund, 1984, pp. 66-67. 
XII, No. 4, 1985, pp. 8-26.) But at least both sides are talking with each other more than ever. Neither can afford not to. Nor can they deny the reality of this powerful economic interdependence.

A recent magazine article, "The Japanese don't know who we are" by Lee Iacocca, Chairman of Chrysler Corporation, provides a good example of how the tension underlying and surrounding the trade friction between Japan and the United States is intensified, on a very emotional level, by a lack of understanding of cultural differences. Journalistic sensationalism that tends to capsulize a part as a whole seems to have contributed to evoking much of the Iacocca's indignation. But what is interesting here is that both the Japanese broadcaster's comment and the Iacocca's reaction to it happen to be quite stereotypically representative of aforementioned cultural values - "man in harmony with nature" vs. "man dominating nature."

Maybe because I didn't grow up on an island, I'll be the first one to admit that I don't fully unerstand what motivates the Japanese. But that works both ways.... A couple of weeks ago I picked up a newspaper article on the anti-American feelings that are cropping up in Japan lately because of U.S. demands for fair trade.... One prominant Japanese television commentator, for example, was quoted as saying: "We've accepted trade friction like changes in the weather -- something natural -- and tried to adapt in a passive way, as you do against a storm or wind." Between those lines I saw exactly the attitude that has caused much of the problem. The Japanese aren't serious about changing their predatory trade practices. They just 
intend to close the shutters and wait for the storm to pass. The attitude has already convinced many Americans that Japanese have to be forced to change, because they'll never do it on their own. The storm won't blow over. The Japanese don't understand Americans or American politics if they believe that we'll continue to tolerate deficit of $\$ 5$ billion a month forever.... The trade conflict between Japan and the United States will continue to fester and get worse if we don't learn to meet each other halfway, but we aren't doing that right now. (This Week, July 29, 1987, sec. A, p. 8)

\section{CULTURAL ACCOMMODATION AS NEGOTIATING POWER}

In the previous sections we discussed the degree to which motives and structurally constrained power relations between parties affect their cultural accommodation. In this final section, however, the focus will be turned around onto the impact of cultural accommodation on negotiating power. Thus, the term power in this case refers to strategic power. But first, the term "accommodating" needs to be qualified in relation to another important term "collaborating" since the insulated definition of "accommodating" contradicts our working definition of it.

\section{Defining Accommodating}

In the dual concern model (Figure 2) which has its origins in Blake and Mouton's (1964) work, five different approaches to conflict (different names are sometimes given by various authors to the dimensions in the model) 


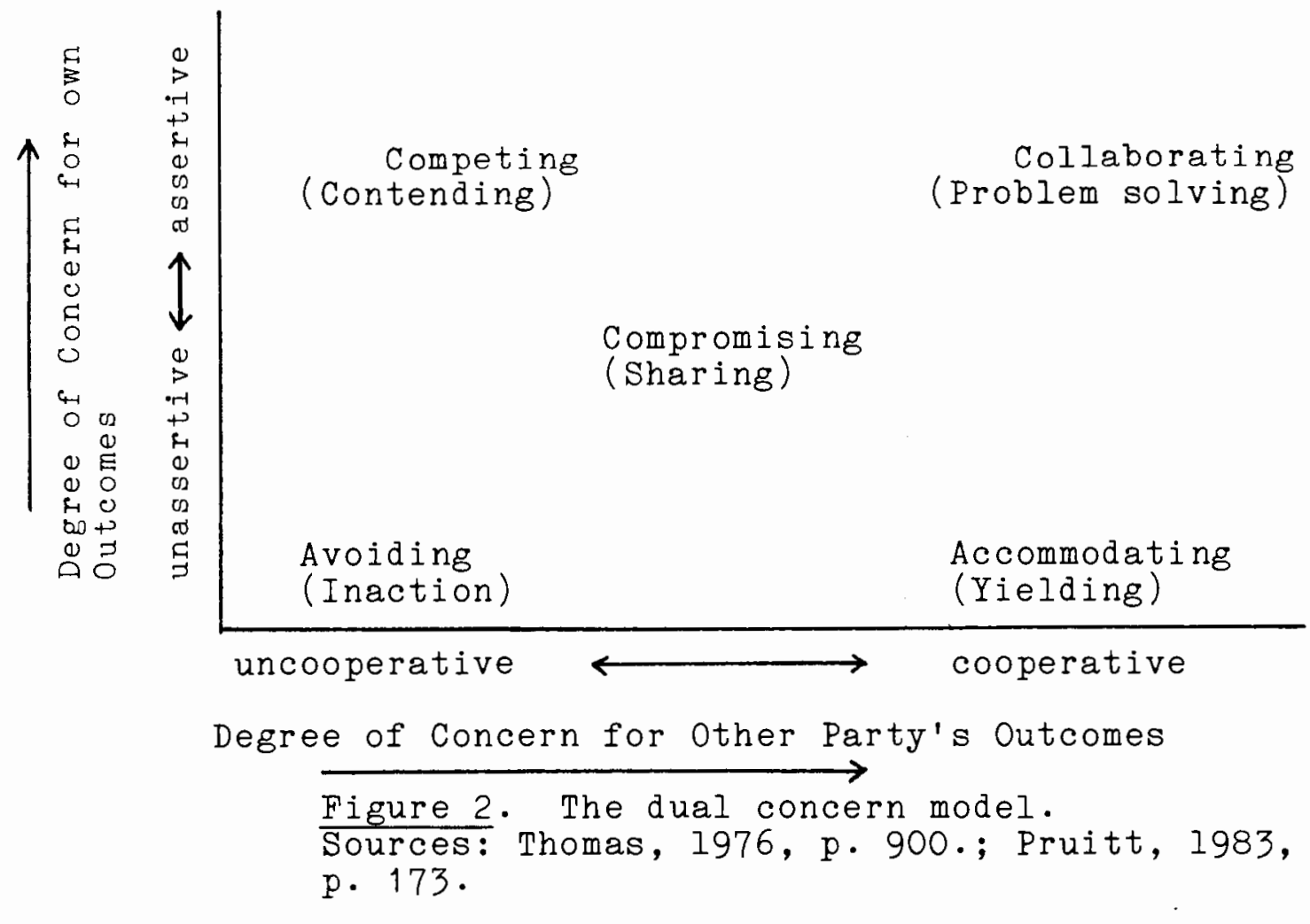

are identified on the basis of the degree to which a party would like to satisfy his own concern and the degree to which a party would like to satisfy the concern of the other: competing (contending), accommodating (yielding), compromising (sharing), collaborating (problem solving), and avoiding (inaction) (Blake and Mouton, 1964; Filley, 1975; Thomas 1976; Gladwin and Walter, 1980; Rahim, 1983; Pruitt, 1983; Lewicki and Litterer, 1985). According to the model, an accommodating orientation or strategy focuses on satisfying the other's concerns instead of attending to one's own. Accommodation involves cooperation and unassertiveness. The assertiveness of a party's orientation or strategy (concern about own outcomes) is in part a result of the importance of the issues 
to a party or a party's "stakes" in conflict. The notion of a party's "stakes" refers to a party's dependence upon the other; the more a party depends upon the other, the greater are a party's stakes in his relationship with the other (Thomas, 1976, pp. 917-918). The cooperativeness of a party toward the other (concern about the other party's outcomes) is to a large extent "a function of his identification with the other that ranges from positive identification through indifference to hostility" (Thomas, 1976, p. 902). Pruitt (1983) argues that there are two basic reasons for a negotiator's concern about the other party's outcomes: genuine concern (one has an intrinsic interest in the other's welfare) and strategic concern (one recognizes one's own dependence upon the other thereby impressing the other with one's concern about his/her welfare to obtain one's ends) (pp. 175-176).

Basically accommodation is assumed to result from one's relatively small stake in a relationship where there is commonality of interest. When one has a great deal at stake in a relationship in which there is considerable commonality of interest, he is expected to engage in collaboration. Thomas (1976) explains:

With common interest, he can generally trust other's intentions and may lose little by deferring to Other's wishes. For example, if a researcher is engaged in several joint research projects, he is likely to devote the least energy to the least important of them, relying upon 
his colleague's judgment and generally accommodating his wishes. ( $p .922$ )

Also, Pruitt's (1983) studies that were designed to test predictions from the dual concern model indicate that as predicted by the model the highest joint benefit was produced by active problem solving behavior (high concern about own outcomes and high concern about the other's outcomes); the contending (high concern about own outcomes and lower concern about the other's outcomes) produced moderately low joint benefit; and a combination of low concern about own outcomes and high concern about the other's outcomes, i.e., the yielding, produced the lowest joint benefit of all (when both parties share the same strategies) (pp. 176-178).

However, in a negotiation situation a negotiator employs an accommodating (yielding) strategy for various reasons and various purposes. Yielding may be used to end negotiation quickly when issues are unimportant and time pressure is high: in other words, when there is little at stake in conflict. But yielding is also used when there is a great deal at stake in conflict. For instance, a negotiator may use yielding on certain issues in order to induce corresponding concessions from the other side on other issues. In Pruitt's (1983) words, it is to "yield to a point that is compatible with the integrative potential and then hold firm while engaging in 
flexible problem solving" ( $p$. 171). In other words, a yielding or accommodating strategy is often used as an integral part of a collaborating strategy where one has a great deal at stake in conflict. The following section will discuss how cultural accommodation may occur as a function of collaboration.

Positive Effects of Cultural Accommodation on Negotiating Power

The following is not a prescription of strategic negotiating power. But what is to be discussed is that cultural accommodation on the basis of astute preparation for and tremendous understanding of cultural differences can be, in fact, critical negotiating power rather than being simply viewed as yielding or subordinating. Of course, familiarity with cultural differences is a necessary but insufficient condition for the success of negotiation. Nevertheless, as stressed by Tung (1984), "unfamiliarity with cultural differences and inability to bridge the cultural gap can lead to the collapse of business negotiation" (p. 76). Particularly such ignorance and inability on the part of the one courting, who may negotite from a position of less clout, can be a highly detrimental element to the outcomes of the cross-cultural business negotiation.

Knowledge is power. Especially in cross-cultural negotiation where there is inherent uncertainty about 
each other's value system and preference of strategies and tactics, access to relevant information is critical. Without knowledge relevant to a particular negotiation, whether it is about "the people involved," "the interests involved," or/and "the facts involved," no negotiating power can be exercised effectively (Fisher, 1983, p. 154). The power of skill and knowledge is a primary factor of Fisher's (1983) six kinds of negotiating power. Five other categories include: the power of a good relationship, the power of a good alternative to negotiating, the power of an elegant solution, the power of legitimacy, and the power of commitment. Fisher (1983) claims that "exercising negotiating power effectively means orchestrating them in a way that maximizes their cumulative impact" (p. 152).

Closely related to the power of skill and knowledge, Fisher's (1983) emphasis on the power of a good relationship is also worth mentioning regarding cultural accommodation. As seen in his and his colleague's (1983) method of "principled negotiation," Fisher's basic approach to conflict appears to be a synergistic creation of the third culture in that the method of principled negotiation is an alternative to (not merely a fusion of) traditional approaches to negotiating. It is a way neither hard nor soft but rather both hard and soft -- hard on the merits, soft on the people, which is designed to deal with a negotiator's interests both in substance and in a good 
relationship without mingling them.

The two most critical elements of a good working relationship are, Fisher (1983) says, first, "trust" and second, "the ability to communicate easily and effectively" (p. 155). Our power depends upon whether those on the other side can trust us rather than whether or not we can trust them; the ability of each to affect favorably the other's decision, namely, power, is enhanced by the ability to communicate, according to Fisher. The importance of establishing a supportive climate (Gibb, 1961) cannot be overemphasized; behavior characteristic of it includes description, problem orientation, spontaneity, empathy, equality, and provisionalism. Gibb's(1961) study revealed a positive correlation between increases in defensive behavior (evaluation, control, strategy, neutrality, superiority, and certainty) and losses in efficiency in communication. The more defensive the climate, the greater distortions. Conversely, as defenses are reduced, the receivers become better able to concentrate on the cognitive elements of the message rather than on the affect loading.

The power of a good relationship which must be based on cultural understanding is easily found as a contributing factor to the success of both the aforementioned MitsubishiChrysler and Boeing-CTDC negotiations. In the former case the Chrysler negotiating team displayed their under- 
standing of the importance of nurturing a relationship to the Japanese in a very empathic way. Kapoor (1975) notes that "one of the reasons for growing confidence in Chrysler by Mitsubishi was the cultivation of personal relations by both sides" (p. 120). As illustrated in Table I on Summary of Japanese and American Business Negotiating Styles, the Japanese tend to devote considerable time and expense to non-task sounding, the first stage of the negotiating process, to establish rapport or size up one another. Graham and Sano's (1984, p. 98) comment that "once the relationship has been established, substantial and complex negotiations will proceed more smoothly" is a widely held view on the Japanese negotiating style. An informal channel of communication was actively explored by both sides (Kapoor, 1975, p. 120). Chrysler opened offices at the Mitsubishi headquarters in Tokyo in May, 1969 for the negotiation period (1968-1971). It made possible "gokigen-ukagai," or "dropping in to say hello" by the Mitsubishi negotiating group from time to time at their discretion and was very useful whenever negotiations were at an impasse. For example, when a problem was caused by the difference in methods used by the Americans and the Japanese to forecast sales, the Japanese visitor would explain the Japanese method of forecasting to his American counterpart. Furthermore, during the negotiations 
the Chrysler representatives gave a party for the Japanese members (including wives) of the negotiating team, which made an extremely good impression on the Japanese involved. This is a good example of the understanding of the importance of an informal channel of communication by Chrysler; it is said that in Japanese negotiation much is accomplished through such an informal channel of communication, including after-hour socializing, which is a common practice in Japan, rather than through a formal communication channel at the negotiation table. But perhaps more important was the flexibility displayed by Chrysler in seeking terms and Mitsubishi's favorable reaction to it (Kapoor, 1975, p. 120). On the other hand, in the joint program in aircraft production between Boeing and CTDC, where the Japanese were very accommodating and willing to follow the American way, a good relationship was cultivated in a different fashion. It was true that Boeing was astute enough to establish good relations, by the courtesy call approach, with Japanese senior-ranking government officials who sponsored the negotiation. But equally true was that the U.S. partner indicated that "most of the decisions were made during office hours, which were 'very productive, effective, and cordial'" (Tung, 1984, p. 127). It must have increased Boeing's confidence in CTDC in this case, thereby helping enhance CTDC's negotiating position vis-a-vis its American partner. 
Cultural Synergy

The dynamics of the negotiation situations in both cases may have been quite different from those of many other business negotiations. The MitsubishiChrysler joint-venture negotiations (1968-1971) took place within the context of growing pressures by Japan's major trading partners, particularly the United States, for capital liberalization. The negotiations encompassed two critical issues: 1) how to gain approval from the Japanese government that was at that time supporting the Ministry of International Trade and Industry's plan for reorganization of the Japanese automobile industry to better compete with larger foreign companies, and 2) how to neutralize the other Japanese automobile companies' negative attitudes toward the joint-venture with a foreign company. The unprecedented Mitsubishi-Chrysler joint-venture negotiation was undertaken under extreme secrecy due to the delicacy of the situation. This forms a striking contrast to the context in which the negotiations between Boeing and CTDC occurred almost a decade later, when the Japanese government actively encouraged and even sponsored joint cooperation with foreign aircraft manufacturers.

But what they had in common with any successful business negotiation is that in both cases there existed a considerable commonality of interests between the parties and a recognition of the mutual benefits of 
joint cooperation, therefore scope for mutual accommodation (even if one party was more accommodating than the other) toward collaborating endeavors and a positive commitment toward the negotiation on the part of both sides. In the Mitsubishi-Chrysler case, the commonality of interests and the mutual benefits were identified as follows:

On the Mitsubishi side:

1. Chrysler was one of the most influentual firms in the world, and it had an excellent reputation for management skills as well as technological know-how based upon long experience in the auto industry.

2. Mitsubishi and Chysler might be able to compensate for each other's weaknesses by sharing their worldwide production. For example, Mitsubishi had the advantage of its truck production and Chrysler its passenger car production.

3. Chrysler appeared to seek more reasonable terms compared to Ford and GM. GM insisted on 100 percent ownership of its subsidiaries, Ford wanted a 50-50 ownership arrangement, and only Chrysler would accept between 20-30 percent ownership.

4. Mitsubishi was weak in the area of an international marketing network, which could be provided by Chrysler.

5. Chrysler simply could not take over the joint venture as it had done in France and Spain. Since the Mitsubishi Group would hold all the shares allotted to Mitsubishi Heavy Industries (MHI) in the joint venture company, none of its shares would be available on the market. Chrysler would not be able to buy a share of Mitsubishi Heavy Industries, nor could it buy any shares of the joint venture company that belonged to MHI unless, of course, MHI decided to sell -- an unlikely occurrence at best. In case Chrysler wanted to obtain any control of MHI' share of the joint venture company's stock, it would eventually have to go through Mitsubishi Group, which was powerful enough to defeat any financial ploys that Chrysler might 
attempt. Considering these circumstances, the possibility of a takeover bid by Chrysler, feared by the Japanese government, would be practically impossible in the MitsubishiChrysler case. (Kapoor, 1975, pp. 113-114)

Chrysler was attracted to Mitsubishi for four key reasons:

1. Japan was the only market that had not been previously invaded by GM and Ford. Chrysler wanted to be the first in that market.

2. Mitsubishi is one of the leading heavy industry companies in many fields. Thus it would be beneficial for Chrysler to tie up up with Mitsubishi in case it wanted to enter into any other heavy industry fields beside that of the auto industry.

3. Chrysler would be able to compensate for some of its weaknesses - for example, in truck production, one of Mitsubishi's strong areas.

4. Chrysler wanted to obtain a share of the small car market by importing Mitsubishi cars to the U.S. (Kapoor, 1975, p. 114)

In the Boeing CDTD negotiations motives to cooperate on each side were:

The Japanese government identified aircraft, both military and commercial, as a potential growth industry because:

1. The aerospace industry is high-technology, export-oriented, and hence worthwhile from the standard of Japanese objectives.

2. For some time the U.S. government has prodded the Japanese to assume greater responsibility for its own defense.

3. The production of commercial aircraft represents a viable route for recouping or recovering the costs of research and development on military defense. (Tung, 1984, p. 115)

Boeing's motivations to embark on a joint program with CTDC were:

1. Risk-sharing: Because of the unique characteristics of the aircraft industry, there are tre- 
mendous risks involved in developing a new airplane. By allowing participation by others, Boeing would share that risk. In a typical program about the half the costs of production are borne by subcontractors and suppliers.

2. Market access: The aircraft is highly competitive; although participation by a country does not necessarily guarantee the purchase of aircraft by a government-owned airline, it does create a more favorable market environment.

3. By involving Japanese firms, it 'keeps these companies (and countries) out of a competitive alignment.' Besides this joint program with Boeing on the 767s and more recently agreed on YXX series, Japan has also entered into an agreement with other U.S. and European firms to form a seven-firm consortium for the construction of a jet engine for use in a new 150-passenger airplane.... (Tung, 1984, p. 116)

In this Boeing-CTDC case it should be also noted that reciprocal cultural awareness on the part of the Americans played an important role for the success (Tung, 1984, p. 123, pp. 126-127). Mutual (cultural) accommodation was a distinctive characteristic of the Mitsubishi-Chrysler negotiation too, as described earlier.

In this respect, it appears that as Moran and Harris (1982) say, "cultural synergy exists only in relation to a practical set of circumstances and it takes place by necessity when two or possibly more culturally different groups come to the mutual conclusion that they need to unite their efforts in order to achieve their respective goals" (p. 5). Conversely, it can be said that a strong underlying commitment toward mutual cooperation on the part of both sides can make formidable cultural barriers 
surmountable (at least at the practical level).

\section{CONCLUDING REMARKS}

The main purpose of this chapter was to examine some of the factors that affect motivation to use an intercultural communication perspective in cross-cultural business negotiation. We discussed two sources of influence upon parties' cultural adaptability: motives to cooperate and power relations.

The review of the relevant literature on U.S.-Japan business negotiation case studies showed that strong enough motivation on the part of both sides leads to reciprocal cultural accommodation. It was suggested that successful cross-cultural negotiation contains an aspect of cultural synergy through such mutual cultural accommodation.

In the following final chapter we will further discuss the importance of cultural awareness and adaptation for the business leaders of the future. 
CHAPTER VI

CONCLUSION

SUMMARY

The term "difference" has been continually emphasized throughout this paper. The assumption of cultural difference is at the core of learning intercultural communication and dealing with difference is the major skill demanded. In other words, as seen in communication of any kind, often it is not difference that breaks up communication -- it is the failure to deal with it. A part of the difficulty of dealing with difference lies in the fact that the ability to accept and appreciate difference demands personal maturity. It includes inner security, high self-esteem, and integrity as well as psychological and cognitive flexibility, all of which permit us to understand the underlying reasons causing differences and to deal with them objectively.

This study was intended to help develop a balanced view of cultural difference for the improvement of crosscultural negotiating skills from the following angles.

Chapters II and III discussed the major differences in the process of business negotiation between the United 
States and Japan and potential friction between Americans and Japanese in business negotiation arising from cultural differences. Specifically Chapter III examined cultural differences in the light of 1) assumptions and values, 2) philosophies of negotiating, 3) communication styles, 4) decision-making processes, and 5) situational constraints and status relationships. However, it should be noted that this study did not attempt to predetermine negotiating behaviors of the two cultural groups. As mentioned everywhere in this paper, negotiating behavior is influenced by various factors such as environmental conditions, (i.e., political, economic, social, and cultural contexts in which negotiators operate), as well as such factors as issues, events, expertise, and personalities. Cultural generalizations and comparisons were made for the purpose of overcoming our natural cultural blindness; in other words, to provide some insights into unconscious factors (i.e., cultural factors) and the degree to which such unconscious factors condition negotiating behavior.

Chapter IV was devoted to the concepts of intercultural communication principles and the applicability and usefulness of an intercultural perspective in enhancing negotiating skills. It was hoped that the concepts of intercultural communication would provide a theoretical framework to see culture-biased communication problems in 
perspective. But more importantly, the underlying interest of this study lay in the hope that with the conception of culture as subjective culture, i.e., an individual's cognitive and perceptual processes, the applicability and usefulness of intercultural perspective could be expanded into other spheres of human interaction. The perspective is based on appreciation of uniqueness of each individual's values and perceptions, which naturally leads to an assumption of value and perceptual differences between cultures. A culture may be himself/herself, male/ female, parent/child, management/labor, American diplomat/ Soviet diplomat, and so on. The larger notion of "culture" is simply a composite view of the consistencies among groups of individual subjective cultures.

Chapter $\mathrm{V}$ focused attention on the impact of situational constraints upon negotiating behavior in terms of cultural adaptability. A party's behavior was seen as a result of and a response to a variety of structural variables surrounding the negotiation process. Structural variables, according to Thomas' (1976) structural model, include 1) parties' behavioral predispositions which stem partially from motives and abilities, 2) social pressure (e.g., constituent pressure, ambient social pressure), 3) incentive structure -- the conflict of interest between parties and their stakes in the relationship, and 4) rules and procedures (pp. 912-926). We were, however, concerned 
with two sources of influence upon the behavior of the parties: motives and power relations between parties that affect "stakes" in the relationship. A review of literature on U.S. - Japan business negotiation case studies suggested that a party's motives and his power relations with the other party tend to influence the degree of his cultural adaptation (the greater a party's motives and stakes are in conflict, the more culturally accommodating a party becomes), thereby minimize the effect of a party's original behavioral orientation, including his culturally predisposed behavior and his personal idiosyncracies. However, this finding is twofold. On the one hand, it suggests that cultural values and norms as ambient social pressure (one structural variable) are constrained and outweighed by another structural variable -- incentives. But on the other hand, a party's cultural sensitivity is in fact encouraged and promoted by incentives into acting out culturally accommodating behavior toward the other party. In other words, even though the influence of a party's original cultural values and norms on his behavior is (or should be) minimized under certain conditions, it is not undermined, rather objectified and modified with practical and functional purposes. This is called cultural adaptation. In this respect, the main point of the discussion on "the reality of living with Western domination" was in an attempt to see the impact 
of structurally shaped power relations between parties on their cultural adaptability in a more general and broader context.

The effectiveness of cultural adaptation on the outcomes of cross-cultural negotiation was also an important point to be made in Chapter $V$ in term of cultural accommodation as negotiating power (strategic power) in contrast to structurally shaped negotiation power. It was argued that it is possible for a party in a position of less power to utilize cultural awareness and accommodation as negotiating power, thus somehow dilute (if not turn around in the long run) the effect of the existing power relations with the other party. However, the reality is that a party who has far more negotiating edge over the other can get by without adequate cultural accommodation, whereas a party in a weaker position cannot afford to ignore cultural differences in order to attain successful outcomes. Kobrin's (1984) research on the nature and importance of international expertise in large American international firms provides some supporting evidence on this connection between power and cultural accommodation: "... expatriate managers who are successful without learning the language are almost always in firms with very strong competitive or product positions" although language competency has remained a controversial topic in international 
business and "there are few places that one cannot 'get by' with English." (p. 30, p. 36).

Yet no doubt the optimal joint benefit is produced by collaborating endeavors on the part of both sides, which include mutual cultural awareness and accommodation. With this implication the term accommodating was qualified as an integral part of collaborating efforts, as opposed to its insulated definition as a strategy resulting from one's relatively little stakes in a relationship where there is commonality of interest. According to this formal definition of accommodating, mutual accommodation leads to the lowest joint benefit among all: collaborating, contending, and accommodating when the same strategy is shared by both parties (e.g., Pruitt, 1983). Regarding this point, the two successful U.S.-Japan business negotiation case studies exemplified 1) the occurrence of cultural accommodation as a result of a party's great stakes in a relationship in which there is considerable commonality of interest, which is considered as a condition of collaboration, and 2) an emergence of cultural synergy through reciprocal cultural accommodation as a result of strong commitment to collaboration on the part of both sides.

THE FUTURE OF CULTURAL AWARENESS IN BUSINESS AND NEGOTIATION

The following discussion is based on the Kobrin (1984) study titled International Expertise in American Business, 
the data of which were gathered through interviews and a mailed survey from a total of 233 managers in 126 large, international, American firms ("Fortune 500" industrial firms), which are statistically representative of the 217 firms included in the study. While the study is about the U.S. managerial perceptions of international expertise, it offers valuable insight into the importance of cultural sensitivity and cultural learning for the business leaders of the future, or anyone who is involved in international business.

Thus, a review of the study is expected not only to lend support to the efforts of this thesis to demonstrate the importance of cultural learning but also to validate and elaborate on the discussion of cultural adaptability in the previous chapter from a more realistic point of view. Two issues will be explored: 1) the importance of international expertise and 2) cultural training implications.

\section{The Importance of International Expertise}

Kobrin (1984) observes U.S. managerial perceptions of international expertise as follows:

- Managers view international expertise from an information and an operating perspective. Economic, social, and political information is necessary for the analysis and forecasting underlying planning and decision making. An understanding of how to interact with people and organizations in other countries, of how to "move around and get it 
done," is required to operate outside of the United States....

- International expertise also can be country specific or general.... No one discounts the value of information and specific country knowledge; indeed it is impossible to do business abroad without them. Yet most of the managers I spoke to are more concerned with operating and comparative expertise.... they sought a general understanding of how to work outside of the United States; sensitivity rather than information or expertise.... An international treasurer claimed he does not need to be the world's leading Philippine expert. Rather, he feels it critical to understand differences in ways of approaching a problem and getting things done....

- The distinction between specific country knowledge and comparative international expertise starts with premise that an international manager cannot expect to develop in-depth expertise about all of the countries with which he or she must deal. What may be more important is recognizing that other countries are different, learning exactly what it is that is likely to vary, and gaining an appreciation of the range that variation can encompass. An international personnel manager stated the idea directly: "The most important thing is to know that there are a hell of a lot of differences between countries." Many of my respondents expressed frustration with their domestic colleagues who simply could not be convinced that business is done differently in other places ....

- International expertise entails the ability to generalize and compare. Many managers, for example, observed that there is a considerable difference in how directly one can approach a problem or a negotiation across cultures. Those who realize that this difference exists, and that Americans are more direct than most, have a clear advantage even if they are not sure how negotiations are handled in a specific country. A senior executive in a computer firm told me about negotiations in progress with China. He said that he knew very little about that country when he started, but he had considerable experience in dealing with other centralized governments and, despite the differences, it was quite helpful. Just knowing the forms that political and cultural differences make, or even that differences exist, is a plus. (pp.9-13) 
Regarding the importance of the assumptions of difference a similar view point is expressed by writers on Peace Corps' experience. When Peace Corps' volunteers psychologically prepared for vast differences between cultural customs, norms, and values, they generally faced less communicative and cultural conflict than those going to apparently similar but actually dissimilar societies (Prosser, 1978, p. 20). However, again, throughout his research Kobrin (1984) observed that one of the problems of U.S. international managers is "convincing their colleagues that other countries are different; that people see things, do things, and approach problems in a variety of ways" (p. 61). Kobrin attributes this in part to circumstantial isolation, that is, to the fact that Americans live on a large and relatively homogeneous continent. In Bennett's (1984) model this describes the "isolation" stage of the state of "denial," the most naive and parochial position of ethnocentrism. From a position of "isolation," due to the lack of a category for cultural difference, "cultural difference is not experienced at all. It simply has no meaning" (Bennett, 1984, p. 10. Refer to the summary of the model in Chapter IV). But it also seems that those who cannot be convinced that "American policies, procedures, and management techniques must be adapted, or might even be inapplicable, in other contexts" could 
be in a position of "superiority," one form of "defense," or in a state of "minimization," using Bennett's terminology. Both the "defense" and "minimization" states "overtly acknowledge" cultural difference and yet the former perceives it as "threatening" and the latter "trivializes" it.

At this point of time, there is no data available about Japanese managerial perceptions of international expertise comparable to the one of the Kobrin study. However, it could be assumed that Japanese managers would not have as much trouble as their American counterparts in convincing their colleagues that other countries are different. Rather, Japanese in general are so conscious and so overly cautious of cultural difference that they tend to imprison themselves in their own paranoiac ethnocentric frame, as discussed in Chapter IV. This may take the form of "rejection" (the intentional erection of physical or social barriers to create distance) in the "denial" state, or could eventuate in the position of "reversal" (a denigration of one's own culture and an attendant assumption of superiority of a different culture) in the "defense" state in Bennett's model. On a personal level many Japanese might follow these patterns. Yet on a business level, as discussed in the previous chapter, many Japanese businessmen overseas appear to be fairly adaptive to cultural differences. A good example of 
this ambivalance of the Japanese behavior overseas can be found in a magazine article about the Bridgestone's successful takeover of the Firestone plant in La Vergne, Tenn. Bridgestone, Japan's No. 1 tiremaker, turned the old tire factory around and pumped new life into the local economy. Management-labor relations have improved significantly. "Morale is at least $300 \%$ better than it was under Firestone," says La Vergne City Manager Richard Anderson. Nonetheless in a social context there has been little interaction between the Japanese and Americans. "The Japanese are pretty closed as a group.... They pretty much keep to themselves," Anderson also comments. (Time, September 14, 1987, p. 60).

Back to Kobrin's (1984) report, survey results were consistent with the aforementioned interviews regarding the managers' perceptions of specific country knowledge vs. comparative international expertise. When respondents were asked to rank six factors in order of their importance to effective international management, the ability to deal with people was ranked first by $49 \%$ of the respondents, whereas country knowledge was much further down the list ranked fifth by only 11\%. Other factors are: functional knowledge (i.e., marketing or finance) second by 32\%; company knowledge third, 26\%; knowledge of industry and competitors fourth, $21 \%$ and technical knowledge last, $10 \%(\mathrm{p}, 12)$. However, it seems safe to see 
the survey results only in the relative importance of operational and comparative international expertise against country knowledge in this case, for if people skills in the survey represent operational and comparative international expertise, the following interview results do not appear to be congruent with the above survey. The question still remains: how really important is international expertise relative to all of the other skills such as functional skills, technical and product knowledge, corporate expertise and the like? Kobrin (1984) points out that while the majority of the respondents interviewed agree that international expertise has some value, they disagree about its importance.

A small minority (10\%) of those interviewed feel international expertise is the critical factor in international business. They believe it to be more important than technical or functional skills or even company experience, and state that it is a major factor in hiring people for international jobs and in promotion decisions. A much larger number (45\%) feel international expertise is important, but not critical. While technical and functional skills clearly come first, international expertise is a very important plus. it helps get the job done or it may even be necessary; however, it is not sufficient. Another substantial group (37\%) characterized international expertise as "nice to have" but relatively minor factor in international business. They feel that they can obtain what is necessary when the need arises. Last, a very small minority (6\%) discount the importance of this sort of expertise almost entirely or even feel it can be a negative influence, providing reasons for people not to do their jobs. While the four groups of managers disagree about the relative importance of international expertise, they all agree that it alone is not sufficient. Basic business skills are 
an absolute requirement. (pp. 18-19)

Again how important is international expertise?

First of all, no one suggested that international expertise can, and will substitute for basic business abilities and skills, not to mention "'horror stories' about individuals who were accomplished linguists or country experts but simply could not function in a business environment" (p. 17). And perhaps more importantly, as a manager who exports heavy equipment to Latin America and who is a Peace Corps alumnus points out, while international expertise is vital, "one needs stronger business and technical ability overseas than at home," and the bottom line is that "international expertise is of value only when converted to business results" ( $p .22)$.

However, it is difficult to measure precisely how much international expertise contributes to effective performance overseas because the importance or effectiveness of international expertise depends largely upon individuals' perceptions of it. Referring to the extreme range of opinion within companies, Kobrin (1984) maintains that differences in assessment of the importance of international expertise reflect "individual background and experience, particularly substantial business (or in a few cases non-business) experience abroad" ( $p \cdot 26)$. Several people interviewed made an interesting and related point suggesting that "perceptions of the importance of inter- 
national expertise may reflect how much international expertise one has. Those without it have difficulty in seeing its value; they really do not know what they are missing" ( $p$. 26). Specifically, Kobrin (1984) explains.

All nine of the managers I interviewed who said international expertise is critical had served abroad themselves. Only one of the six who discounted its value had done so. Fifty-four percent of those who had previous overseas assignment feel it is important compared to $31 \%$ of those who had not, while only $31 \%$ of those who had been abroad characterize international expertise as unimportant compared to $52 \%$ of those who had not. (The differences are not statistically significant at conventional levels.) Survey results support this observation. Managers who have been assigned abroad are less likely to disagree, and more likely to agree, that international expertise affects promotion decisions. (p. 25)

In summary, Kobrin (1984) raised three important points about managerial perceptions of international expertise as follows;

1) Perceptions are derived from experience - the value of international expertise may not be apparent to those who do not have it;

2) There is a tendency to consider "the ability to do the job" and international expertise to be independent of one another, to define the former in terms of business skills alone. That separation of the task from its context may not be warranted;

3) There is a tendency to see adaptability as a result of basic personality traits; the implication is that international managers are born not made. Adaptability, however, may well be learned; it may come with an appreciation of individual and national differences. It may result from developing international expertise. (pp. 28-29)

The third point was made based on the quite interesting fact that a number of managers who do not value inter- 
national expertise highly speak well of the value of adaptability in international business nonetheless, but in terms of basic personality traits ( $p .27)$. By adaptability they mean such traits as flexibility, openness, and sensitivity to others. They argue that "what is important internationally is not so much knowledge of differences, but the ability to adapt to them" (p. 27). In other words, they do not seem to consider adaptability as an essential part of international expertise. But in fact, they are arguing the relative importance of two major elements of international expertise. "Knowledge of differences" appears to represent specific country knowledge and "the ability to adapt to them" operative and comparative international expertise. Adaptability may have a lot to do with personality. But in the author's opinion it is also a learned quality through an interplay of pragmatic purposes and intellect. And adaptability certainly includes a willingness to learn differences.

While virtually everyone agrees that excellence in basic business abilities and adaptability are the critical factors in international business, there is a considerably wider range of opinion about the edge that international expertise provides. But again, can we really afford to discount international expertise? Kobrin (1984) comments on this question and it seems to help 
reinforce the importance of cultural adaptability in international business discussed in the previous chapter.

There has been a great deal of discussion about restoring American competitiveness abroad in recent years. While the problem is complex, and would entail a thorough analysis that is beyond the scope of this report, in many industries the U.S. technological advantage has narrowed, or even been eliminated. As never before, we face competition from Europe, Japan, and even many of the more advanced developing countries. While managers may be able to get by with minimal international expertise, they may not be comtitive internationally if European and Japanese firms do a better job of adaptation and interaction. I suspect that as the technological gap narrows, that will apply to language also. While many people abroad can deal in English, many would rather not. Furthermore, the market and political-economic information gained as a result of language competency may provide an important competitive advantage $(p \cdot 63)$.

\section{Cultural Training Implications}

As discussed in the previous section, sensitivity to cultural differences has a great deal to do with both the quality and the quantity of one's intercultural experience. As Kobrin (1984) says, "many whose international exposure is limited understate both the differences and similarities between the world at large and their own country" (p. 61). It is largely because of one's lack of categories and of psychological mechanisms for dealing with a wide variety of stimuli. In the Bennett (1984) model this is characteristic of the "isolation" stage of "denial," as discussed earlier. In this stage the lack of a category for cultural difference is 
due to circumstantial physical isolation, i.e., "limited international exposure."

In Kobrin's (1984) study managers in general acquired country knowledge and international expertise through experience, through business travel and assignment abroad. However, the study revealed that opportunities for expatriate assignments have been reduced significantly for the past decade due largely to the effectiveness of local nationals operating in their own environment. Consequently many Americans can no longer have an option to develop international expertise through extensive experience abroad. And yet the study also shows a dramatic increase in international involvement of those firms in the same period (see the survey results in Table VIII). International involvement includes travel and other international responsibilities and cross-cultural interactions which now become a part of "domestic" jobs. For instance, "plant managers in Michigan find that they need to coordinate producion with their counterparts in Munich and Mexico City and purchase materials from Korea or Taiwan. Product development people and product managers who have not been, and probably will not be, assigned abroad routinely coordinate their activities globally" (p. 51). As Table VIII shows, fifty percent of the firms surveyed said the number of American expatriates abroad had decreased over the last ten years, $26 \%$ said it stayed the 
same and only $23 \%$ reported an increase. On the other hand, sixty-seven percent of those firms reported an increase in the number of Americans involved internationally during the past decade, whereas only $14 \%$ of the firms noted a decrease in the same time period and $18 \%$ claimed

\section{TABLE VIII}

THE INTERNATIONALIZATION OF MANAGERS
Decreased
$\not 6$
$\not 0$
Increased

Past 10 years:

Expatriates
abroad
50.0
26.1
$22 \cdot 7$

Americans

Involved

$\begin{array}{llll}\text { Internationally } & 13.6 & 18.2 & 67.0\end{array}$

In the Future:

Expatriates

abroad

40.9

39.8

$18 \cdot 2$

Americans

Involved

$\begin{array}{llll}\text { Internationall } & 17.0 & 25.0 & 56.8\end{array}$

Source: Kobrin, 1984, p. 52 .

no change. The interview results are consistent with the survey. Seventy-three percent noted a reduction in use of expatriates, while only $8 \%$ claimed an increase; nevertheless, most reported a marked expansion of international involvement (Kobrin, 1984, p. 52). 
Furthermore, these two opposing trends are projected to continue: a further reduction in expatriates and a continual increase in international involvement as domestic positions become more and more internationalized. In other words, "just as the demand for international expertise appears to be on the verge of increasing significantly, its traditional source is drying up" (Kobrin, 1984, p. 55). If that is the case, how do the next generation of U.S. international managers develop their perceptions of the importance of cultural sensitivity and international expertise in the absense of extensive experience abroad? Two things have to be kept in mind. First, "only a very small proportion of the managers (Kobrin spoke with) were committed internationalists to begin with. A great many developed their interest in, and commited to, international management as a result of assignments abroad." Second, "it is not only the expertise itself that has come from assignments abroad, but the development of individual perceptions of its importance, of the value of language and of adaptability" (Kobrin, 1984, p. 64). It seems that all of this suggests the importance of raising an awareness of cultural learning that not only sensitizes one to cultural differences but provides a framework that helps understand the differences systematically. (This paper itself is intended to be a process of cultural learning). In Kobrin's (1984) study it was mentioned re- 
peatedly that most of the managers are more concerned with the ability to establish "ground rules" quickly when visiting other countries, i.e., operating and comparative expertise, rather than with in-depth knowledge of conditions in specific countries. The author believes that Chapter III provided an example of how such ground rules can be developed through organizing major differences and similarities between cultures in such categories as cultural assumptions and values (basic conceptualizations of the self, family, society, and the universe), communication styles (verbal and nonverbal processes, including such concepts as time and space), decision-making processes, and so forth. The ability to conceptualize and categorize cultural patterns can be a basis of identifying similarities and differences in political and economic systems between countries. In fact, political and economic systems cannot be fully comprehended without taking into account the cultural context of which they are parts. As summed up well by Hoopes (1979), "the multicultural person is the person who has learned how to learn culture" (p. 21). Culture can be, and needs to be learned systematically without depending upon the "sink or swim" approach in the past. In reality the costs associated with such a conventional approach may no longer be tolerable for many firms. While no amount of cultural training may be able to help escape one's feelings of frustration 
or discomfort in the face of the clash of conflicting cultural patterns, at least being psychologically prepared for that occurrence can make one more tolerant of and capable of dealing with difficulties when they arise. Cultural learning and training can assist in such conscious efforts toward the integration of a three-dimensional i.e., cognitive, affective, and behavioral learning process. Prospective business leaders should start developing their cultural awareness as early as possible in their school years, through foreign language training programs, through foreign student exchange programs, through Peace Corps assignments and so on. Resources are available and the magnitude of the experience is beyond one's imagination.

\section{SUGGESTIONS FOR FUTURE RESEARCH}

First of all, one of the major limitations and shortcomings of this study should be noted. Perceptions and experience of negotiators reported in this study were mostly those of one side of the negotiation table. By the same token, the relevant negotiation theories were all derived from the Western literature. This might undermine the persuasiveness of this study. Other studies could incorporate the following: 1) a review of the relevant literature written by the Japanese on the Japanese approach to negotiation, to conflict and conflict management; and 2) re- 
search on the Japanese managerial perceptions and experience of negotiation and international expertise.

Other possible suggestions would be: 1) a controlled study on U.S.-Japan business negotiation involving those with much intercultural experience and those with limited intercultural exposure, all else equal, to explore the effectiveness and the edge that cultural sensitivity can provide to cross-cultural negotiation skills; and 2) in terms of the selection of effective expatriates abroad, a comparative study on managers who have high intercultural sensitivity with limited international business experience versus managers who have enough international business experience and yet may lack intercultural sensitivity. 


\section{BIBLIOGRAPHY}

Abegglen, J.C. The Japanese Factory. Glencoe, IL: The Free Press, 1958.

Adler, P.S. "Beyond Cultural Identity: Reflections on Cultural and Multicultural Man." In Samovar, L.A. \& Porter, R.E. (Eds.), Intercultural Communication: A Reader. 3rd Ed. Belmont, CA: Wadsworth, 1982, 389406 .

Ballon, R.J. "Understanding Japanese Management Techniques." In Norbury, P. \& Bownas, G. (Eds.), Business in Japan. New York: A Halsted Press Book, 1974, 88-110.

Barna, L.M. "The Stress Factor in Intercultural Relations." In Landis, D. \& Brislin, R.W. (Eds.), Handbook of Intercultural Training, Volume 2: Issues in Training Methodology. New York: Pergamon Press, 1983, 1949 .

Barnlund, D.C. Public and Private Self in Japan and the United States. Tokyo: Simul Press, 1975.

Bennett, M.J. "Overcoming the Golden Rule: Sympathy and Empathy." In Nimmo, D. (Ed.), Communication Year book 3. Washington, D.C.: International Communication Association, 1979, 407-422.

- "Towards Ethnorelativism: A Developmental Model of Intercultural Sensitivity." Paper presented at the Annual Conference of the Council on International Educational Exchange. Minneapolis, MN., November 2, 1984 .

Bennett, J.M. "Modes of Cross-Cultural Training: Conceptualizing Cross-Cultural Training as Education." International Journal of Intercultural Relations, $1 \overline{0}$ (1986), $117-134$.

Blake, R.R. \& Mouton, J.S. The Managerial Grid. Houston: Gulf Publishing, 1964 .

Brislin, R.W. Cross-Cultural Encounters: Face-to-Face Interaction. New York: Pergamon Press, 1981. 
Burgoon, M., Dillard, J.P., Doran, N.E., \& Miller, M.D. "Cultural and Situational Influences on the Process of Pursuasive Strategy Selection." International Journal of Intercultural Relations, 6(1982), 85100 .

Casse, P. \& Deol, S. Managing Intercultural Negotiations. Washington, D.C.: SIETAR International, 1985.

Christopher, R.C. The Japanese Mind. New York: Fawcett Columbine, $19 \overline{83}$.

Cleveland, H., Mangone, G.J., \& Adams, J.C. The Overseas Americans. New York: McGraw-Hill, 1960.

Cohen, H. You Can Negotiate Anything. New York: Bantam Books, 1980 .

Condon, J.C. "Perspective for the Conference." In Condon, J.S. \& Saito, M. (Eds.), Intercultural Encounters with Japan. Tokyo: Simul Press, 1974, 3-26. - With Respect to the Japanese: A Guide for Americans. Yarmouth, ME: Intercultural Press, 1984.

Condon, J.C. \& Yousef, F. An Introduction to Intercultural Communication. Indianapolis: Bobbs-Merrill, 1981 .

Daniels, J.D., Ogram, E.W. Jr., \& Radebaugh, I.H. Inter national Business: Environments and Operations. Menlo Park, CA: Addison-Wesley, 1976.

Darlin, D. "U.S., Japan Are Said to Reach an Accord on Tokyo's Imports of Some Farm Goods." Wall Street Journal, (January 6, 1988), p. 14.

De Mente, B. (Ed.), How to Do Business in Japan: A Guide for International Businessmen. Los Angeles: Center for International Business, 1972.

Doi, I.T. The Anatomy of Dependence. Translated by Bester, J. Tokyo: Kodansha International Ltd., 1973. (a)

- "Omote and Ura: Concepts Derived from the Japanese Two-Fold Structure of Consciousness." Journal of Nervous and Mental Disease. 157 (4) (1973), 258-261. (b) 
Hoopes. D.S. "Intercultural Communication Concepts and the Psychology of Intercultural Experience." In Pusch, M.D. (Ed.), A Cross-Cultural Training Approach.

Chicago: Intercultural Network, 1979, 10-38.

Iacocca, L. "The Japanese Don't Know Who We Are." This Week, (July 29, 1987), Sec. A, p. 8.

Ikle, F.C. "Bargaining and Communication." In Lewicki, R.J. \& Litterer, J.A. (Eds.), Negotiation: Readings, Exercises, and Cases. Homewood, IL: Richard D. Irwin, $1985,168-176$.

Ilich, J. Power Negotiating. Reading, MA: Addision-Wesley, 1980 .

Inagaki, T. "Japanese Industry Speaks Out." Japan Echo, 12 (3) (1985), 16-24.

Ito, K. \& Kamiya, F. "Laying the Ground Rules for Fair Trade." Japan Echo, 12 (4) (1985), 21-26.

Japan External Trade Organization. (Ed.), How to Succeed in Japan: A Guide for the Foreign Businessman. Tokyo: The Mainichi Newspapers, 1974 .

Jastram, R.W. "The Nakodo Negotiations." California Management Review, 17 (Winter, 1974), 88-90.

Johnson, R.T. \& Ouchi, W.G. "Made in America (Under Japanese Management)," Harvard Business Review, 52 (September-October, 1974$), 61-69$.

Kapoor, A. "MNC Negotiations: Characteristics and Planning Implications." Columbia Journal of World Business, 9 (winter, 1974), 121-130.

- Planning for International Business Negotiation. Cambridge, MA: Ballinger, 1975.

Karatsu, H. "Don't Blame Japan Alone." Japan Echo, 11 $(1984), 25-29$.

Karsh, B. \& Cole, R.E. "Industrialization and the Convergence Hypothesis: Some Aspects of Contemporary Japan." Journal of Social Issues, 24, (1968), 45-63.

Katz, D. "Nationalism and Strategies of International Conflict Resolution." In Smith, C.D. (Ed.), Conflict Resolution: Contributions of the Behavioral Sciences. Notre Dame Press, 1971, 416-444. 
Kay, P. "Some Theoretical Implications of Ethnographic Semantics." Current Directions in Anthropology.

Bulletins of the American Anthropological Association 3 (2) (1970).

Kelley, H.H. \& Schenitzki, D.P. "Bargaining." In McClintock, C.G. (Ed.), Experimental Social Psychology. New York: Holt, Rinehart and Winston, 1972, 298-337.

Kobrin, S.J. "International Expertise in American Business." Paper prepared for the Institute of International Education. New York, 1984.

Koepp, S. "For Sale: America." Time, 130 (September 14, 1987), 52-62.

Kraemer, A.J. Development of a Cultural Self-Awareness Approach to Instruction in Intercultural Communication. Alexandria, VA: Human Resources Organization, 1973.

Kunihiro, M. "The 'Japan as Number One' Syndrome." Japan Echo, 11 (3) (1984), 44-51.

Lee, E.H. "Business and the Law." In Norbury, P. \& Bownas, G. (Eds.), Business in Japan. New York: A Halsted Press, $1974,32-48$.

Lee, J.A. "Cultural Analysis in Oversea Operations." Harvard Business Review, 44 (March-April, 1966), 106114 .

Lee, S.M. \& Schwendiman, G. (Eds.), Japanese Management. New York: Praeger, 1982.

Lewicki, R.J. \& Litterer, J.A. Negotiation. Homewood, IL: Richard D. Irwin, 1985.

- (Eds.), Negotiation: Readings, Exercises, and Cases. Homewood, IL: Richard D. Irwin, 1985.

Lustig, M.W. \& Myers, S. "Compliance-Gaining Strategy Selection: A Comparison of Six Countries." Paper presented at the Western Speech Communication Association Annual Convention, Albuquerque, NM, 1983.

Marwell, G. \& Schmitt, D. "Dimensions of Compliance-Gaining Behavior: An Empirical Analysis." Sociometry, $30(1967), 350-364$.

McCarthy, w. "The Role of Power and Principle in Getting to YES." Negotiation Journal, 1 (January, 1985), $59-66$. 
Moran, R.T. \& Harris, P.R. Managing Cultural Synergy. Houston: Gulf Publishing, 1982 .

Nakane, C. Japanese Society. Berkeley and Los Angeles: University of California Press, 1970.

Nakatani, I. "Proposal for a Tax Summit." Japan Echo, $12(3)(1985), 31-37$.

Neuliep, J.W. \& Hazleton, V. Jr. "A Cross-Cultural Comparison of Japanese and American Persuasive Strategy Selection." International Journal of Intercultural Relations, 9 (1985), 389-404.

Nierenberg, G.I. The Art of Negotiating. New York: Hawthorn Books, 1968 .

- Creative Business Negotiating. New York: Hawthorn Books, 1971.

Nomura, N. \& Barnlund, D. "Patterns of Interpersonal Criticism in Japan and the United States." International Journal of Intercultural Relations, 7 (1983), 1-17.

Norbury, P. \& Bownas, G. (Eds.), Business in Japan. New York: A Halsted Press Book, 1974 .

Osgood, C.E., May, W.H., \& Miron, M.S. Cross-Cultural Universals of Affective Meaning. Urbana, II: University of Illinois, 1975.

Ouchi, W.G. Theory Z. New York: Avon Books, 1982.

Pascale, R.T. \& Athos, A.G. The Art of Japanese Management. New York: Warner Books, 1982 .

Pascale, R.T. \& Maguire, M.A. "Communication, Decision Making and Implementation Among Managers in Japanese and American Managed Companies in the United States." Sociology and Social Research, 63 (October, 1978), $1-23$.

- "Comparison of Selected Work Factors in Japan and the United States." Human Relations, 33 (July, 1980), $433-455$.

Peterson, R.B. \& Schwind, H.F. "A Comparative Study of Personnel Problems in International Companies and Joint Ventures in Japan." Journal of International Business Studies, 8 (Spring-Summer, 1977), 45-55. 
Prosser, M.H. The Cultural Dialogue: An Introduction to Intercultural Communication. Boston: Houghton Mifflin, 1978.

Pruitt, D.G. "Choice of Conflict." American Behavioral Scientist, 27 (November/December, 1983), 167-194.

Pusch, M.D. (Ed.), A Cross Cultural Training Approach. Chicago: International Network, 1979.

Rahim, M.A. "A Measure of Styles of Handling Interpersonal Conflict." Academy of Management Journal, 26 (1983), 368-376.

Ramsey, S. \& Birk, J. "Preparation of North Americans for Interaction with Japanese: Considerations of Ianguage and Communication Style." In Landis, D. \& Brislin, R.W. (Eds.), Handbook of Intercultural Training, Volume 3: Area Studies in Intercultural Training. New York: Pergamon Press, 1983, 227-259.

Raven, B. \& Rubin, J.Z. "The Interdependence of Persons." In Lewicki, R.J. \& Litterer, J.A. (Eds.), Negotiation: Readings, Exercises, and Cases. Homewood, IL: Richard D. Irwin, 1985, 35-52.

Richardson, B.M. \& Ueda, T. (Eds.), Business and Society in Japan. New York: Praeger, 1981.

Rubin, J.Z. \& Brown, B.R. The Social Psychology of Bargaining and Negotiation. New York: Academic Press, 1975.

. "Editor's Introduction." Negotiation Journal, 1 (January, 1985), 5-8.

Ruhly, S. Orientations to Intercultural Communication. Chicago: Science Research Associates, 1976.

Samovar, L.A., Porter, R.E., \& Jain, N.C. Understanding Intercultural Communication. Belmont, CA: Wadsworth, 1981 .

Samovar, I.A. \& Porter, R.E. (Eds.), Intercultural Communication: A Reader. 3rd Ed. Belmont, CA: Wadsworth, 1982 .

Sawyer, J. \& Guetzkow, H. "Bargaining and Negotiation in International Relations." In Kelman, H.C. (Ed.), International Behavior, A Social-Psychological Analysis. New York: Holt, Rinehart and Winston, 1965, 464-520. 
Schelling, T.C. The Strategy of Conflict. Cambridge, MA: Harvard University Press, 1963.

Shea, G.F. Creative Negotiating. Boston: CBI, 1983.

Shimomura, 0. "U.S. Trade Demands Go Too Far." Japan Echo, 12 (3) (1985), 25-30.

Shinpo, S. "Don't Blame Japan's Saving Surplus." Japan Echo, 12 (4) (1985), 15-20.

Singer, M.R. "Culture: A Perceptual Approach." In Samovar, I.A. \& Porter, R.E. (Eds.), Intercultural Communication" A Reader. 3rd Ed. Belmont, CA: Wadsworth, 1982, 54-62.

Stepsis, J.A. "Conflict-Resolution Strategies." In Pfeiffer, J.W. \& Jones, J.E. (Eds.). The 1974 Annual Handbook for Group Facilitators. La Jolla, CA: University Associates Publishers, 1974, 139-141.

Stevens, C.M. Strategy and Collective Bargaining Negotia tion. New York: McGraw-Hill, 1963.

Stewart, E.C. American Cultural Patterns: A Cross-Cultural Perspective. Yarmouth, ME: Intercultural Press, 1972.

Strauss, A. Negotiations: Varieties, Contexts, Processes and Social Order. Los Angeles: Jossey-Bass Publishers, 1978.

Suzuki, T. "A Global Role for the Japanese Language." Japan Echo, 12 (3) (1985), 79-84.

Takashina, S. "Internationalizing Japanese." Japan Echo, $12(3)(1985), 78$.

Takeuchi, $Y$. "Peer Pressure in Japanese Organizations." Japan Echo, 11 (3) (1984), 53-59.

Thomas, K.W. "Conflict and Conflict Management." In Dunnette, M.D. (Ed.), Handbook of Industrial and Organizational Psychology. Chicago: Rand McNally, $1976,889-935$.

Thorelli, H. "The Multi-National Corporation as a Change Agent." The Southern Journal of Business, (July, $1966)$. 
Tsurumi, Y. "Japanese Business Organization." In Richardson, B.M. \& Ueda, T. (Eds.), Business and Society in Japan. New York: Praeger, 1981, 1-13. (a)

"Social Relations and Business Practices." In Richardson, B.M. \& Ueda, T. (Eds.), Business and Society in Japan. New York: Praeger, 1981, 305$322 \cdot(\mathrm{b})$

Tung, R.I. Business Negotiations with the Japanese. Lexington, MA: Lexington Books, 1984 .

Upham, F.K. "Litigation in Japan." In Richardson, B.M. \& Ueda, T. (Eds.), Business and Society in Japan. New York: Praeger, 1981, 149-155.

Uraga, K. "No Magic Cure for the Trade Surplus." Japan Echo, 12 (3) (1985), 11-15.

Useem, J., Useem, R., \& Donoghue, J. "Men in the Middle of the Third Culture: The Role of American and NonWestern People in Cross-Cultural Administration." Human Organization, 22 (Fall, 1963), 169-179.

Van Zandt, H.F. "How to Negotiate in Japan." Harvard Business Review, 48 (November-December, 1970), 4556.

Vogel, E.F. Japan as Number 1. New York: Harper Colophon Books, 1980.

Ways, M. "The Virtues, Dangers, and Iimits of Negotiation." In Lewicki, R.J. \& Iitterer, J.A. (Eds.), Negotiation: Readings, Exercises, and Cases. Homewood, II: Richard D. Irwin, 1985, 19-25.

Wells, L.T. "Negotiating with Third World Governments." Harvard Business Review, 55 (January-February, 1977), $72-80$.

Whorf, B.I. "The Relation of Habitual Thought and Behavior to Language." In Carroll, J.B. (Ed.), Language,

Thought and Reality. Cambridge, MA: M. I.T.Press, $1956,134-159$.

"Working for the Japanese." Time, 130 (September 14, 1987), 60 .

Yamazaki, M. "Survival Tactics for a Non-Western Power." Japan Echo, 13 (3) (1986), 56-63. 
Zartman, W. The 50\% Solution. New York: Anchor Press, 1976.

Zimmerman, M. How to Do Business with the Japanese. New York: Random House, 1985. 